7.7. 


\section{THE UNIVERSITY}

OF ILLINOIS

\section{LIBRARY}

583.951

J98e

Brolosir.

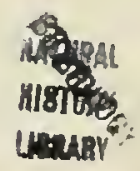
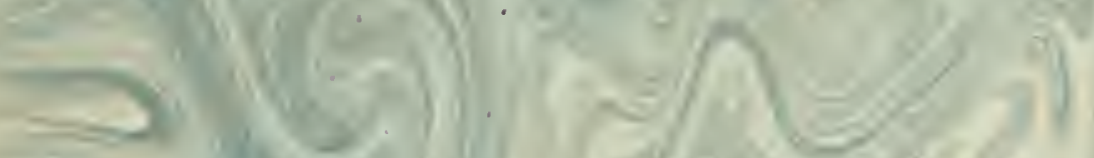


\section{UNIVERSITY LIBRARY UNIVERSITY OF ILLINOIS AT URBANA-CHAMPAIGN}

The person charging this material is responsible for its renewal or return to the library on or before the due date. The minimum fee for a lost item is $\$ 125.00, \$ 300.00$ for bound journals.

Theft, mutilation, and underlining of books are reasons for disciplinary action and may result in dismissal from the University. Please note: self-stick notes may result in torn pages and lift some inks.

Renew via the Telephone Center at 217-333-8400, 846-262-1510 (toll-free) or circlib@uiuc.edu.

Renew online by choosing the My Account option at: http://www.library.uiuc.edu/catalog/

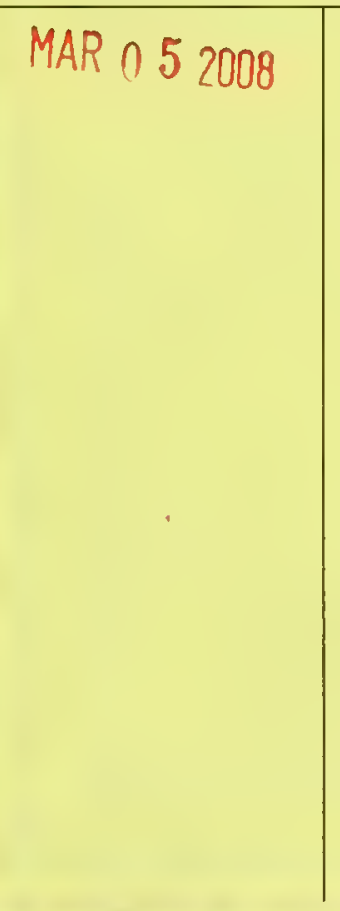




\section{Digitized by the Internet Archive in 2011 with funding from University of Illinois Urbana-Champaign}

http://www.archive.org/details/deeuphorbiacearu00juss 


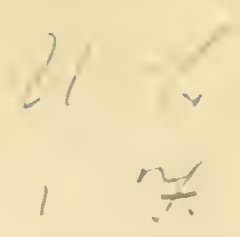



Inssien, Adrien de

$\mathrm{DE}$

\section{EUPHORBIACEARU்M}

GENERIBUS

MEDICISQUE EARUMDEM VIRIBUS

\section{TENTAME N,}

TABULIS ENEIS IS ILLUSTRATUM,

A C CTORE

Adriano DE JUSSIEU,

Doctore medico, è Societate historix naturalis parisieusi.

\section{P A R IS I IS,}

EX TYPIS DIDOT JUNIORIS,

Typographi Facultatis medica parisinæ.

1824 . 


\section{-}

(II)|A1) $10.71,1,11$ 1.1111

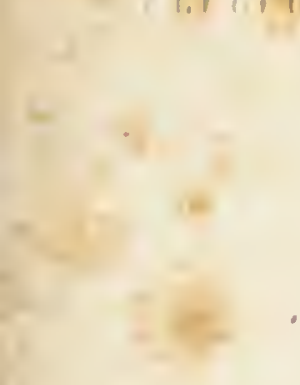

t

a

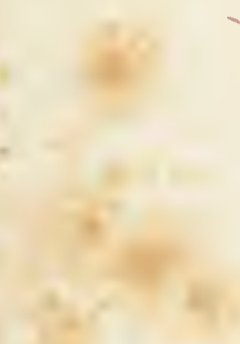

wat

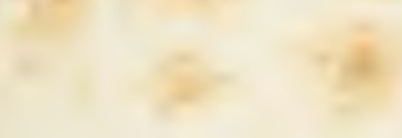

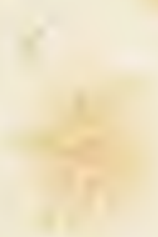

1
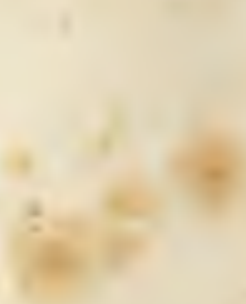

$\sqrt{2}+x^{2}$

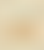

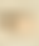

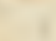

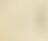

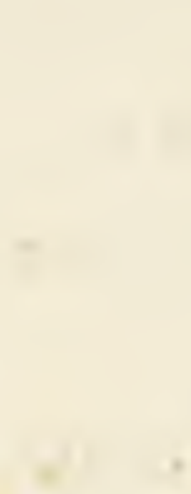

(1)<smiles>C1CC1</smiles><smiles>C1CCCC1</smiles>

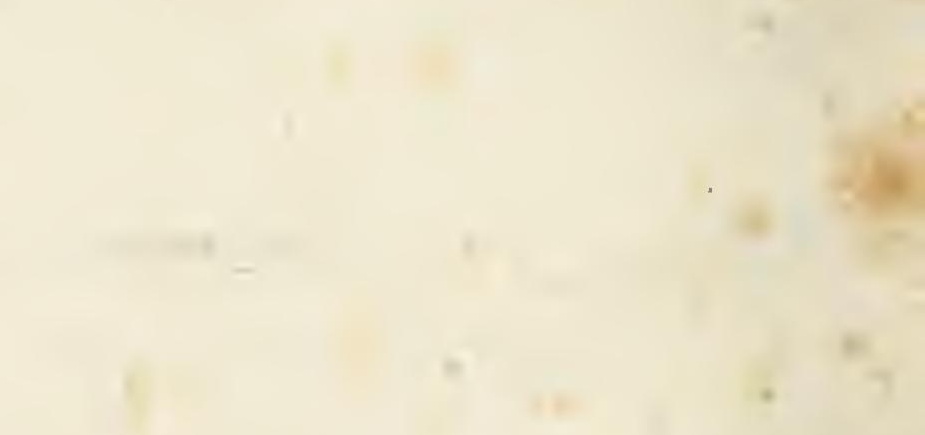




$$
\begin{aligned}
& 583.951 \\
& \text { I9se }
\end{aligned}
$$

$\infty_{\infty}^{0}$

$\frac{3}{3}$

0

4

हे

ㅁ

A. DE JUSSIEU.

7
5
$i$
0 
10,1118

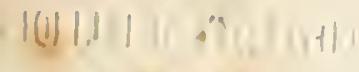

$1 / 1111$

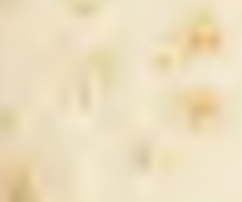

(1)

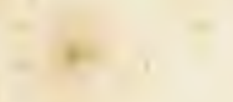

1

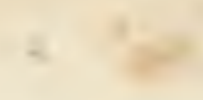

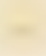

$\sqrt{2}+2$

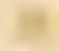

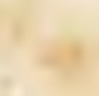

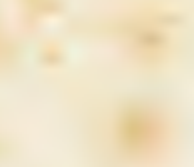

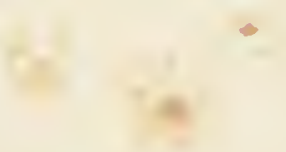

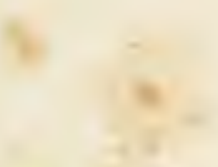

$+1$

a

4

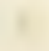

4

?

4

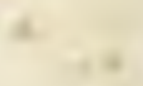

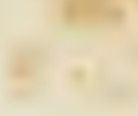

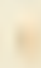

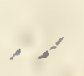

$+$

10

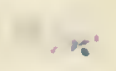

$+$ 
STublo botanices deditus, in sumendo medicæ thesis argumento, tale quasivi quale utrique scientia commune foret; mentique occurrit linnatanus ille aphorismus : "Plante que genere conveniunt, " etiam virtute conveniunt; qure ordine naturali continentur, etiam "virtute propiùs accedunt." Fœcundissima sanè atque utilissima sententia, ex quâ optimus ordinum naturalium conditor non pharmacologiæ minùs quàm rei herbarix auxilietur; fiat medicamcutorum. facilior cognitio tutiusque experimentum; quibusdam deficientibus, alia succedanea semper in promptu sint; $c$ in longinquis ignotisque regionibus, plantarum vixdùm cognitarum vires jam præsagiri possint, tentari atque mederi.

Opera jam exstant dno quibus illa veritas cxplicatur atque confirmatur : alterum scilicet elegantissimum clari De Candolle de proprietatibus plantarum tentamen, in quo familia omnes recensentur, et quænam luuic legi pareant, quænam ab eâ recedant pauciores aut minùs notx, docetur, sed summatim et compendiosè, ut auctorem peritum in opere generaliori decet; alterum nuperrimè ab amicissimo A. Pichard editum, qui tùm botanicè tùm medicè plantas secundùm ordines naturales dispositas describit, sed eas tantùm quæcumque sunt in.usu. Animus mihi fuit de tot familiis unam tantùm seligere de quâ fusiùs dissererem, expositis, hinc generum ejus omnium characteribus, indè virtutibus qubus horun unumquodque valere dicitur; cùmque Euphorbiacearum genera quedam ubscura sint, et omnia prætereà virium similitudine insignia, de his agere pretium operæ milhi visum est.

Dividitur igitur liæce dissertatio in partes duas, hanc botanicam, illam medicam. Sed posterior præsertim quàm sit imperfecta non me fugit, qui hanc scripserim, sæpiùs vagis viatorum botanicorumque documentis, rarò certioribus medicorum testimoniis, nunquàm pro- 
prix experientix innixus. Inusitata enim medicamenta explorent tan tùm viri consummatissimi : nobis autem tyronibus periculum facere non licet, sed diù aliena restigia sequi tantùm, antequàm ipsi longo labore atque usu edocti duces aliis ficri possimus. Quantulìm igitur in me fuit, feci; libros medicorum nostratum exterorumque, sicut et peregrinatorum qui de historiâ naturali scripserunt, evolvi; sedulù quidquicl ad meam materiam spectaret collegi, assertionibus singulorum inter se comparatis et anctoritate ponderatâ.

In luâc parte quæritur quænam sit Euphorbiacearum vis generalior, et quemadmodìm ipsa, quamvis ejus natura sibi semper constet, variis tamen modis operetur; quibusnam principiis sit tribuenda, ac ideù quo modo leniùs vehementiùsve agere, quo mitigari aut dissipari possit; quænam denique alia principia sint in pluribus speciebus notanda. His expositis, ut exemplis confirmentur, enumerantur deindè ordine alphabetico species, quascumque vi aliquât valere narrant auctores. Quorum ipsissima verba transcripsi, quotiès potis me fuit : multa igitur vocabula, hodiè medicina et physiologiæ progressibus planè obșoleta, hìc invenientur, quæ retuli tantìm ne sensum interpretando adulterarem. Quotiès autem textus ipse servari non poterat, nunc diversâ linguâ scriptum summâ fide in latinam transtuli, nunc longiorem sedulâ analysi contraxi. Si quæ tandem proposito meo contradicere videbantur, nulla tamen omissa sunt, ut fieri decet.

Iṇ parte botanicâ genera recensentur octoginta quinqie; cuilibet additur specierum tùm ab auctoribus descriptarum, tùm in hcrbariis ineditarum, numerus et patria; et indicantur prætereì, si quæ paulisper à congeneribus discrepent, aut peculiari quâdam notâ insigniantur. Genera quædam retera delenda aut aliis dubiè consocianda mihi visa sunt; quædam nova instituenda è plantis, sire jam cognitis, sed in genere suo anomalis, sive novis, qua mihi non pauca? suppetierunt, cùm herbaria urbis ditissima lıumanissimè, ut fit, meis indagationibus patuerint.

Gratix hic persolvenda omnibus hujusce lahoris fautoribus, ut viro 
non benerolo minùs quàm docto R. Desfontaines, et doctissimis quoque, quamvis junioribus, C. Kunth, A. Richard, A. de SaintHilaire, qui me nunc suarum divitiarum parlicipem fecêre, nunc talibus adjuverunt eonsiliis, qualibus ego nihil melius atque anteponendum censeo, nisi tamen ipsorum amicitiam. De optimo patre codemque magistro taceo : sed ad eum cui me quidquid cgo sum aut scio debere fateor, semper, quantulùm laudis tribuetur mihi, recurret, reluti rivulus ad fontem undè defluxit uberiorem. Utinam hoc tentamen cjus nomine non nimis indignum judicetur!

\section{NOMINA AUCTORUM LIBRORUMQUE ABBREVIATA.}

Adans. - Adanson. Familles des plantes.

Ait. - Aiton. Hortus kewensis.

Alib. - Alihert. Elémens de thérapeutique et de mat. médic. , 4. édit.

Ann. Hus. - Amales du Muséum d'histoire naturelle.

A. P. T. - Aubert du Petil-Thouars. - Gen. mad. - Genera nova madagascariensia.

Voy. - Voyage dans les îl. aust. d'Afrique, parlie botanique.

Aubl. - Aublet. Histoire des plantes de la Guiane française.

Barb. - Barbier. Matière médicale.

Boerh. - Boerhaave. Index. plant. hort. Lugduno-Balav., $172 \%$.

Boupl. - Bonpland. Vor. Humboldt.

P. Br. - Browne (Patrik). The civil and natural history of Jamaïca.

R. Br. - Brown (Robert). Gen. rem. - General remarks on the botany of Terra australis.

Obs. herb. Cong.--Observ. on an herharium from the Congo.

Prorlr. - Prodramus floræ Noyæ-Hollandia.

Burn. Ind. - Burmann. Flora indica.

Cav. ic. - Cavanilles. Icones et descriptiones plantartim.

C. B. - Caspar Bauhin. 


\section{(s)}

Clus. - Clusius.

Commel. - Commelya. Hortus amstelodamensis.

Conmers. - Commersou. Mss. et icones ineditx.

D. C. - De Candolle.

Deshois-Rochefort. - Matière médicale, édit. de Lullier-Winslow.

Desc. - Descourtils. Florc médicale des Antilles.

Desf. - Desfontaines.

Des R. - Des Rousseaux. Voy. Encyclopédie.

Enc. - Encyclopédie méthodique, partic Lolanique, par MII. Lamarck, Des Rousscaur et Poiret.

Forsk. - Forskàl. Flora ægyptiaco-arabica.

Forst - Forster. Characteres plant. quas in itinere ad insul. maris Austratis,etc...

Geïsel. - Geïseler. Crotonis monographia.

Gœrt. - Gœrtner.

Gouan - Traité de botanique et de matière médicale.

Hall. - Haller. Historia stirpium Helvetia,, ;68.

Houst. - Reliquiæ houstounianæ.

Hunıb. Bonpl. Pl. æq. - Humboldt et Bonpland. Plantes équinoxiales.

Jacq. - Jacquin. - Aner. - Selectarum stirpium americanarum historia.

Hort. schœnb. - Hortus schœubrunnensis.

Jourı. bot. - Journal de bolanique.

J. - A. L. De Jussieu. Genera plantarum.

Kunth. - Yoy. de MM. Humboldt et Bonpland. Nora genera et species plautarum.

La Bill. - La Billardière. - Plantarum Novæ-Hollandiæ Specimen.

Lanck. - Lanıarck. Foj. Encyclopédi :.

Ill. - Illustration des genres.

L. - Linnæus. - Genera. - Species. - Systema. - Mautissa.

Fl. suec, - Flora suecica.

M. m. - Materia medica.

L. f. - Linnæus filius. Supplementum plautarum.

Lob. - Lobelius.

Lois. Dcsl. - Loiselcur Deslonchamps. Mlanuel des plantes usuelles indigèncs.

Lour. - Loureiro. Flora cochinchinensis, edent. Wildcnow.

Nlareg. - Marcgravius. Vid. Piso.

Mém. Mus. - Mém. du Muséum d'histoire naturelle.

Michx. - Nichaux. Flora boreali-anericana.

Moris. - Morison. Plantarum historia universalis, $169 y$.

Nurr. - Murray. Apparalus medicaminum. 
Neck. - Necker. Elementa botanica.

Orf. - Orfila. Toxicologie générale, 3. ${ }^{\circ}$ édit.

- Ort. Dec. - Ortega. Rariorum aut novarum plantarum decades.

Pis. Nlarcg. - Pisonis de mediciná brasiliensi libri ıv, et Marcgravii historix rerum naturalium brasilia libri viı. Elsev. 1648 .

Pers. - Persoon. Synopsis plantarum.

Peyr. - Peyrilhe. Matière médicale.

Plum. - Plumier. Plantæ anericanæ, edent. Burmanno.

Poir. - Poiret. Foy. Encyclopédic.

Reed. - Hortus malabaricus.

A. Rich. - Richard (Achille). Botanique médicale.

Roxb. - Roxburgh. Plants of tbe coast of Coromandel.

R. P. Prodr. - Ruiz et Pavon. Flora peruvianæe et chilensis pendronus.

Rumph. - Rumphii herbarium amboïnense.

Sclureb. - Schreber. Genera plantarum.

Scop. - Scopoli. Introductio ad hist. uatur.

Sloane. - A natural history of Janaiica.

Sw. - Swartz. - Fl. - Flora Indiæ occidentalis.

T. - Tournefort.

$$
\text { Prodr. - Prodromus descript. veget. Ind. occ. }
$$

Thunb. - Thunberg. Flora japonica.

Vahl. Ecl. - Eclogæ americanæ.

- Symb. - Symbolæ botanicæ.

Vent. - Ventenat. Jardin de Cels.

Vill. Dauph. - Villars. Flore du Dauphiné.

W. - Willdenow. Species plantarum. 


\section{EUPHORBIA CEIS.}

\section{PA R S PR IM A,}

SIVE BOTANICA.

Character ordinis.

F erors monæci aut diœci.

CaLIX monosepalus, laciniis (sæpiùs 4-5-6) definitis, rariùs 2-autpolysepalus, interdùm nullus, sæpissimè intùs appendicibus variis squamiformibus aut glandulosis auctus.

Petala (seu appendices petaloïdex), nunc in plerisque nulla, nunc calicinis laciniis numero æqualia et alterna, aut rariùs iisdem plura, rarissimè basi inter se coalita.

- Froribus masculis, stamina indefinita aut sæpiùs definita, centro floris, nonnunquàm sub pistilli rudimento inserta. Filanenta libera aut coalita. Antmen biloculares, loculis extùs in longum dehiscentibus, interdùm distinctis.

Floribus foemineis, ovariun superum, sessile aut rarissimè stipitatum, 2-3-pluri-loculare, loculis circa placentarium centrale in orbem dispositis. Ovula solitaria geminatave, angulo interiori sub apice suspensa. STyL tot quot loculi, nunc distincti, nunc inter se 


\section{(11)}

connati in unum simplicem aut divisum, interdùm nulli. Stigra multiplex aut unicum pluri-lobatum.

Fructus sub integumento communi (sarcocarpium. Rich.), tenui, fibrosore, aut carnoso, 2-5-pluri-coccus, coccis (endocarpinm. Rich.) nunc distinctis, elastice bivalvibus, nunc rarissimè indehiscentibus aut in nucem multi-locularem connatis.

Semixa solitaria, aut geminata, placentario seu axi centrali, sæpissimé persistenti, superiùs annexa, arillata. Eмвrro perispermo carnoso involutus. Cotyledones planx. Radicula hilum spectans, supera.

Arbores, frutices aut herbæ, quædam lactescentes.

Folia plerunquè stipulacea, alterna aut rarissimè opposita nullave, simplicia aut in paucissimis composita.

Flores axillares aut terminales, variè dispositi, plerumque bracteati, bracteis quibusdam interdùm majoribus, involucriformibus.

\section{GE I ERA.}

\section{SECTIO I.}

Fuores monœci aut diœci. Calix 4-5-6-partitus ; præfloratio convolutiva (1). Petala o (exceptâ Richeriâ et interdùm Saviâ). mascul. Stamina 4-5-6, sub pistilli rudimento sessili inserta. roEsıx. Ovarium 2-5-loculare, loculis 2-orulatis. Fructus carnosus aut capsularis, $\bar{\jmath}$-coccus, coccis 1-2-spermis.

Arbores fruticesve, rarissimè herbæ, foliis glabris, lucidis veno-

(1) Præforationen convolutivam roco, cùm calicis corollæve partes, non omnes juxıả positæ, sed aliæe externæ suut, aliæ internæ, posteriores prioribus partim involutæ. Si partes gemina adsint, altera altcram obtegit; si tres, una obtegit, una obtegitur, tertia ambabus intermedia; si quinque, duæ externæ sunt, duæ isternæ, quinta iutermedia ( præfl. quincoueiali D. C.) ; si quatuor aut sex, duæ aut tres cxteriores cæteras alternas obtegunt (præfl. alternativa D. C.). 
sisve (exceptî Pachysandrâ). Flores plerumquè fasciculati glomerative, fasciculis glomerulisque ạxillaribus solitariis, aut in axi communi spicatim dispositis, rariùs racemosi aut spicati ; focminei interdùm subsolitarii. Bracteæ plurimæ, parvæ, persistentes.

DRYPETES. Vahl.

Flores diœci. Calix 4-6-partitus, inæqualis. sasc. Stamina 4-6 (8 ex Vahl) exscrta, sub disco centrali ad ambitum sinuato inserta. FOE.I. Stylus duplex aut lateralis unicus; stigmata totidem capitata, emarginata ; ovarium disco glanduloso impositum, 2-loculare, loculis 2-ovulatis, aut abortu 1-loculare, ovulis latere pendulis. Fructus drupæformis, nunc rarissimè subbilobatus, 2-locularis : nunc abortu unilobatus, hinc planus, loculi alterius vestigium exhibens, indè convexus 1-locularis, 1-spermus.

Arbores aut frulices. Folia alterna, stipulacea stipulis brevissimis, integra subserratave, subcoriacea, glabra, lucida, venosa. Flores axillares, fasciculati, fasciculis multi-bracteatis.

observ. Species 5 antillanæ. - Staminum numerus divisuris calicinis non semper aqualis, neque constans respeclivus utrorumque situs, atternus aut oppositus. - Charact. ex Poiteau (Nem. Mlus. 1. 152. tab. 8-10) et ex sicco.

\section{THECACORIS.}

Flores diøci? masc. Calix 5-6-partitus. Stamina 5 in præfloratione erecta, laciniis calicinis opposita, sub pistilli rudimento obconico inserta; filamentis flexuosis, quorum apici dilatato, utrinque annexi antherarum loculi distincti, ovati. Glandula 5 staminibus alternæ. foex. Calix 5-partitus. Styli 3 crassiusculi, apice bifidi; ovarium disco glanduloso impositum, glabrum, 5-loculare, loculis 2-ovulatis. Fructus....

Caulis lignosus. Folia alterna, 2-stipulacea stipulis minutis, caducis, petiolata, integra, glabra. Flores in racemis basi bracteatis, axillaribus terminalibusve, solitariis aut geminatis, laxi, breviter pelunculati, singuli bractcolati. 
oвs. Species unica madagascariensis, qux in herbariis sub nomine Acas lyphas glabrater. Vahl. mss. - Nomen à loculis antherarum distinctis. - Flore diversi sexûs in diversis speciminibus, an et in arboribus?

PACHYSANDRA. Michx.

Flores monoci. Calix 4-partitus, laciniis 2 interioribus, 2 exterioribus alternis. susc. Stamina 4 , inserta sub pistilli rudimento parvo; filamentis exsertis, latis, complanatis ; antheris summo filamento adnatis, introrsis, post anthesim arcuatis. row. Styli 5 recurri, crassi, intìs glandulosi et sulcati ; stigmata 3 ; ovarium breve, 5-loculare, loculis 2-ovulatis. Fructus (ex Michx. 2. 177. tab. 45) capsularis, subglobosus, stylis persistentibus tricornis, 3-coccus, coccis 2-spermis.

Herba. Folia alterna, crenata, glabra. Flores in infimo caule spicati, spicà ad basim squamis imbricatis cinctâ; masculi superiores 1-bracteati, fœminei inferiores, pauciores, 3 -bracteati, bracteis sepaliformibus:

OBS. Species unica ex montibus alleghanis.

\section{BUXUS. L.-J. - Buts.}

Flores monoeci. Calix 4-sepalus, sepalis inæqualibus, 2 interioribus, 2 alternis, exterioribus, quibus adpressa bractea similis, unica in masculis, triplex in foemineis. MAsc. Stamina 4 inserta sub pistilli rudimento simplici trilobove, filamentis exsertis, antheris adnatis, introrsis, post anthesim contortis. FoEM. Styli 3 crassi, intùs glanduloso-eanaliculati ; ovarium glabrum, inter stylos torulosum, 3-loculare, loculis 2-orulatis. Fructus capsularis, globosus, 3-rostris, èxtùs coriaceus loculicido-trívalvis, valvis è stylorum bipartibilium persistentiâ 2-cornibus; intùs 3-coccus, coccis tenuibus, 2-spermis. Semina lavia, lucida, nigra.

Arbores, frutices suffruticesve. liolia opposita, integra, quibus laminæ duæ, nisi ad ambitum, distinctæ, superior coriacea, venosa, inferior membranacea; petiolata, peliolo brevi decurrente in ramulos 


\section{$(1 /)$}

indè 4-gonos, oppositos, stipulis minimis persistentibus (gemmarum reliquiis) infrà cinctos. Flores axillares, glomerati ; in quolibet glomerulo bracteis imbricatis ad basin involucrato, masculi plures cingentes fœmineum unicum centralem, aut omnes abortı masculi.

obs. Species dux europacine, in hortis priesertim frequentes. - Congener

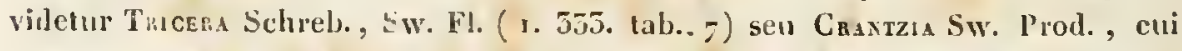
similiter flores monoci; calix 4-5-partitus; stanius 4 sub pistilli rudimento inserta, filaueutis lutis, exsertis, antheris introrsis arenatis; styli 5 crassi, persislentes, 2-partibiles; capsula trilariám dehiscens, intùs 5-cocca, coccis 2-sperusis; semina lævia, lucida, nigra. Differt laıtùm strueturá foliorum, quibus lanina simplex, et dispusitione llorum, qui racemosi sunt, fomineus unicus, terminalis, sessilis, masculi phures, ambientes, longiüs pedunculati, racemo pedunculisque ad basim bracteatis : qux scilicet inflorescentia fiat Buxi ipsius, in quo glomeruli axis, florunıque pedicelli subnuili elongentur. Tricerce species 3 cx Americà æquinoctiati.

\section{SECURINEGA. J.}

Flores diœci. Masc. Calix 5 -partitus. Stamina 5 opposita, filamentis exsertis, imà basi connatis, antheris oblongis, introrsis, cincta glandulis 5 alternis, discove glanduloso sinuato inserta, sub pistilli rudimento 5-partito lineari. ғoes. Calix 4-6-partitus, reflexus. Stigmata 3 subsessilia, reflexa, subbiloba; ovarium disco glanduloso impositum, 3-loculare, loculis 2-ovulatis. Fructus capsularis, 5-coccus, coccis 2-valvibus, seminibus levibus, nigris (ut in Buxo).

Arbores ligno durissimo. Fclia alterna, integerrima, coriacea, glabra, nitida, venosa. Flores axillares; masculi glomerati, multibracteati, bracteis ciliatis, conglobatis; fœminei longè pedunculati, pedunculis fasciculatis, ad basim bracteatis.

овs. Species proter Serurinegam nitidam W., borbonicam : undè genus illud institutum, altera mauritiana ( in herb. J.) qux tanseı forsản præcedentis lantùn varietas. Sed diversa certè $S$. nitida Lindley (Collect. tab. 9), otahítensis, cujus flores, ex auctore.monœci, axillares, subsolitarii ; instructi cálice ampliori; flamentis in discu magno inserfis; autheris parvis, subrotundis, Iransversè delsiscentibus; pistilli rudimento simplici, minuto ; ovario supcriủs in stylum erassum attenuato. 
SAVIA. W.

Flores diœci. Calix 5-parlitus. Petala 5-5, interdùm nulla, breviora, circa discum glandulosum inserta. masc. Stamina 5 , filamentis breribus, antlıcris, adnatis, introrsis, disco inserta sub pistilli rudimento simplici tripartitove. FoEM. Styli 5 reflexi, apice bifidi; stigunata 6; orarinm disco impositum, 5 -loculare, loculis 2-ovulatis. Fructus capsularis, 5 -coccus, coccis 2 -valvibus, 1 -spermis.

Frutex. Folia alterna, 2-stipulacea, stipulis minutis, caducis, integra, glabra, venosa. Flores masculi, glomerulati, glomerulis pluri-bracteatis, subspicalis ; fominei axillares, solitarii, bractcati, subsessiles.

oвs. Species unica ex Hispanioli, quæ Croton sessiliflorum Sw. Fl. - Placentarimm 5-alatum. - Orula è summo toculo pendula, mediante nrassả caruosà multò majori, quæ ea obtegit loculunque implet, indè prinı aspectu monospermun ; posteả, fructu ad maturitaten vergente, decrescit scusim, ferè mulla in maturo; in quo semen afterum abortivum. Similis massa, sed minor, occurrit in aliis generibus, ut Amanoa, Securinega, Leplonema. Cujus quænam natura? Non-ne arilli amborum seminum in unum corpus coaliti?

AMANOA. Aubl. - J.

Flores monœci diøcive. Calix 5-partitus. sasc. Stamina 5, filamentis brevibus, antheris summo filamento dilatato adnatis, introrsis; disco glanduloso 5-lobo imposita aut 5 glandulis interposita, sub pistilli rudimento 5 -lobo 3 -fidove. Foes. Stigmata 5 sessilia, crassa, sub-biloba ; orarium disco glanduloso impositum, 5-loculare, loculis 2-ovulatis. Fructus (ex Richard mss.) capsula drupæformis, obtusè 3-gona, intìs 5 cocca, coccis 2-valvibus, 1-spermis.

Arbores aut frutices. Folia alterna, 2-stipulacea, integra, glabra, lucida, nervosa. Flores glomerulati, glomerulis in spicas axillares, terminalesve dispositis, bracteâ squamosâ aut interdùm foliaceà stipatis; in quolibet glomerulo omnes masculi aut fœmineus unicus pluribus ruasculis mixtus, bracteis multis, in: rqualibus interjectis.

овs. Species, præter Amanoam guianensem Aubl. (tab. 1Q1), duæ ineditæ (in Herb. Rich.) ipsæ guiancnses. 
RICHERIA. Vahl.

Flores diøci. Calix 4-5-partitus. Patala 4-5. musc. Stamina 4-5, tetidem glandulis alterna, filamentis exsertis, antheris oblongis, ereclis, inserta sub pistilli rudimento conico, simplici. Focs. Stylus brevissimus; stigmata 5 -revoluta, suprà canaliculata ; ovarium disco carnoso impositum. Fructus suberosus, 6 -sulcus, intùs subcartilagineus, 5-locularis, loculis à basi 2-valvibus, 1-spermis.

Arbor ingens (habitu Mammex). Folia alterna, integra, subcoriacea, glabra, subtùs venosit. Flores in spicis axillaribus bracteati.

OBS Speries unica antillana. - Genus certè euphorbiaceum, confirmante situ et structura seminis, quod pendulum ex axi centrali reliquiis dissepimentorum quasi 5 -aluto, perispermoque instructum albicante, in quo embryo planus, flavicans, radiculà superâ. An loculi in ovario 2-ovulati, iidem in fructu abortu 1-spermi ? - Charact. ex Vahl Ecl. (1. 3o. tab. 4). - Ex Ryanio autem, à quo genus hoc primo detectum Vahlioque communicatum, flores quidam hermaphroditi, capsulæ 1-spermæ calice tectæ subbaccato, semen pulpâ molli involutum, corolla monopetala, calix 5 -sejalus. Valdè discordant igitur inter se amborum anctorum descriptiones, seu naturà varient mirum in modum flores, seu alteruter in obscrvationc defecerit.

FLUGGEA. W.

Flores diœci. Calix profundè 5-partitus. masc. Stamina 5, filamentis exsertis, antheris extrorsis, inserta sub rudimento pistilli bis bifido. His glandulæ 5 interpositæ. roEm. Stylus subnullus; stigmata 2-5 reflexa, 2-fida 2-partitave ; ovarium disco membranaceo insidens, 2-5-loculare, loculis 2-orulatis. Fructus capsularis aut subbaccatus. Semina 2 in quolibet loculo, quorum unum quandoquè effetum.

Frutices ramosi, ramis alternis, in spinam desinentibus. Folia alterna, glabra, parva. Flores axillares, fasciculati, fasciculis multibracteatis.

oвs. Specics, præter Fluggeam leucopyrum W., quæ Phyllanthus leucopyra Kœn., 2 aut 5 (in Herb. J. et Mus.) ineditæ, omnes coromandelianæ. - In semine Fluggece leucopyri perispermum paulisper incurvatum, depressaque extùs chalaza. Eadem in F. xerocarpá (Herb. J.) perforata, ibique semen 
parvâ cavitate intủs instructum, undè major perispermi et embryonis incurvatio.

\section{S E C T IO I I.}

Frores monœei aut diœci. Calix 4-5-6-partitus ; præfloratio convolutiva (exceptâ Briedeliâ). Petala o, rariùs 5 ; præilıratio convolutiva. susc. Stamina 2-5, rarius plura, centro calicis inserta, filamentis nunc liberis, nunc omnind aut partim coalitis, interdùm in stipitem pistilli abortivi. FoEM. Ovarium 2-10-loculare, loculis (sæpiùs 3 ) 2-ovulatis (exceptâ cluytiâ). Fructus rariùs carnosus aut baccatus, sæpissimè capsularis, 2-10-coccus, coccis 1-2-spermis.

Arbores, sæpiùs frutices, rarissimè herbe Folia nunc alterna et tunc sæpiìs pinnatim disposita, nunc rarissimè opposita. Flores fasciculati, aut glomerati, aut subsolitarii, axillares. Bracteæ plurimæ, parvæ, persistentes.

EPISTyliUm. Sw. Fl. - Omphalee spec. Sw. Prodr.

Flores monœci. sasc. Calix 4-partitus, laciniis 2 interioribus, majoribus, 2 exterioribus, alternis. Glandulæ 4 alternæ. Filamentum unicum, apice incrassatum; antheræ 2 divaricatæ, loculis summo filamento utrinque adnatis. FoEv. Calix 5-partitus. Glandulæ 5 minimæ alternæ. Stylus brevis aut nullus; stigmata 5 subbiloba; ovarium carnosum, 5-loculare, loculis 2-ovulatis. Fructus (ex Sw. Fl. $109^{5}$. tab. 22 ) capsularis, oblongus, obtusè 3-gonus, 3-valvis, 3-locularis, loculis 1-2-spermis.

Arbores fruticesve. Folia alterna, 2-stipulacea, integerrima, glabra, nitida, renosa. Flores faseiculati, fominei masculis pluribus mixti, fasciculis supra axem communem axillarem racemosim dispositis.

oвs. Species duæ jamaïcenses montanæ.

GYNOON.

Flores monæci. yasc. Calix 5-partitus. Filamenta 3 infrà coalita, 
superiùs distincta. Antheræ 3 extrorsæ, filamentis sub apice adnatæ. FoæM. Calix 6-partitus. Stigmata 3 hinc convexa, indè angulata, connata in massam unicam, ovoïdeam, duplò ovario majorem, 3-partibilem. Ovarium globosum, 6-sulcum, 3-loculare, loculis 2-ovulatis. Fructus....

Caulis lignosus. Folia alterna, 2-stipulacea, integra, coriacea, glabra. Flores fasciculati, fasciculis axillaribus, multi-bracteatis; fæminei masculis pluribus mixti.

овs. Species unica zeilanensis. - Nomen à stigmatum conıatorum formâ.

\section{GLOChidion. Forst. - Bradieïa. Gœrt.}

Flores monœei aut? diœci. Calix 6-partitus. masc. Stamina 3-6; filamentis infrà coalitis; antheris extrorsis, filamento sub apice adnatis, indè cuspidatis. Foen. Stylus crassus aut nullus. Stigmata 6 brevia, obtusa, erecta conniventiare; ovarium carnosum, 6-loculare, loculis 2-ovulatis. Fructus capsularis, globoso-depressus, umbilicatus, extùs 12-sulcus, corticatus, loculicido-6-valris; intùs 6-coccus, coccis chartaceis, 2-spermis. Semina fenestrata.

Arbusculæ aut frutices.' Folia alterna, integra, subcoriacea, supernè glabra, subiùs venosa. Flores axillares, pedunculati, solitarii fasciculative, in fasciculis masculi fom... cis mixti aut omnes ejusdem sexûs.

OBS. Species 4 descriplæ ab anctoribus (Goert. 2. 127. tab. 109. - Lamck. Ill. t. $77_{2}$. - Cav. ic. 571 . - W. Spec. ; quædam prætereà iu diversis herbariis ineditæ. Una ex insulis Societatis et novis Hebridis, una sinensis; cæteræ zeïlanenses, javanenses, philippenses. Sed propter statum imperfectum, hinc descriptionum, indè ş̣ecimiusum, valdè dubium adhùc, an speeies quæ innominatæ cælem novæ sint neque cognilarum conspecificæ. Onnes igitur sedulo in libris et herbariis conferendæ atque recognoscendæ. - Genus hoc Phyllantho affine, diversum tamen stigmatibus subsessilibus, simplieibus; eapsulis 6-cnccis; seminibus (ut Gœrtnerus primus optinè indicavit) sæpè in singulo loculo superpositis, duplieique cavitate instructis, alterâ inani , sub pelliculà tenui I-3-lenestratả, alterà embryoniferà, curvatâ, angustiori : hỉnc maxima perispermi, interdim vix ullius, tenuitas atque colyledonum incurvatio. 


\section{( 19 )}

anisonema. - Phyldanthi spec. Poir.

Flores monœci. masc. Calix 5-partitus. Glandulæ 5 alternæ. Stamina 5 , filamentis crássis, quoruuı 2-3 media, longiora, planè inter se coalita, 3-2 lateralia, sublibcra ; antherarum loculi utrinque filamentorum apici adnati. FoeM. Calix 4-6-partilus. Glandulæ totidem alternæ. Stigmata 6-1o brevia, sessilia; ovarium 6-30-loculare, loculis 2-ovulatis. Fructus capsularis, globoso-depressus, umbilicatus, 6-10-sulcus. Semina in quolibet loculo gemina, superposita, angulata, nonnulla sæpè abortiva.

Frutices ramosi. Folia in ramulis fasciculatis subpinnatim disposita, alterna, stipulacea, integra, fusca. Flores axillares, bracteati, pedunculati, masculi fasciculati, fœminei subsolitarii, occasu foliorum quasi racemosi.

Oвs. Species 2 indicæ, altera quæ Phyllanthus reticulatus Poir., altera inedita (il Herb. Mlus.). - Nomen à filamentis inter se inæqualibus.

\section{Leptonema. - Acalyphe spec. Poir.}

Flores diœci. Calix 5-partitus. Mśsc. Stamina 5 , rariùs 6 ; filamenta libera, capillacea, exserta; antheræ crassiores, loculis distinctis, in præfloralione pendulis, posteà erectis. Foæm. Styli 3-5, profundè 2-partiti ; ovarium 3-5-loculare, loculis 2-spermis. Fructus capsularis, globoso-depressus, intùs 3-5-coccus (sæpiùs 5), coccis 2-valvibus, 2 -spermis.

Frutex ramosus. Folia alterna, stipulacea, longè petiolata, subintegra, villosa. Pedunculi solitarii, axillares; in fremineis longiores, uniflori; in masculis multiflori, floribus subumbellatis, multibracteatis. Bracteæ lineares, longiusculæ.

OBS. Species unica nuadagascariemsis quæ Acalypha venosa Poir. - Nomengeneris à tenuitate filamentorum fito araneæ comparandâ. - Placentarium dissepinıntis quasi 3-5 alatum, superius expanditur in totidem inassulas, siigulas in singulis loculis pendentes, sub quibus excurrunt 2 funicuii, quiljus senina inseruntur. 
CICCA. L.-J. - Cheramelier.

Flores monœci, diøcive.Calix 4-partitus, intùs glandulis 4 alternis discove glanduloso instructus. Masc. Stamina 4, filamentis liberis, antheris adnatis, extrorsis. Foeu. Styli $4-5$ reflexi, bifidi; ovarium carnosum . 4-5-loculare, loculis 2-ovulatis. Fructus bacciformis, intùs 4-5-coccus, coccis 1-2-spermis.

Arbores aut frutices. Folia alterna, in ramulis alternis, deciduis subpinnatim disposita, stipulacea, integra, glabra. Flores axillares, fasciculati, fasciculis multibracteatis, foliorum casu vel abortu racemos mentientibus. Habitus Phyllantorum.

obs. Species 4, una indica radice lactescente (quæ Cheramela Rumph. 7. tab. 55), una javanensis, una cochinchinensis, quarte antillana (Herb. J. et Rich. ) - In Ciccri distichä seu Phyllantho longifolio, flores interdum exstant hermaphroditi, ex Jaç. (Hort. Schœnb. tab. 194).

Non-me affine Tricarios Lour. (681), arbuscula cochinchinensis, foliis alternis, integris, glabris, cui, ex auctore: flores monœci, racemosi; calix 4-phyllus, glandulis 4 instructus, stamina 4 , stigma laciniatum, fructus drupaceus, intìs 5 -coccus, 3 -spermus; discrepaus tantùm numero coccorum. - Quæ tamen, ex Wildenow, affinior Argythamniæ.

EMblica. Gœrt. - Phyllantil spec. L.

Flores monœci. Calix 6-partitus. uasc. Filamenta coalita in unum superiùs 3-antheriferum, antheris extrorsis, filamento sub apice adnatis, indè cuspidatis. Glandulæ 6 aut nullæ. FoEx. Styli 5 dichotomi, oblongi, rellexi; ovarium tubo membranaceo, 5-fido : inæquali cinctum, aut disco carnoso impositum, 5 -loculare, loculis 2-orulatis. Fructus (ex Gœrt. 2. 122. tab. 108.) drupæeformis, intùs 5-coccus, coccis 2-valvibus, 2 -spermis.

Arbores aut arbuscule. Folia alterna, stipulacea, parra, in ramulis alternis pinnatim disposita, decidua. Flores axillares, fasciculati, fasciculis post occasum foliorum densè quasi spicatis ; omnes masculi aut masculis focminei mixti; bracteati, bracteis persistentibus.

oвs. Species 2 indica, quarum altera Myrabalanus emblica C. B. - An vere congeneres Emblica grandis Gœrt. et E. palasis llamilton (Linn, soc. 15. 507), 


$$
\text { (21) }
$$

quarum fructus tantủm noti, integumento quiden carnoso, sed coccis in posleriore (cæterìm habitu dissimili) sæpè quatuor, in utràque monospermis?

Kinganelia. J. - Ardinghelia. Commers. mss, et icon. Purleaxthi spec. W.

Flores monœci. ussc. Stamina 5 , quorum 2 breviora; filamentis in columnam coalitis; antheris 5 terminalibus, 2 lateralibus. Focu, Fructus baccatus, absque coccis, 5 -locularis, loculis 2-spermis. Cietera ut in Pliyllantho.

Frutex. Folia pinnatim disposita, flores fasciculati et habitus Phyllanthorum.

oss. Species unica mauritiana et indica, quæ Phyllanthu's kirganelia W., eadem ac $P$. fasciculata Poir. Huc prætereà revocandæ species 2 aut 3 in herbariis inter Phyllanthos coliocatæ, floribus masculis monadelphis, peutandris, et fructu baccato. - Embryo colyledonibus planis, ovatis, incurvatis, ochroleucus intra perispermun colore ferrugineo.

PHYllanthuS. L. - J. - Nireri. Adans. - Conam. Aubl.

Flores monœci aut rariùs diœci. Calix profundè 5-6-partitus. Masc. Stamina 3 , rariùs plura ; filamenta infrà coalita in columnam glandulis 5-6 cum calice alternantibus basi cinctam, aut disco glanduloso 5-6 lobo impositam. Fox. Styli 3 basi interdùm connati, plerumquè bifidi ; stigmata 6 ; ovarium glandulis 5-6 cinctum, aut disco glanduloso membranaceove impositum, 3 -loculare, loculis 2-ovulatis. Fructus capsularis,, 3 -coccus, coccis 2-valvibus, 2 -spermis.

Arbores aut fructices, rariùs herbæ. Folia alterna, stipulacea, nunc magna, venosa, nunc sapiùs minora, in ramulis alternis pinnation disposita. Flores axillares subsolitarii, aut sæpins fasciculati, post occasum foliorum quasi racemosi ; multibracteati, bracteis acutis, persistentibus, interdìm conglobatis; in fasciculis nunc omnes ejusdem sexûs, nunc fominei $1-4$ masculis pluribus intermixti.

oвs. Species hujus generis circiter $; 0$ ab auctoribus descriptæ, quarum 50 americanæ, pleræque è plagis æuuinoctialibus; totidem asiatiæ, 4 scilicet sinen- 
scs, a urabicæ, cæteræ ex Indià, Javà, Ceylone; 10 africanæ, a scilicet capenses, aliæe madagascaricnses, borbunienses, mauritiauæ, quarın quadam indicarum conspecificæ. Nonnullæ prætereà in diversis herbariis novæ, è variis regionibıs, atque imprimis è Novâ-Hollandiâ, et insulis Oceani australis, undè paucissinæ in lucem hucusquè editæ.

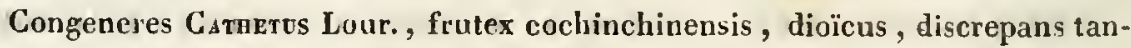
tùm foliis fasciculatis; et Nrmpasatus ejusdem, in quo filamentum unicum antheran gerens, ex auctore, 4-6- luculare $m$, babendum pro filamentis coalitis in unum apice 2-3-antheriferum. In hoc genere quatuor arbores aut frutices cochinchiucnses Phyllanto niruri consociantur.

Breynı Forst. ( ab. 75 ), frutex tannensis, foliis pinnatim dispositis, cui, ex dcscriptione et tabulâ auctoris : flores polygami ; calix 4-5-partitus; in hermaphroditis, antheræ 5 stylo adnata, stigma 1, bacca 5-locularis, 6-sperma; in masculis, glandulæ 5 et stamina 5 libera; in fœmineis stigmata 5 , capsula 5-locularis, 5-sperma, disco annulari cincta : his omnibus characteribus recedit à Pliyllanto. At in specimine (Herb. Mus.) manu Forsteri inscripto, flores masculi quidem cum descriptione concordant, fœeminei autem nihil aliud sunt nisi ramus $P h y$-llanti cernuce speciei in insula Timor quoque crescentis. Genus igitur aut delendum aut recognoscendum.

Puyclanthes cernua, P. rhamnoüdes, et quædam aliæ vicinæ indicæ aut timorenses, foliis in herlıario nigrescentibus, quibusdam cliaracteribus à Phyllantho discrepant. His enim flores monœci, axillarcs, fasciculati, bracteati bracteis sxpè imbricatis. Masc. Calix campanulatus aprice 6-lobus, lobis introflexis, brevibus; stamina 3 inclusa, filamentis brevibus coalitis, antheris 5 extrorsis, filamento sub apice adnatis, indè cuspidatis. Fam. Calix orbiculatus, 6-fidus, laciniis 5 interioribus, persistens. Stigmata 5 biloba bifidave, sessilia aut stylo brevi insidentia ; ovarium calice brevius, carnosum, 5-loculare, loculis 2-ovulatis. Capsula 5-locularis, 6-spcrma. Senina placcutario brevi, crasso affixa, pelliculà tenui vestita, iıtùs cavitate instructa duplici, alterà inani, liueari-5-fenestratâ, alterâ embryoniferá, curratâ, nuajori ; perispermum cum embryoue iscurvatum. An inde novum genus instituendum, medium Phyllantum inter et Glochidion?

Non-ne potiùs, nediım nuva genera à Phyllantho detrahantur, ipsi quædam alia consocianda, ut Xylophylla, Emblica, Kirganelia, Cicca, Menarda, Agyncïa, pleraque à quibusdam auctoribus ei jam adjuncia? Embryo spiralis, đquo Gortnerus (2. 123-25. tab. 108) Plbyllantum à Xylophyllà dis- 


\section{$(25)$}

cernit, neque pro charactere generico adhibcri posse, neque præterea in omnibus Phyllanthis existere videtur.

XYlOPHYLLA. L.-J.-Gœrt. - Genesiphylla. Lher. - Piy leantui spec. Sw.-Kunth. - Pharnacei spec. Pall.

Flores monœci. masc. Stamina $2-\overline{3}$, filamentis infrà aut omninò coalitis. Foex. Styli 3 reflexi; stigmata 3 lacera. Cætera ut in Phyllantho.

Frutices aphylli, extremis ramulis 2-stipulaceis, complanatis, dilatatis, crenatis , folia mentientibus. Flores in crenulis ramulorum fasciculati, omnes ejusdem sexûs aut fœminei masculis mixti, muitibracteati, bracteis persistentibus.

obs. Species 10, quarun una indica, una siberica, cæteræ ex Americâ æquinoctiali. - Flores hermaphrodiri, pentandri, cx Linnæo, fortè glandulas pro antheris habente. Quibus characteribus rejcetis, genus hoc vix à Phyllantho diversum, nisi tamen peculiari quodam habitu, propter ramulos dilatatos, à plerisque pro foliis veris descriptos. Sed diversam foliorum istorum naturam demonstrant analogia et structura, tùm in ipsis separatim inspecta, tùm comparata cum ramis junioribus, tùm denique notata in quibusdam speciminibus ubi ex corum crenulis non flures oriuntur, sed folia similia, ipsa interdum foliifera.

MENARDA. Commers.

Flores monœci. Calix magnus persistens, 5-partitus. uAsc. Stamina 5 , filameutis liberis, antheris adnatis, extrorsis. Glandulæ 5 calici alternæ. Foes. Styli 3 crassi, bipartiti; ovarium disco glanduloso latiori impositum. Catera ut in Pliyllantho.

Arbuscula, ramis oppositis alternisve. Folia alterna, aut sapiùs opposita, stipulacea, integra, glabra. Flores axillares, solitarii, aut pauci fasciculati, fominei masculis mixti, longissimè et tenuissimè pedunculati, bracteati.

oвs. Species unica madagascariensis (Herb. J. et Mus. ). - Congener videlur Phyllanthus multiflora Poir., qua ex eadem regione. 


\section{MICRANTHLA. Desf.}

Flores monœci. nasc. Calix coloratus, 6-sepalus, sepalis 3 alternis, interioribus, majuribus, petaloïdeis. Stamina 3 libera, circa discum glandulosum trilubum inserta. roes. Calix 6-partitus, laciniis subulatis. Styli 3 simplices, breves ; stigmata 3 ; ovarium 3-loculare, loculis 2-ovulatis. Fructus capsularis, stylis persistentibus acuıninatus, 5-coccus, coccis bivalvibus, 2-spermis. Semina teretia; embryo, intra perispermum conforme, gracilis.

Suffrutex. Folia ternatim fasciculata, alterna, linearia. Flores breviter pedunculati, 1-5 axillares.

oвs. Species unica ex Novà-Hollandiâ, quæ Micranthea ericoüdes Desf. (Mem. Mus. 4. 253. tab. 14), undè character hic desumptus.

\section{AGYNEİA. L.-J.-Vent.}

Flores monœci. Calix 6-partitus. masc. Stamina 3, filamentis coalitis in columnam centralem, apice 5 -lobam, lobis extùs antheriferis, antherâ adnatâ, infrà inpositam disco 6-lobo membranæformi, calicem intùs partim restienti. Föir. Ovarium apice foveolatum, in foveâ 5-stylum, stylis bifidis, 5-loculare, loculis 2-ovulatis. Fructus capsularis, ab apice ad basim 6-valvis, 5-locularis, loculis 2-spermis. Semina (ex Richard) arillata, arillo fissili in tres partes, unam dorsalem caducam, duas laterales persistentes appositasque placentario indè quasi 1 2-alato.

Frutices aut herbæ. Folia alterna suboppositare, stipulacea, parra. Flores fasciculati, axillares, fasciculis paucifloris, bracteatis, in quibas fominei 1-2 longiùs pedunculati, cateri masculi.

овs. Species 4, duæ sinenses, duæ indicx, quarum una Phyllanthus bacciformis L. - Agyneïa obliqua et $A$. multilocularis W. quibus ex descriptione ( in Spec. 1,22, et Act. sociel. natur. curios. Berci. 4. 20/i) antheræ 5 filamentis in unum coalitis adnata, stignata 5 simplicia, capsula 5-locularis, fulia magna glaucescentia; hine dimovendie et forsàn Glochidio afliniores.

ANDRACHNE. L.-J.

Flores monœci. Calix 5-partitus. siasc. Petala 5 membranacea: 


\section{$(25)$}

interjectis squamulis 5 bipartitis aut nullis. Stamina 5 , antheris introrsis, filamentis infrì connatis in stipitem pistilli abortivi. roEM. Petala 0. Styli 5 breves, divaricati, bifidi; stigmata 6 ; ovarium basi nudum aut squamulis 5 bifidis, calici alternis, cinctum, 3-loculare, loculis 2-ovnlatis. Fructus capsularis, 5-coccus, coccis 2-valvibus, 2-spermis. Semina punctata.

Frutices aut herbæ. Folia alterna, stipulacea. Flores axillares, solitarii aut fasciculati, bracteati.

obs. Species 4; duæ cditæ, attera italica et orientalis (quæ Telephioïdes T. et Hoencl.., Limeum et Eraclissa Forsk.), allera indica, cujus exstat varietas (Chutice spec. L., Arachne Neck.) calice in masculis orbiculato, 5-dentalo; duæ aliæ novæ timolenses (in Herb. Mus.).

Cluytia. Ait.-W. - Clutia. Boer.-L.-J. - Altora. Adans. Cratochwilia. Neck.

Flores diøeci. Calix 5-partitus. Petala 5 laciniis calicinis alterna; iisdem opposite appendices 5, 2-3-fidx, glandulos $x$. Irasc. Stamina 5 ; antheris in præfloratione introrsis, posteà versatilibus; filamentis infrì connatis in pistilli abortivi stipitem, basi cinctum glandulis 5 simplicihus aut bifidis. ғоем. Styli 3 reflexi, bifidi; ovarium interdùm pedicellatum (ex Gœrt. 2. 117.tab. 107), 3--oculare, loculis ı-ovulatis. Fructus capsularis, globosus, intùs $\bar{j}$-coccus.

Arbusculæ aut frutices. Folia alterna, stipulacea, sæpè angusta rigidaque. Flores axillares, bracteati, breviter pedunculati, solitarii fasciculative.

OBS. Species circiter 20, quarum una arabica, 14 capenses. Quinque autem alias, quarum 4 indicæ, una cochinchinensis, quamvis capsula 3-loculari donatas, crediderim potiùs congeneres Briedeliæ. His enim (ex Lour. 784 et Roxb. lab. 169-1;0) flores interdum monœci; calix 5-fidus acutus, cui petala 5 parva inserta, non appendicibus glandulosis instructus, sed disco simplici in mascutis, tubo in fœmin is; loculi ovarii quandoquè 2-ovutati; folia majora; habitus denique totus similior. 


$$
\text { ( } 26 \text { ) }
$$

BRIEDelia. W. - Cuuytia spec. Roxb.

Flores monœci. Calix 5-fidus; præfloratio valrata. Petala 5 minuta, calici inserta, alterna; præfloratio convolutiva. ussc. Stamina 5, antheris introrsis, filamentis connatis in pistilli abortivi stipitem, impositum disco basi calicis adnato, ad ambitum sinuato. Fozs. Styli 2 bifidi; orarium tubo (nectarium Roxb.) apice 5-fido inrolutum, 2-loculare, loculis 2-ovulatis. Fructus bacciformis, 2 -locularis, loculis 1-2-spermis.

Arborcs aut arbusculæ interdùm scandentes. Folia alterna, stipulacea, integra. Flores glomerati, glomerulis bracteatis, axillaribus aut in ramulis (non-ne occasu foliorum?) quasi spicatis; nunc omnes ejusdem sexûs, nunc fœminei masculis mixti. Ex Wildenow, quiỏam lermaphroditi.

овs. Species 4 indicæ, Cluytiæ primò adnumeratæ, C. retusa scilicét, et tres aliæe $4 x$ Rosb. (tab. 171-73). Duæ prætereà ineditæ è Congo (Rob. Brown. Obs. he1b. Cong. 25).

\section{SE C T I O III.}

Flores monœci aut diœci. Calix $2-5$ aut rariùs plurifidus partitusve; præfloritio valvata aut convolutiva. Petala o aut 5-10, rariùs in corollam monopetalan coalita; prefloratio convolutiva aut rariùs contorta. IIAsc. Stamina definita aut indefinita, filamentis nunc liberis, receptaculo plano aut convexo insertis, nunc inter se variè coalitis. FOEM. Ovarium 2-5-loculare, loculis 1-orulatis (exceptâ Hyænanche). Fructus carnosus aut sxpiùs capsularis, 2-5-coccus.

Arbores aut frutices, rariùs herbe. Folia alterna, nunc simplicia, nunc pluripartita, nunc rarissimè 3-5-phylla. Flores fasciculati, racemosi, paniculative aut sepius spicati.

ARGYTHAMNIA. P. Br. - J. - Sw. Fl.

Flores monœci. sasc. Calix 4-partitus, villosus ; prefloratio valrata. Petala 4 alterna, villosa, colorata, subunguiculata. His opposita sta- 


$$
\text { (27) }
$$

mina 4, antheris introrsis, filameutis exsertis, imâ basi coalitis sub pistilli rudimento centrali, minuto. Glandulæ 4 alternæ. Foњ 5 -partitus, villosus, persistens, cujus laciniis oppositæ 5 squamulæ. Corolla o. Styli 5 bis bifidi, breves; stigmata lacera; ovarium villosum, trisulcum, 5 -loculare, loculis 1 -ovulatis. Fructus capsularis, 5-coccus, coccis bivalvibus; semina punctata.

Frutex. Folia alterna, nerrosa, colore puniceo imbuta, sicut et flores, qui in racemulis axillaribus, brevissimè pedunculati, singuli bracteati; masculi plures, superiores, minuti ; fominei subsolitarii, inferiores, majores.

овs. Species unica antillana. - Congener, ex Adanson, Ateramnus P. Br., jamaïcensis.

\section{DITAXIS. Valıl.}

Flores monoci. Calix 5-partitus; præfloratio valvata. Petala 5 alterna; præfloratio convolutiva. Masc. Stamina 10 , antheris introrsis, filamentis infrà connatis in stipitem pistilli abortivi, verticillata quinque superiora, quinque inferiora. foæ.M. Glandulæ 5 , calicinis laciniis oppositæ. Stylus 3-fidus, laciniis 2 -fidis; stigmata 6 lobato-crenulata; ovarium villosum, 5-loculare, loculis 1-ovulatis. Fructus capsularis, calice persistente cinctus, 3 -coccus, coccis bivalvibus ; semina lævia.

Caulis liguosus, cinerascens. Folia alterna, solitaria fasciculatave, præsertim cùn juniora, integra aut serrulata, colore puniceo imbuta, sicut et flores. Pedunculi axillares, bracteati, paucitlori, flore fœmineo unico, terminali, majori, masculis 2 , rarò pluribus, in frà sitis, oblongis, citò deciduis, bracteatis, bracteis persistentibus Totus habitus Argythamnix.

obs. Species 5 , duæ antillanæ (in Herb. J., Desf. et Mus.), tertia marauonensis (in Herb. Kunth.).

CROZOPHORA. Neck. - Tounnesolia. Scop. - Crotonis spcc. auctorum.

Flores monoci. siasc. Calix 5-partitus; prefloratio valvata. Petala 5 
extùs furfuracea ; præfloratio convolutiva. Stamina 5 aut sæpiùs 8-10, quorum 5-5 superiora; flamentis in profloratione erectis, infrai connatis in columnam receptaculo glanduloso impositam; antheris extrorsìm sub apice filamentorum adnatis, indè cuspidatis. ғоEм. Calix 10-páritus, laciniis linearibus. Petala o. Styli 3 bifidi; stigmata 6 ; ovarium plerumquè squamulis furfuraceis argenteum, 5-loculare, loculis 1-orulatis. Fructus capsularis, 3-coccus.

Frutices aut sæpins herbæ. Folia alterna, stipulacea stipulis deciduis, sinuata, sæpè plicata molliaquc. Flores in apice aut dirisuris ramorum racemosi, bracteati bracteis longiusculis, linearibus; forninei in racemis inferiores, longiùs pedunculati, masculi densi superiores. Plantæ diversæ partes extùs pilis stellatis tomentosæaut rariùs farinaceæ, intùs in plerisque colore puniceo imbutæ.

овs. Species cireiter 8, duæ senegalenses, cæteræ ex Arabià ant Afrieà boreali, quarım duæ et in Europâ australi crescunt : inter quas scilieet, Croton tinctorium L., C. obliquum Valıt., C. plicatum Vahl., $C$. verbascifolium W., C. oblongifolium Delite, C. senegalense Lanck. Quibus, ex descriptione, forsån eongeneres $C$. mollissimus Geis. et $C$. Rotlleri Geis., alter sinensis, alter indieus.

CROTON. L.-J.-Kunth. - Crotonis spec. auctorum.-Ricinö̈des.T. - Croton, Arotoy, Luntia, Cinogasum. Neck. - Tridesmis. Lour. Cascarilla. Adans.

Flores monœei, rarissimè diœci. 3asc. Calix 5-partitus; præfloratio valvata. Petala 5 ; præfloratio convolutiva. Glandulæ 5 petalis alternx. Stamina definita $(10-20)$ aut rariùs indefinita; filamenta libera, in præfloratione inflexa, posteì erecta, exsertil, receptaculo nudo aut villoso imposita; antherx apici filamentorum adnatæ, introrse. roєм. Calix 5-partitus, persistens. Petala o. Styli 3 nunc bifidi, nune (Luntia. Neck. - Tridesnis. Lour.) pluripartiti; stigmata 6 aut plura; ovarium, basi glandulis aut appendiculis 5 cinctum, 5-loculare, loculis 1-ovulatis. Fructus capsularis, 5-coccus : coccis 2-ralvibus. 
Arbores, frutices, suffrutices aut herbx. Folia alterna, slipulacea, basi sxpè 2-glandulosa, integra, serrata aut lobata, nunc squamulis argenteis auratisre, nune pilis stellatis, presertim subtùs, punclata aut obsita, ramulis, pedunculis, calicibus, capsulisque plerumquè similiter squamulosis aut pilosis. Flores laxé aut densè dispositi in spicis racemisve, axillaribus aut sepiùs terminalibus, nunc brevibus capitulaque xmulantibus, nunc longis aut eliam longissimis; in quibus singuli bracteati, nunc omnes ejusdem sexûs, nunc maseuli fæmineis intermixli, nunc sæpissimè masculi superiores, inferiores fominei.

ops. Sub nomine Crotonum species ferè 200 ab auctoribus descriptze. Sed è genere nunc severiùs circumscripto circiter 50 ad alia depellendæ, totidem imperfectè adhùc cognitæ, too certè lıujus generis; multæ prælered̀ in herbariis novæ et inedilæ. Veri Crotones ferè omnes americani, cimn ex centum suprà dictis decima pars tantùm ex Asià ct Africà oriatur, id est, sex indici, zeilonenses, cochinchinenses, sex madagascarienses, mauritiani, borbonienses, capenses adnumcrentur, cùmque inter novas species vix una mihi non americana occurrerit. Inter Crolones minùs cognitos, è quibus plerique quoque americani, major tamen respectivus numerus specierum asiaticarum et africanarum. Sed ipsæ ì Crotonibus plerumquè discrepant quibusdam, signis, ut foliis utrinque glabris, pilisque simplicibus : qux discrepantia non levis est, cùm folia sola sxpissimè in his describantur, non visis floribus, et pili stellati characterem magni momenti in hoc genere suppeclitent.

Inter species è Crotonibus depellendas, multæ in hàc dissertatione diversis generibus (Savia, Crozophora, Rottlera, Codiarum) consociantur. Alix supersunt indicaudæ, quarum quædam exstant undè nova genera aut instituta finerint neque rccepta, aut sint forsàn in posterum instituenda.

Crotos denticulatum Geis., herba syriaca, nibil alind est nisi species Euphorbix.

Свотох eriospermum Lamck., brasiliense ; cujus folia opposita, flores ignoti, racemosi, frnctus 5-locularis, loculis polysperınis', semina lảná rufescente involuta, perispermo mullo temuissinove, recedit ab liuphorbiaceis, affinius forsàn Trigunix.

Cвотоs microphy.llum Lamck., herba peruviaua, in qua flores monœeci, calix 5-partitus, petala o, stamina 5 basi 5-glandulosa, styli 3 bifidi, capsula 
3-locularis, loculis a-spermis; characteribus habituque aflinior Phyllanthis.

Свотом monanthogynum Michx., herba carolinensis, habitu quidem Crotonibus simillima, sed floribus masculis calix 4-fidus, petala 4, glandula totidem alternæ; stamina 4 antheris introrsis, flamentis liheris insertis sub rudimento pistilli centrali, bipartito; fominis, ovarium 2-loculare, 2-spcrmum, styli a bipartiti.

Croton ricinocarpos L. qui Ricinocarpos Buer. seu Brunsvia Neck., ex his auctoribus, instructus calice duplici, utroque 5-partito, in masculis 8-andro.

Crotons viscosi La Bill. (2. 72 . tab. 222 ) fulia integra, viscosa; flores monœci pedunculis axillaribus 1-2-floris; calix 5-fidıs. Masc. Petala 5, sæpiùs o; stamina 50-40, flamentis brevibus, antheris extrosis. Fom. Styli 5, simplices, breves, stigmata 5 .

Свотомıs quadripartiti La Bill. (2. 75. tab. 223) folia opposita, serrata, glabra; flores diœci, bracteati : masculi spicati, terminales, quibus calix 4-partitus in præfloratione valvatus; stamina plurima, flamentis brevibus in præfloratione erectis, antheris adnatis, apiculatis, introrsis : foninei racemosi, axillares, quibus calix 5-7-partitus, styli 5 bidentati.

Cвотоn cyanospermum et C. cardiospermum Gort. (2. 120. tab. 107), species zeïlonenses, quarum nulla pars nota præter capsulam 3-coccam ; il priori 6-spermam, cotyledonibus obliquè cordatis ; in posteriori extís à basi 6-valvem, 3-spermam, seminibıs infrà perforatis, absque ullo dubio ad Crotones non speolant ; monente Goertnero.

In Crotone castaneifolio L. et C. palustri L.- Kunth., herbis americanis : flores monceci. Masc. Calix 5-partitus; petala 5 altcrna; stamina 10 , anthcris introrsis, flamentis infrà connatis in stipitem pistilli abortivi, verticillata 5 supcriora, 5 inferiora. Fom. Calix 5-partitus, aut 6-partitus laciniis 5 alternis, brevioribus; petala 5-6 alterua, citò decidua aut ıulla; styli 3 flabellato-multilidi, glabri; fructus 5-coccus, coccis 2-valvibus, 1 -spermis. Flores in spicis axillaribus umlaterales, bracteati; superiores masculi plures, decidui; inferior s foeminei. Folia alterna, oblonga, serrata, nerrosa, juuiora subviolacea. Hispidi caules, petioli, nervi, pedunculi, calices, fructus, pilis simplicibus, in altcrâ specie, apice glandulileris. Non-ne novum genus indè instituendum?

Croton tricuspidatus Lamck. scu lanceolatus Cuv. (icon. 6) et $C$. quinquecuspidaius (Hırb. Mus.), herbæ, altera chilénsis, ältera peruviana, affines præcedentibus habitu, influrescentia, foliis oblongis, serratis, violaceu colure, sicut flores, inbuis, sed dissimiles calice 5 -glanduloso, in masculo flore petalis 5 colo- 
ratis, unzuiculatis, limbo 5-5-cuspidato, staminibus 5 monadelphis; in fomineo, stylis bifidis. Planta medix inter Ditaxim et Crozophoram.

Crotos solanifolius Geisel., herba javanensis, à veris Crotonibus differt calicis 5-partiti pr'æloratione convolutiva, petalorum defectu, staminibus plurimis, ercetis, in globum compactis, ovario pilis simplicibus hirsuto, foliis glabcrimis toto habitu.

\section{CROTONOPSIS. Michx.}

Flores monoci. Masc. Calix 5-partitus; petala 5 alterna, receptaculo inserta ; stamina 5 filamentis liberis, exsertis, antheris apicifilamentorum dilatato adnatis, introrsis. Foer. Calix 5-partitus, laciniis 2 sxpiùs abortientibus, intùs squamulis totidem oppositis instructus. Stigmata 5, subsessilia, biloba; ovarium uniloculare, 1-ovulatum. Fructus siccus, indehiscens.

Caulis herbaceus, squamulis furfuraceis punctatus. Folia iisdem subtùs argentea, alterna, angusta. Flores in extremis ramulis axillares, occasu foliorum quasi spicati, fominei inferiores, bracteati. Calices et fructus pilis stellatis obsiti.

oвs. Species unica carolinensis, quæ C. linearis Michx. (2. 185. tab. 46), varians foliis linearibus ellipticisve. - Genus affine Crotoni, habitu, calicibus, foliis lepidotis, pilis stellatis; Euphorbiaceum inverso seminis et embryonis situ et perispermo carnoso, abnome tamen fructu 1-loculari. An abortu? At mihi in ovariis junioribus loculus semper unicus occurrit.

ADELIA. L.-J.- (non Michx.) - Bernardia. Houst.

Flores diœci. Calix 5-6-partitus; præfloratio valvata. Petala o. sasc. Stamina plurima filamentis in prefloratione erectis, basi coalitis, antheris globosis. Fo: S. Stigmata 3 subsessilia, lacera ; ovarium disco impositum, 5 -loculare, loculis 1-ovulatis. Fructus capsularis, 3-coccus.

Frutices, ramis interdùm in spinas desinentibus. Folia alterna, integra ant subserrata, nunc glabra, nunc pilis stellatis subtùs tomentosa, sicut et ramuli, pedunculi, bractex, calices. Flores axillares aut ferminales, spicati aut fasciculati, aut etiam solitarii, bracteati. 


\section{$(52)$}

oвs. Species 7 , sub numine Adelice, in libris et herbariis, quarum 6 americüse. Quxdam autem habilu aut nousullis characteribus dispares. - In $A$. forruginea' Poit. (Herb. Il us et Desf.) stamina 10 inserta ad ambirum disci glandulosi, centralis. - A. virgata Enc. suppl., sub nomiue A. Acidoton? In hortis culta, cujus flores foeminci tantùm noli, Flnggeæ aflinior habitu, foliis parvis, apice subemarginatis, præfloratione convolutià, stylis 5 brevibus bifidis, loculis 5 2-ovulatis. - A. anomala Enc. supp., ex Sierrà-Leoud, cui spinæ in ramis opposita, ad quarum axillas folia alterna, glubra, subcrcuata ; flores masculi, in racemis axillaribus fasciculati, fasciculis 2-0̃ -lloris, basi bractcatis; calix 3-partitus, in præfloratione valvalus; stamina plurima receptaculo villoso inserta, loculis antherarum distinctis, in apice filamenti erectis (planè ut in Claoxylo); hinc huic gemeri affuior quàm Adelia, si tamen Euphorbiacea. Flores autem fomineos, racemosos, minutissimos, stigmatibus $2-3$ reflexis (ex descriptione Encycl.), quamvis in coden specimine, nullos reperi. Forsàn pro talibus habiti pedunculi $2-\overline{5}$-fasciculati, bracteis infrà cincti, post occasuın florum reflexi.

\section{ACIDOTON. SW.}

Flores monœci vel diœci. Issc. Calix profundè 5-partitus, reflexus. Petala o. Stamina plurima, filamentis receptaculo globoso insertis, antheris erectis. Foxur. Calix profundè 6-partitus, patens. Stylus brevis, 5-fidus; stigmata 5 reflexa, tomentosa. Fructus capsularis, 5-coccus, coccis 2-ralvibus, 1 -spermis.

Arbuscula frutexve. Fo!ia stipulacea, alterna, integra, glabra, nerrosa. Flores in diversis racemis masculi et fominei, fœmineis longioribus, plerumquè terminalibus, bracteis minutis stipati. Rami, petioli, pedunculique setis urentibus hispidi ; foliaque iisdem ciliata.

овs. Species unica jamaïcensis. - Charact. ex Sw. Fl. $9^{52}$ tab. 18.

ROTTLERA. Roxb. - Crotoris spec. auctorum.

Flores dioci aut? monoci. MAsc. Calix 5-5-partitus, laciniis in præfloratione valratis, posteà reflexis. Petala o. Stamina plurima in prefloratione erecta; filamenta libera, aut tanlùm basi coalita, inserta receptaculo nudo aut villoso, plano aut conrexo; antherarum loculi adnati apicifilamentorum dilatato autinterdùm graniformi. Foc.y. Cialix 
3-5-partitus. Petala o. Stylus 2-3-partitus aut styli $2-3$ reflexi, intùs plumosi ; ovarium 2-5-loculare, loculis ı-ovulatis. Fructus capsularis, $2-\tilde{J}$-coccus, inermis aut molliter echinatus.

Arbores aut frutices. Folia alterna, basi interdùm 2-glandulosa, integra aut crenata, renosa, nunc pilis stellatis subtùs punctata obsitare, nunc rariùs adultiora utrinque glabra. Flores in spicis racemisve axillaribus aut terminalibus, simplicibus aut ramosis, solitarii glomerative, bracteati. Capsulæ pilis stellatis, sicut pedunculi, bracteæ, flores, plerumquè obsitæ, interdùm granulis coccincis flavisve pulverulentæ.

OBS. Species circiter 20 , indicæ, zeïlanenses, javanenses, philippicæ, sinenses, , juædam timorenscs; inter quas adnumeranda, Croton philippense Lamck. , C. punctatum Retz., C. acuminatum Lamck., C. paniculatum Lamck., C. ricinoïdes Pers., Ricinus apelto Lour., et forsann quoque Craton nutans Forsk. et C. chinensis Geisel. Cæleræ species aut novæ (Herb. Mus. et J.), aut quædam forsản Crotonum imperfectè cornitorum conspecificx.

Aftinis babitu Trewia nudiflora W. spec., qux Roltlera indica ejusdem (Goett. diar. hist. nat. 1. 8. t. 5), cui : flores dioci. Calix 3-4-partitus, in præfloratione valvatus, posteà reflexus. Masc. Stamina plurima, erecta, filamentis basi coalitis. Fom. Stylus 4-partitus, laciniis oblongis, reflexis, intủs plumosis; ovarinm 4-loculare, luculis 1-ovulatis. Fructus (ex Commel. mal. 3 et Recd. 1. =6. tab. 42) 3-coccus. Sed tanen non tantùm à Rottlerá, sed etian ab Euphorbiaceis depellenda est, utpotè conspecilica, ex Willdenow, Tetragastris ossexe Gœrt. (2. 1 jo. tab. 109), in quâ fructus baccatus, intùs 4-pyreuus, pyrenis 1-spermis, seminibus pendulis, perispermo destitutis.

MaLlotes Lour, arbor sinensis consociata Trewiæ à Willdcnow, affinior tamen Rottleræ ex descriptione (Lour. 780 ); nam : folia tricuspidata, tomentosa; flores racemosi, diœci ; calix 3-phyllus, foliolis pilosis patentibus; in masc. stamina plurima receptaculo inserta; in foen. styli $\mathbf{j}$ oblongi, reflexi, hirsuti, colorati; fructus capsularis 3-lobus, 3-locularis, loculis 2-valvibus, 1-spcrmis, viltis multis, tomgis, mollibus septus.

COdieull, Rumph. - Prrmlaurea. Lour. - Grotons spec. L.

Flores monœci. sasc. Calix 5-partitus, reflexus ; prefloratio convolutira. Pelala 5 alterna, minora, squamiformia, quibus glandula 5 interiores alternæ. Stamina plurima; filamenta in præfloratione erecta, 
libera, receptaculo inserta; antherarum loculi utrinque apici filamentorum adnati. FoEm. Calix 5-fidus. Petala o. Styli 5 simplices, oblongi, reflexi; ovarium infrà squanulis 5 cinctum, 5 -loculare, loculis 1-orulatis. Fructus subbaccatus (ex Rumph.) aut capsularis, 3-coccus.

Arbores aut frutices. Folia alterna, integra, glaberrima, lucida, interdùm eleganter variegata. Flores axillares aut terminales, racemosi, in racemis diversis masculi et fæminei, bracteati singuli.

obs. Species 2; altcra (Crolon variegatum L., seu Codicaum Rumph. 4.65 tab. $25-25$ ) indica, cochinchineosis, moluccana, japonensis, cujus plures varietates; altera timorensis (in Herb. Mus.).

GELONIUM. Roxb.-W.- ( non Gœrt. et A.P. T.)

Flores diæci. Calix 5-partitus, reflexus; prefloratio convolutiva. Petala o. masc. Stamina 12 aut multò plura, receptaculo multiglanduloso imposita, filamentis exsertis, antheris adnatis, extrorsis, oblongis. Foen. Stigmata $2-\overline{3}$ sessilia, lacera; orarium carnosum, disco glanduloso impositum, 2-j-loculare, loculis 1-ovulatis. Fructus capsularis , 2-5-coccus.

Caulis lignosus. Folia alterna, integra aut apice tantùm serrata, coriacea, glaberrima, lucida, venosa ; juniora (ex W. in G. bifario) involuta stipulâ simplici, ante explicationem vaginante, mox caducâ (ut in Ficu). Flores fasciculati, fasciculis axillaribus, multibracteatis.

овs. Species 3-4, una timorensis (Herb. Mus.), cæeteræe indicx.

\section{HISINGERA. Hell.-IV.}

Flores diceci. masc. Calix 4-sepalus. Petala 0. Stamina 15-25, filamentis distinctis. Glandulæ minutæ, difformes, ad basim staminum quadratim locatæ. Foєм. Calix 6-sepalus. Petala o. Styli 2 breres, crassi; stigmata capitato-depressa, anticè bidentita. Bacca subrotundo-didyma, 2-locularis, 2-sperma.

Frutex ramosus, ramis alternis. Folia (carpini) alterna, apice serrata, glabra, coriacca, nitilla. Flores axillares, conferti, pedunculati, pedunculis nnifloris, brevibus. 
obs. Species unica antillana. - Charact. ex Hellen. (Act. holmiensia. $179^{2}$ 32. (ab. 2).

MOZINNA. Orteg. - Loureïr. Cav.-W.

Flores diœci. Calix 5-partitus. Corolla urcenlata, 5-loba. Glandulæ 5. Masc. Stamina $8-15$, filamentis infrà coalitis, 5 exteriora, breviora. Fow. Stylus bifidus; stigmata 2 lata emarginata aut 4 linearia. Capsula calice persistente infrà cincta, 2-valris, 2-cocca, coccis 1-spermis, interdùn abortu 1-locularis, 1-sperma.

Frutices succo foti gummoso. Folia alterna aut fasciculata, stipulacea, integra aut rariùs lobata, pilis glanduliferis interdìm (sicut calices) ciliata. Flores bracteati, axillares aut terminales, fominei solitarii geminative, masculi fasciculati aut corymbosi.

obs. Species 2 mexicanæ. - Charact. ex Cav. (ic. 5. 17. tab. 429-30) et Ort. (dec. 105. tab. 15).

\section{AMPEREA.}

Flores monœci aut? diœci. Masc. Calix campanulatus, 4-5-fidus; præfloratio valvata. Petala 0. Stamina $S$ exserta, filamentis subliberis, 4 exterioribus brevioribus; antherarum loculi distincti, è connectivo granuliformi utrinque pendili, orati, lutei, in longum secundùm lineam fuscam dehiscentes. FoEx. Calix 5-partitus, laciniis rigidis, persistens. Stigmata 5 erecta, bifida, divisuris acutis. Fructus capsularis, ovoïdeus, pericarpio tenui, 5 -cocco, coccis 2 -ralvibus, 1 -sper- mis, deciduis.

Suffrutices? ramis compressis, erectis aut virgatis. Folia alterna aut sparsa rariora, brevia, linearia, acuta. Flores axillares, selitarii aut fasciculati, fasciculis 2-aut-plurifloris, masculis aut fomineis, multibracteati, bracteis rigidis, acutis, interdùm ciliatis. Habitus à plerisque Euphorbiaceis valdè diversus.

овs. Species 5 è Novà-Hollandià (in Herb. Dus.) - Genus dicatum claro Ampere, ex acad. scient. 
RICINOCARPOS. Desf.

Flores monœci. Calix 5-partitus. Petala 5 longiora. yasc. Stamina numerosa, filamentis connatis in columnam glandulis 5 cinctam, à basi ad apicem antheriferam, antheris adnatis, extrorsis. FoEsr. Styli 3 bipartiti ; orarium squamulis 5 cinctum, papillosum. Capsula globosa, trisulca, aculeis conferlis cchinata, 5-locularis, loculis 1 -spermis.

Frutex. Folia alterna, linearia, mucronala. Flores terminales, pedicellati, bracteati, solitarii corymbosive, corymbis paucifloris. Capsula et semina Ricini.

oвs. Species unica è Novâ-Hollandiâ.-Charact. ex Desf. (Men. Mus. 3. 459. tab. 22 ).

\section{RICINUS. L.-J. - Hicin.}

Flores monœci. Calix 3-5-partitus; præfloratio valvata. Petala o. Masc. Filamenta plurima mullifariàm ramosa ; antherarum loculi distincti, sub apice filamentorum utrinque adnexi. Foem. Stylus brevis; stigmata 5 profundè bipartita, oblonga, colorata, plumosa ; ovarium globosum, 3-loculare, loculis 1-ovulatis. Fructus plerumquè echinatus, capsularis, 5-coccus.

Arbores fruticesve aut herbæ interdùm arborescentes. Folia alterna, stipulacea, palmata, peltata, petiolo ad apicem glanduloso. Flores paniculati, terminales, inferiores masculi, fœminei superiores; omnes cum pedunculis articulati, bracteis quandoquè biglandulosis stipati.

obs. Species 6, quædam fortè tantùm varietates, africanæ et indicæ, quarum una quoquc europæana australis. - Prætereà nonnutlæ foliis indivisis $a b$ auctoribus describuntur; sed aliæ ad alia genera (Mappan, Rottleram) depulsx; dure adhùc reliqua à Ricino ipsæ profectò rejiciendx, ulpotè discrepantcs habitu florumque el foliorum characteribus. Hæ dua species scilicet sunt : $1^{\circ}$ l: icinus integrifolius $W$. , arbor manritiana, cui flores monœci, racemosi, bractcati; nasculi calice 5-partito, filamentis numerosis, simplicibus, à basi coalitis; fominti superiores, calice 5-partito, hineari, stylis 3 simplicibus, capsulis echinatis. $2^{\circ}$ Ricinus globosus W. seu Croton globosum Sw. , frutex jamaïcensis, cni ( $\mathrm{cx} \mathrm{Sw}$. Fl. 1181) flores monceci, racemosi; masculi catice tubulato, 5-fido, filamentis 7 coatitis, 5 mediis longioribus; foeminei 


\section{$(37)$}

calice nulto, stylis 5 bifidis, stigmatibus vitlosis, capsulis globosis echinato-hispidis. - In Crotone salicifolio Geis., cui tamen folia iudivisa, subintegra, filameuta occurrunt polyadelpha, ramosa ut in veris Ricinis. - R. viridi flores quidam hermaphroditi.

JANIPHA. Kunth. - Mavinot. Adans. - Jatrophe spec. auctorum.

Flores monœei. Calix campanulatus, 5-partitus; prælloratio convolutiva. Corolla o. sisc. Stamina 1 o libera, margini disci carnosi inserta, quinque alterna breviọra. ғоєм. Stylus brevis ; stigmata 5 plurilobata, lobis in massam unicam sulcis sinuosis exaratam quasi connatis; ovarium disco carnoso impositum, 3-loculare, loculis 1-ovulatis. Fructus capsularis, 3-cóccus, coccis 2-valvibus.

Arbores aut frutices lactescentes. Folia alterna, palmata. Flores racemoso-ṕaniculati, axillares aut terminales. Radix quarumdam tuberculosa, esculenta.

OBs. Specics 5 americanæ (quæ vernacule $Y$ uca, Yuquilla, Manihot, etc., nuncupantur), inter quas Jatropha janipha et $J$. manilot L. - Charact. ex Kunth (2. 106. tab. 109), et ex sicco.

JATROPHA. Kunth. - Jатrophe spec. L. - Crotonis spec. Forsk. - Castiglionia. R. P. - Curcas. Adans. - Bronfeldia. Neck. Jussievia. Houst. - Médicinier.

Flores monœci. Calix 5-partitus aut 5-lobus; prafloratio convolutiva. Corolla 5-partita aut nulla; præfloratio contorta. Glandulæ aut squamulæ 5 , rariùs nullæ, nunc distinctæ, nunc in annulum sinuatum discumve coalitæ. Masc. Stamina 8-10, filamentis iufrà connatis, quorum 5-5 interiora, longiora. Foæм. Styli 5 bilobi bifidive áut pluriès dichotomi ; stigmata 6 aut plura; ovarium 3-loculare, loculis s-ovulatis. Fructus capsularis, 3-coccus.

Arbores ant frutices, rariùs herba, lactescentes. Folia alterua, basi interdùm glandulosa, nunc integra, nunc sepiùs palmata lobattave. glabra aut setis glandulosis urentibusve hispida. Flores axillares aut terminales, corymbosi, plerumque non obscurè colorati.

oss. Species circiter $20 ; 5$ arabicæ aut indicæ, cæeteræ è regionibus utriusque 
America calidioribus. - Non-ne ex his duplex genus instituendum $\hat{\text { Alterum }}$ (Circas Aduns. - Castiglionia 1.: P. - Bromfeldia Neck.) compleutens specios corollatas, stylis bifidis aut bilubis; allerum (Jussievia Houst. tal). 15), species corollà destitutas, slylis plurifidis. - Occurrit interdùn rudinemtum pistilli in floribus masculis, staminum in fominis. An inde flores hernıphruditi quos Ruiz et Pavo (Prodr. tab. 5 ) suæ Castigliunixe tribunut? - Au verè congener Jat'opha divaricata Sw., cujus flores raccmusi, pallidi, parvi, styli 5 brevissimi , stigmata crassiora, capsula 2-5-locularis, loculis dispermis?

ELEOCOCCA. Commers. - Dryañdra. Thunb. (non R. Br.) Verricla, Lour.

Flores monœci aut? diœci. Calix 2-5-partitus; prefloratio valvata. Petala 5 duplù longiura; prafloratio contorta. Nasc. Stamina 10-12 ( 9 ex Th.), filamentis infrà connalis, 5 exterioribus, brerioribus; antheris introrsis, duabus superioribus sæè abortivis. foen. Stigmata 5-5 subsessilia, simplicia aut bifida ; orarium 5-5-loculare, loculis 1-orulatis. Fructus carnoso-fibrosus, intùs $5-5$-coccus.

Arbores. Folia alterna, longè peliolata, basi 2-glandulosa, integra aut inferiora lobata, glabra juniorave pubescentia. Flores paniculati, terminales, pedunculis articulatis.

oвs. Genus nullatenùs diversum ab Aleurite ex R. Brown (Prodr. 59;), qui generi cuidam Proteaceo tribuit hoc Dryandræ nomen, eam ob causam lị̂c immutatum. - Species 2, altera japonica (Dryandra cordata Th. 15 et $2 \%$, tab. $2 \%$ - Abrasin Kompf. Amœn.), altera sinensis et cochinchinensis (Vernicia montana Lour. 250. - Dryandra vernicia. Correa. Aun. mus. ög. tab. $5_{2}$ ). Hlæc vulgò Arbor vernicis, illa Arbre d'huile, nuncupatur, ex usu seminum qua admonlum olcaginosa sunt, sicut in generibus vicinis Anlda, Aleurite, Jatrophâ, Ricino, etc. - In ovario, loculi pleni quodam muco partim per aquam solubili.

AleuriteS. Forst.-J. - Ambinex. Commers. - Camrriuy. Rumph. - Crotonis et Jatroph spec. L.

- Fiores monœci. Calix 2-5-partitus; priefloralio valvata. Petala 5 coloratd; prafloratio convolutiva. Interior discus 5-lobus, lobis squamiformibus. srasc. Stamina plurima, filamentis brevibus, cotznatis 
in receptaculum conicum columnare, antheris adnatis, introrsis. FOEM. Styli 2 bipartiti ; orarium tunicà involutum distinctà, conformi, villosâ, supcriùs fissâ, biłoculare, loculis 1-ovulatis. Fructus (cx Commers., Forst. 56, Rumph. 2.181. tab. 58.) carnosus, intùs 2-coccus, coccis interiùs sub apicc hiantibus, 2-valvibus.

Arbores. Folia alterna, longe petiolata, basi 2-glandulosa, integra aut lobata. Florum paniculæ magnæ, ramosæ; in paniculis partialibus, fœminei inferiores, rari, crassè pedunculati, masculi superiores, multibracteati. Ferè omnes partes pilis stellatis minutissimis quasi farinosx.

obs. Species 2-5 moluccanæ, zeilonenses, javanenses, ex insulis Societatis. An tunica cum ovario concresceus? an caduca?

\section{ANDA. Pis. - Joannesia. Yelloz.-Gomes.-(non Pers.)}

Flores monoci. Calix campanulatus', 5-dentatus. Petala 5 longiora, breviter unguiculata, patentia. His glandulæ 5 alterna. Insc. Stamina 8 , filamentis coalitis, antheris incunbentibus; 3 interiora, longiora. FoEM. Stylus brevis, bifidus; stigmata 2 læria, dentata. Fructus magnus, pulverulentus, carnosus, fœtus putamine 2-angulato, utrinque in angulis sub apice fenestrato, 2-loculari, loculis, 1-spermis.

Arbor magna, lactescens. Folia quinata, foliolis integerrimis, nerrosis, nitidis, petiolata petiolo glandulis 2 sessilibus ad divisionem instructo. Flores paniculati, terminales; masculi pedunculati, pedunculis. bibracteatis, biglandulosis, fominei subsessiles.

oвs. Species unica brasiliensis (Andaaçu incolarum). - Charact. ex Bern. Gomes. (Observ. bot. med. de brasil. plant. 5. tab. 1. in Mem. acad. Lisb. 111), et nucis quoque ex siccá.

SIPHONIA. Rich.-W. - Hevea. Aubl. - Játrophe spec. L. f.

Flores monœci. Calix 5-fidus aut 5-partitus; præfloratio valvata. Pelala o. sasc. Filamenta connata in columnam apice liberam (an pistilli rudimentuni?), infrù 5-10 antheriferam, antheris quiuatim verticillatis, subsessilibus; adnatis, extrorsis. FoEM. Stigmata 3 sessilia, 


$$
\text { ( } 403)
$$

sub-biloba ; ovarium basi calicis circulari persistenti impositum, 6-costatum, 3-loculare, loculis 1-ovulatis. Fructus (ex Aubl. 871. tab. 335), capsula magna, cortice fibroso vestita, 3-cocca, coccis elasticè 2-valvibus, interdùm abortu 1-2-sperma.

Arbores lactescentes, ramis apice foliosis. Folia longè petiolata, ternata, foliolis integerrimis, glabris, renosis. Flores racemoso-paniculati, axillares et terminales, in racemo quolibet fomineus unicus terminalis, cæteri masculi.

овs. Species 2 guianenses et brasilienses, quarum altera succum fundit aqueoresinosum facitè concrescentem in massas elasticas (Caoutchouc. Gomme élastique), ad usus varios usurpatas.

\section{MIABEA. Aubl.-J.}

Flores monœci. MAsc. Calix 5-dentatus. Petala o. Stamina 9-12 receptaculo subconico inserta, filamentis subnullis; antheris adnatis, extrorsis. Foæy. Calix 5-fidus, æqualis, aut 6 -fidus laciniis 5 exterioribus, brevioribus. Stylus oblongus, 5-fidus; stigmata 5 filiformia, contorta; ovarium globosum, 5-loculare, loculis 1-orulatis. Fructus capsularis, 5-coccus.

Arbusculæ lactescentes ramis sarmentosis pendentibus. Folia alterna, stipulacea, integra aut subcrenata, venosa, supernè lucida. Flores densè paniculati, terminales; pedunculi basi aut superiùs bracteati, bracteâ utrinque glandulosâ, fominei inferiores, pauciores, longissimi, 1-flori, masculi 5-fidi, 3-flori.

oвs. Sppecies guianenses 2 editæ (Aubl. 867. t. 554), quædam edendæ.

HYENANCHE. Lamb. - Toxicopendron. Thunb.

Fores diœci. sasc. Calix 5-7-sepalus. Stamina $10-\bar{j} 0$, fllamentis brevibus, antheris oblongo-ovatis. ғож. Calix polysepalus, sepalis imbricatis, deciduis. Styli 2-íf; stigmata 4 reflexa, glandulosa, fimbriata. Fiuctus suberosus, extùs 8 -sulcus, f-coccus (3-coccus ex Thunb. Act. holm. 1796. 185. tab. 7), coccis 2-valvibus, 2-spermis.

Arbor. Folia 3-4-verticillata, petiolo brevi canaliculato, integra, 


\section{(41)}

lucida, venosa, crassiuscula. Flores axillares; foeminei pedunculis brevibus, paucifloris; masculi in racemis longioribus, congestis, bracteati.

ors. Species unica capensis. - Charact. ex Vahl et Lambert (Dissert. de Cinchon. 52. 1ab. 10), qui Hycenanchen globosam conspecificam asserunt Jatrophar globosa Goert. (2. 122. tab. 109). An" rectè ? Củn ista differre videatur et patrià, quippè qua à Curaçao missa, et formâ fructùs, de quu tamen solo mentio apud Gœrtnerum facta. - An flores masculi verè polyaudri, sep̧alis pluribus dislinctis, imbricatis? Non-ne poliủs, habilà ralioue, tùm variantis sepalorum numeri situssque ct magnitudisis, tùm ipsorum staminunque aucti sensim numeri in extremis racemi flòribus, flores ideò adnittendi singuli staminibus et sepalis seu bracteis instructi paucioribus, sed plures inter se coaliti, floren unicum poly-epalum et polyandirum mentientes? - Genus à vicinis calicis et florum fœmineorum structurà, coccisque dispermis dispar : an Buxo affinius?

GARCIA. Rorh.-Vahi.

Flores monœci. Calix 2-partitus; præfloratio valvata. Petala 10 (10-11 in masc. $7-9$ in fom., ex Valh.) longiora, reflexa, pilososericea. s.sc. Stamina plurima, antheris adnatis, filamentis liberis, insertis receptaculo carnoso, hæmisplierico, villoso, ad ambitum multiglanduloso. Fosx. Stylus brevis; stigma trilobum, coloratum; ovarium disco ad ambitum incrassato impositum, 5-gonum, 3-1oculare, loculis 1-ovulatis. Fructus capsularis, subglobosus, tricoccus.

Arbuscula. Folia alterna, integra, glabra, venosa. Pedunculi terminales, 5-6-flori , floribus bracteatis, fœmineo unico, cæteris masculis superioribus ; (ex Vall , masculi in distincto ramo à fomineis)

obs. Species unica ex provincià americanâ Sanctâ-Hlartbà._Charact. ex sicco et ex Yahl (Symb. 3. 100. et Act. soc. hafn. 2. 218. tab. 9).

\section{S E C T IO I V.}

Flores monœci aut diœei. Calix 2-5-partitus; præfloratio valvata. Petala 0 . sasc. Stamina $2-5$ aut plura definita, filamentis liberis aut 


\section{$(42)$}

coalitis, loculis antherarum connexis aut sapè distinctis. FoxM. Stylus simplex 2-5̃-partitus aut styli 2-3 ; stigmata simplicia, sxpiùs plumosa laciniatave ; ovarium 2-5-Joculare, loculis 1 -ovulatis. Fructus capsularis, 2- 3 -coccus.

Arbores, frutices aut herbæ. Folia alterna, plerumquè serrata. Flores bracteati, bracteis interdùm maximis, multifloris ; nunc sxpiùs masculi glomerati, glomerulis spicatim in axi communi dispositis, fœminei in spicâ eâdem diversà ve aut solitarii ; nunc rariùs racemosi, masculi superiores, fœminei inferiores.

\section{alchornea. Sw. - Heriesia. Boupl.}

Flores diœci. Calix 2-5-partitus, in fominis sæpiǹs dentatus. srasc. Stamina 8 , filamentis basi in annulum coalitis, antheris introrsis. Foexr. Stylus oblongus, profundè bipartitus; stigmata 2 ; orarium didymum, 2-loculare, loculis 1-ovulatis. Fructus (ex Sw. Fl. 1153), cápsula baccata, 2-cocca. Rarissimè stigmata et loculi 3.

Arbores aut arbusculæ. Folia alterna, subintegra aut serrata, glabra, fragilia, nervis prominentibus subtùs instructa. Flores axillares aut terminales; masculi in spicis plerumquè ramosis glomerati, glomcrulis alternis, bracteatis; fominei solitarii aut spicati, spicâ simplici.

obs. Species 5; duæ editæ, altera jamaïcensis (Alchomea latifolia Sw.), altera ex Americæ æquinoctiatis continente (Hermesia castaneifolia. Humb. Boupt. Pl. req. tab. 46); cæteræ ineditæ, quarum una brasiliensis (in Herb. Mlus.), dnæ africanæ (in Herb. J.), senegalenses, guianensesve. - Congeneres fot tè pratereà species $1-2$ habitu el inflorescentiâ similiores, sed floribus masculis 4-5-andris, lœmineis ignutis.

\section{CONCEVEÏBUII. Rich.}

Flores diœci. sasc. Calix 5-partitus. Stamina 3-4 exserta, filamentis infrà coalitis, antheris aduatis, introrsis. Fow Calix 5-fidus; styli 5 ; stigmata plumosa; ovarium 3 -loculare, loculis 1-ovulatis. Fruetus capsularis, 5-coccus. 


\section{$(43)$}

Arbores , quadam succo viridi scatentes. Folia alterna, stipulacea, longè petiolata, subserrita, supernè glabra, subtus nervis prominulis reticulata. llores in spicis axillaribus aut terminalibus, simplicibus fasciculatisve ; masculi glomerati, glomerulis multibracteatis ; fominci solitarii, pedunculo incrassato ad basim bracteato insidentes.

obs. Species 2 guianenses, altera $C$. cordatum (Herb. Rich.) ex qua character hic desumptus; altera $C$. opatum (Herb. Rich.) seu Canceveïba guianensis Aubl. ( $925.1 \mathrm{ab} .555$ ), an verè congener? Hac enim priori affinis habítu, floribus, inflorescentiá; sed flores ejus fœenaiıei tantủm noti, quibus : pedunculi crassi, articulati, bracteà glandulosả stipati; callix 5-6-partitus, laciniis rigidis, acutis, sub quibus alternæ glandula totidem bilobæ; stylus brevis, tripartitus; stigmata 5 biloba; ovarium Irigonum pilis fasciculatis quasi putverulenlum, inıủs $\tilde{\mathbf{5}}$-loculare, loculıs basi villosis, $\mathbf{l}$-ovulatis ; fructus angulatus, coriaceus, (ex Auhi.) trifariảm dehisccus, loculis 2-valvibus, seminibus calyp̣trâ carnosả, eduli vestitis.

\section{CLAOXYLON. - ACALYPHe spec. auctorum.}

Flores diœci. MASc. Calix 3-4-partitus. Stamina 15 aut plura ; filamenta receptaculo hemisphærico inserta; antherarum loculi in apicc filamenti distincti, erecti, ab apice in longum dehiscentes. Foxı. Calix brevis, 3-partitus; alternæ appendiculæ 3, subcarnosæ, coloratæ. Styli 2-5 reflexi, breves, intùs plumosi ; ovarium 2-3-loculare, loculis 1-orulatis. Fructus capsularis, 2-3-coccus.

Arbusculæ aut frutices. Folia alterna, serrata, scabra. Flores in spicis aut racemis axillaribus, solitarii aut laxe fasciculati, fasciculis I-bracteatis, singuli bracteolati, brevissimè pedunculati, plerunquè imbuti colore purpureo, præsertim in præfloratione.

OBs. Species 5; 5 borbonienses ibiquè, ex Cummers., vernaculè Bois cassant nuncupatæ (in Herb. J. et Hus.); 2 indicæ, quarum una est Acalypha spiciflora. Burm.

MaCARANGA. A. P. T. - Pavopia. Noronl.

Flores diceci. yasc. Calix 4-partitus; stamina 8-12, filaunentis 


\section{(44)}

exsertis, liberis, antheris terminalibus, complanatis, cruciatim bisulcis (ut in Mappâ). foen. Calix ureeolatus, minimus. Ovarium desinens in stylum liguliformem, cui hinc adnatum stigma villosum. Fructus follicularis, sxpè tuberculosus, 1-locularis, 1-spcrmus. Semen è summo loculo pendulum; embryo intra perispermum carnosum minimus radiculâ superâ.

Arbores vel frutices resinifluæ. Folia alterna, stipulacea stipulis caducis, basi 2-glandulosa, cordata peltatave. Flores axillares, masculi in spicis ramosis glomerati, glomerulis bracteatis; fœminei sapiùs solitarii bracteis glandulosis stipati.

oBs. Spccies circiler 4, Ires scilicet madagascarienses (Macaranga incolis), una mauriliana (vernaculè Bois violon). - Genus Euphorbiaceum, confirmante habitu, situ et structurà seminis, contradicente unitate stigmatis et loculi. Sed fructus visus, semel quidem, dicoccus. - Characteres desunpti ex Aubert du Petit-Thuuars (Gen. mad. 88), aut ab ipso comnunicati; quidam ex sicco.

\section{MAPPA. - Ricini spec. L.}

Flores monœci diœcive. masc. Calix 3-partitus. Stamina 3-10; filamenta libera aut imâ basi coalita ; antherarum loculi globosi, in longum sulcati et dehiscentes. Foe M. Salix 2-5-fidus. Styli $2-3$ oblongi, reflexi, intùs plumosi, stylusve unicus $2-3$-partitus ; orarium echinatum, 2-5-1oculare, loculis 1-ovulatis. Capsula 2-3-cocca, echinis raris, longioribus armata.

Arbores aut frutices. Folia alterna, longissimè petiolata, 2-stipulacea stipulis magnis, deciduis, peltata, subintegra, nerrosa. Flores spicati, spicis axiltaribus, pluriès ramosis, bracteati : bracteæ sessiles, magnæ, in fœminis 1-floræ, in masculis multifloræ. Capsulæ conspersæ granulis resinosis, luteis (quibus odor gummi ammoniaci); foliaque punctulis similibus notata.

овs. Specir's circiter 4 : una indica et moluccana, quæe Ricinus mappa L., Acalyphæ à Willdenow adjuncta ; una timorensis, qua forsàn conspecifica Ricini tanarii L., indici el cuchinchinensis, hủc quoque referendi; una pratoreà ivedita (Herb. Mus.) zeïlanensis. An tandem congener Ricinus diö̈cus Forst? 
Caturus. L.-J. - Galurus. Spreng. - Acalyphe spec. Burm.

Flores diøci. masc. (ex I.) Calix 5-fidus ; stamina 3 , filamentis exsertis, antheris subrotundis. foem. Calix 5 -partitus. Styli 3 laciniati, laciniis plurimis irregularibus; ovarium 5-loculare, loculis 1-ovulatis. Fructus capsularis, 5-coccus.

Arbuscula aut frutices. Folia alterna, stipulacea, serrata. Flores axillares, spicati ; focminei in spicâ dcnsî, longissimâ, stylorum laciniis coloratis hispidà, glomerati, singuli bracteati, bractcî 5 -partitá.

овs. Species 2, altera indica (Acalypha hispida Burm. Ind. tab. 61. - Cauda felis Rumph. 4. tab. 57); altera cochinchinensis, scandens ( Lour. $; 51$ ). - An flores masculi, qui, confitcnte ipso Linnæo, miıùs distinctè visi, verè $\mathbf{3}$-andri? In speciminibus masculis Caturo spicifloro similioribus ( H crb. Ulus.) flores milhi occurrerunt in spicis oblongis glomerati ; instructi calice 4-partito, valvato; 8-andri, loculis antherarum distinctis, utrinque connectivo globuloso appensis, oblongo-ovatis. Qna si verè Caturi conspecifica sint, gcuus hoc abolendum et Acalyphæ adjungendum. Specics enim cochinchinensis, cujus flores fominei ignoti, nullins momenti esse potest.

ACALYPHA. L.-J. - Kunth. - Cupdnew. Adans. - Ricinelle.

Flores monœci aut diœci. sasc. Calix 4-partitus. Stamina S-16; filamenta basi incrassatâ connata ; antherarum loculi distincti , utrinque filamento sub apice appensi, libcri, oblongo-flexuosi, vermiformes. rox. Calix 5-partitus. Styli 3 multilaciniati, laciniis tenuibus, inæqualibus, irregularibus, plerunıquè rubris; ovarium 3-loculare, loculis 1-orulatis. Fructus capsularis, 5 -coccus.

Arbores, frutices, aut sapins lierbe (habitus Urticæ aut Amaranthi). Folia alterna, stipulacea, serrata aut rarissimè subintegra, glabra aut villosa. Flores axillares aut terminales, spicaii ; in spicis, masculi glomerati, glomerulis bracteâ minutâ stipatis ; fominei bracteati, bractcâ 1-5-florâ, ipsis longiore, persistente, plerumquè scratì lobatîve. Spicæ amentiformes, nune androgyna floribus masculis superioribus, inferioribus fomineis, quorum interdim unus abortivus terminalis; nunc unisexuales in diversà stirpc, aut in eâdem 


\section{$(46)$}

et tunc mascula terminales reliquis fœmineis, vel eontrà terminales fœmineæ reliquis masculis.

obs. Genus admodìm naturale, ab omnibus stylorum et imprimis staminum struclurà distinctum. Cujus itả circumscripti species circiter 60 descriptæ exstant, 40 scilicet americanæ, 10 indicæ, madagaścarienses, borbonienses, mauritianæ, paucæ utrique conlinenti communes, cæeleræ dubiæ aut patriâ iğnotâ. Quædam quoque in herbariis ineditæ, et huc prætereà referendæ nonnullæ Trigiæ species, ut Tragia marginala, T. colorata, T. filiformis (Encycl.), et rerisiniliter quoque T. virgata. Eneycl. et T. mercurialis. L. - Acalypha tiliafolia. Poir. Enc., arbor antillana, cui flores fominei ignoti, masculi 4 -andri, filamentis liberis, tenuibus, receptaculo villoso insertis, antheris ovatis, 1-locularibus? Certè ab hoc gencre, forsàn etiam ab Euphorbiaceis depellenda.

\section{MERCURIALIS. L.-J. - Mercuriale.}

Flores monœci aut sæpiǹs diøci. Calix 3-4-partitus. sasc. Stamina 8-12 aut plura; filamentis liberis, exsertis; antherarum loculis in apice filamenti distinctis, globosis. Foem. Styli 2 breves, latiusculi, denticulati ; ovarium didymum, 2-sulcum, 2-loculare, loculis ı-ovulatis. Filamenta 2 brevia, sterilia, ex imis sulcis enata ct ovario adpressa. Capsula echinata tomentosave, 2-cocca.

Frutices aut sæpiùs herbæ. Folia opposita aut rariùs alterna, stipulacea, dentata subintegrave, sicca colore violaceo interdùm imbuta. Flores axillares et terminales; masculi glomerali, glonerulis spicatis, bracteatis; foninei spicati, fasciculati aut solitarii.

Species circiter 10 , pleræque europæanæ, oppositifoliæ, 2-coccæ; duæ tantủm exoticæ, allera senegalensis, altera indica, eædem alternifoliæ, sæpè 3-coccæ. - Plantæ, in Act. par. 1719, duæ steriles, masculæ, foliis alternis, capillaceis, à Harcliantio memorantur lanquàm $M$. annuce varietates hybridæ.

\section{ANABENA.}

Flores monœci. Calix 5-partitus. ussc. Filamenta infrà coalita, squamulis 4 cincta, superius libera, 10 antherifera, antheris 4-lobatis. unum slerile medium apice globoso-echinalum ( an styli et sligmalis rudimentum?) Foes. Stylus crassus, oblongus; stigma 


\section{(4)}

trilobum, lobis extùs glandulâ scutiformi notatis; ovarium 3-loculare, loculis 1-ovulatis. Fructus capsularis, 3-coccus, coccis subcarinatis, integumento tenui 6 -partibili restitus ; semina angulata, ossea.

Frutex volubilis. Folia alterna, longè petiolata. Flores racemosi, axillares, fœemineus unicus, inferior, longè pedunculatus, masculi plures, cum pedunculis brevibus articulati, bracteati.

obs. Species unica brasiliensis (in Herb. Nus. et J.). - Nomen à caule scandente. - Habitus, inflorescentia multaque alia Pluknetix. An dno genera in unum, charactere paulisper immutato, confundenda?

PLUKNETIA. Plum. - L.-J.

Flores monœci. Calix 4-partitus. Masc. Stamina 8 aut plura, filamentis coalitis, basi cincta glandulis 4 barbatis (ovarium abortivum ex Plum.). ғовм. Stylus longissimus, proboscideus; stigma peltatum, 4-lobum, lobis medio suprì punctatis. Capsula depressa, 4-cocca, coccis anguloso-carinatis, 2-valvibus, 1-spermis.

Frutices rolubilcs. Folia alterna. Flores axillares, racemosi ; fœmineus unicus inferior, masculi plures, breviùs pedunculati.

oвs. Species 5, duæ americanæ, una indica (Sajor. Rumph. 1. tab. 59. f. 2) quæ fructu interdùm 5-cocco. - Charact. ex l'lun. (220. tab. 226), J. et W. sp.

tragia. Plım. - Tragie spec. auctorum. - Schorigeram Adans.

Flores monœci. Masc. Calix 5-partitus. Stamina 2-3; filamentis breribus. Foess. Calix 6-rariùs-5-8-partitus, laciniis interdùm pinıatifidis, persistentibus. Stylus 3-fidus ; stigmata 3. Fructus rapsularis, hispidus, 5-coccus, coccis subglobosis, 2-valvibus, 1-spermis; seminibus conformibus.

Herbie aut suffrutices, interdùm scandentes aut volubiles. Folia alterna, stipulacea, serrata lobatave aut rarius pinnata. Flores axillares, racemosi; in racemis, fœminei inferiores, unicus aut pauci, 
longissimè pedunculati ; masculi plures brevissimè pedunculati; ombes bracteati, bracteâ angustâ, simplici aut 2-j̄-partitâ. Ferè omnes plantie partes sxpiùs hispidæ.

овs. Species circiter 15, quarum dimidia pars ex Americâ, præserlin boreali; cæelerx indicx, arabicæ, owaricnses, capenses. Huc referenda Acalypha pinnata. Enc. suppl.

\section{SECTIO V.}

Frores monœci aut diœci. Calix 2-4́-sepalus-partitus-fidus-dentatusve, interdùm nullus; præfloratio convolutiva. Petala, glandulæ et appendices o. sisc. Stamina 2-10, filamentis liberis aut rariè coalitis. FocM. Orarium 2-3 rariìs-4-7-1 8-loculare, loculis 1-0rulatis. Fructus nunc capsularis, nunc rariùs suberosus aut caruosus, $2-5$ rariùs4-7-18-coccus, coccis distinctis aut rarissimè in unum nuciforme connatis.

Arbores aut frutices, sxpissimè lactescentes. Folia simplicia, sæpè basi 2-glandulosa. Flores, nunc sæpiùs spicatim (in Omplaleâ paniculatim ) dispositi, bracteati, bracteâ plerumquè 2 -glandulosâ, in masculis superioribus multillorà, in fominis 1-florâ; nunc masculi amentacei squamis staminiferis, fominei bracteati, bracteis imbricatis.

\section{MiCROSTACHYS. - Tragle spec. L. et Valh.}

Flores monœci. Calix 5-partitus. nasc. Stamina 5 , filamentis brevibus. foex. Stylus profundè 3-partitus, relexus; stigmata 5. Capsula glabra ant regulariter echinata, prismatico-5-cocca, coccis 2-valvilous, 1-spermis; semina teretia.

Suffrutices, rarissimè berbæ. Folia alterna, 2-stipulacea stipulis minutissimis, argutissimè serrulata. Flores axillares aut extrà-axillares, bracteati, bracteâ 2-glandulosì, uniflorâ in fomineis, qui solitarii, breciter pedunculati, multiflorâ in masculis, qui distichè spicati, spicis brevibus, admodùm gracilibus. 


\section{(49)}

obs. Genus à Tragiâ distinctum prælloratione, calice in foeminis 5-partito, stylo 3-partito, ovarii, capuula seninumque formà, inflorescentii, toto denique habitu; affinius Sapio et Stillingia. - iluc referende Tragia chameloen L., T. corniculata Valıl, T. bicarnis Vahi (Herb. J.), et quædam prælcreà in herbariis ineditæ, onnes aıncricanæ ex Antihlis, Guiauâ, Brasiliâ. - Nomen à spicarum tenuitate.

\section{SAPIUM. Jacq.-J.}

Flores monoci. MAsc. Calir bifidus. Stamina 2, filamentis exsertis, basi coalitis; anthera adnata, cxtrorse. roem. Calix 3-dentatus. Stylus breris, 3-fidus ; stigmata 5 ; ovarium 5-loculare, loculis 1-ovulatis. Fructus globosus, capsularis, 5-coccus; semina globosa.

Arbores lactescentes. Folia alterna, stipulacea, sæpissimè basi 2 -g'andulosa, integra aut serrulata, glabra, plerumquè lucida. Flores, masculi in spicis terminalibus glonerati, glomerulis 1-bracteatis; fœuinei inferiores in eàden spicâ, aut rariùs ab ipsâ remoti, solitarii, axillares terminalesre, singuli bracteati. Bracteæ plerumquè basi utriuque glandiulosæ.

OвS. Species 10 , quarum 6 americanæ, cæteræ indicæ, borbonienses aut mauritianæ. - In $S$. obtusifolio Kunth, calicis laciniæ 5 subulatæ, stamina 3 , flores fominei terminales, solitarii, sessilcs. An ideò, auctore ipso monente, congener?

STILLINGIA. Garden.-L.-J.

Flores monoci. masc. Calix (corolla L.) tubulosus, limbo crenulato. Stamina 2 exserta, filamentis subliberis. Focm. Calix 3-fidus. Stylus crassus ; stignata 3 reflexa ; ovarium 3 -loculare, loculis 1-orulatis. Fructus globosus, capsularis, 5-coccus.

Frutices aut arbores lactescentes. Folia alterna, obsoletè stipulacea, basi nuda et glandulosa, integra serrulatave. Florum spice terninales suprà masculæ, infrà fomineæ. Bracteæ (calix L. - involucrum J.) basi utrinque glandulosæ, multifloræ in masculis, qui pedicellati . singuli bracteolati; unifloræ in fomineis, qui crassè pedunculati multòque panciores. 


\section{(50)}

OBS. Genus forsàn conjungendum Sapio, à quo vix distinctuma, nisi calice in masculis crcnulato, non bifido. Item in fominis superus, ex Linnæo. - Species 3 amcricanæ, quarum una (Croton sebiferum L. ) sinensis quoque, seminibus materia quâdam sebosà involutis. - In S. ligustriná Michx. calix 5-partitus, prælloratione convolutivà, staminaque 5 .

\section{TRIADICA. Lour.}

Flores diœci. Calix minimus, campanulatus, 3-4-fidus. uase. Stamina 2, filanentis planis, brevissimis, antheris bilobis. Foen. Stylus brevis, crassus ; stigmata 5, oblonga, erecla. Bacca exsncea, 5-locularis, loculis 1 -spermis.

Arbores. Folia alterua, integerrima, glabra. Florum amenta subterminalia, filifurmia, nuda, distincta tuberculis (non-ne bractex basi tuberculosa?) multifloris,

ons. Species 2 , altera cochinchincnsis, altera sinensis. - Charact. ex Lour. 748 .

\section{OMALANTHUS.}

Flores monoci. Calix 2-sepalus, sepalis basi emarginalis, glandulosis . in fominà caducis. masc. Stamina 6 aut 10 , filamentis brevibus, couplanatis, partim cunnatis ; antheræ adnatæ, extrorsæ. Fow. Stylus 2-ficus; stigmata 2 glindulosa, stylo extus quasi adnata, bași et apice biloba; ovarium oblongum, 2-loculare, loculis $\mathbf{1 - o v u l a t i s . ~}$ Fructus capsularis bivalvis.

Frutices. Folia alterna, longè petiolata petiolis apice glanduliferis, integra, glabra. Flores spicati, terminales; maseuli glomerati, glomerulis sxpiùs 3-fluris, confertis, bracteatis bracteâ basi 2-glandulosâ; fominei simili bracteâ instrucli, longiùs pedunculati , nunc in eàdem spicấ $i_{\imath}$ feriores, unnc in diversî remoti.

ors. Species 2 inedita (Ilerb. Mns. et J.), altera javancnsis et philippensis, altera è Novit-Hollándià. Habilus Stillingix sebiferæe. - Nomen à lloribus compressis. -. Structura singularis endocarpii (quod non, ut in cateris, 2-coccum coceis in!crue Uehiscentibus, sed testaceum bivalve) iterum examinanda, quonium milsi in fructu unico imperfecto observata. 


\section{(51)}

HIPPOMANE. L.-J. - Maxcanild. Plum.-Adans. - Mancenillier.

Flores munœci. MAsc. Calix turbinatus, bifidus. Filamentum apice 2-antherifcum, antheris adnatis, cxtrorsis. Focs. Calix 3-paritus. Stylus crassus, brevis; stigmata plüa, sxpins 7, radiata ; wrarii loculi totidem 1-ovulati. Fructus carnosus, lactescens, poniformis; intùs multicoceus, coccis concretis in nucem liguosan, superficie insqualem et sinuosam, indehiscentem, 1-spermis aut quibusdam abortivis.

Arbor lactescens. Folia alterna . stipulacea, longè petiolata, petiolo apice 1-glauduloso, subscrata, glabra, lncida, venusa. Flores, mascuii in spic is teruinalibus glomerai, glomerulis multifloris, alternis, stipatis lracieâ basi utrin!çue glandulusà ; fominei solitarii.

oвs. Species unica ex Anericà æequinoctiali.

HURA. L.-J. - Sablicr.

Flures monœci. masc Amentum densè multiflorum, squamis imbricatis. I-floris. Singulis calix brevis, urceslatus, truncatus; filamentum unum, incrassalum, medio tuberculatum tuberculis duplici aut triplici ordine verticillatis, singulis subtis antheriferis. Fow. Flos solitarius. Calix urceolatus integer, ovario arctè circumpositus aut maturatione 5-partitus. Siylus 1 longus, infundibuliformis; stigma maximum, concavo-peltatum, 12-18-radiatum. Capsula lignosa, orbiculata, depressa, 12-18-torosa, 12-18-cocca, coccis elasticè bivalvibus, i-spernis.

Arbores lactescentes. Folia alterna, stipulacea stipulis caducis, petiolo supernè 2-glanduloso, juniora involuta. Anentum masculum simplex, longiùs pedunculatum, terminale aut ramulis axillare; flos fomineus, solitarius, amento proximus.

ов. Species 5 americanx. - Charact. ex J. 391 ; Trew, P'lant. select. tab. 34-35; et Turpin Planch. du Dict. des scienc. natur.

SEBASTIANIA. Spreng.

Flores monøci. Squamx sessiles, basi 2-glandulosæ, 1-floræ Misc. 


\section{$(52)$}

Stamina 5, filamentis discretis, squamulis acntis, subimbricatis (an pro calice habendis?) basi stipata. FoEy. Squamula majores; stylus crassus, brevis, 3-partitus; sligmata 3 reflexa; ovarium 3-loculare, loculis 1-spermis. Fructus capsularis.

Caulis lignosus. Folia subupposita. Flores spicati, spicis axillaribus, solitariis geminatisre, basi fœunineis, suprì masculis.

obs. Speeies unica brasiliensis. - Charact. ex Sprengel (Neue Entdec. 2. 118. tab. 5 ). - Genus medium inter Sajium et Excæcariam.

EXCECaRia. L.-J. - Sw. H. - Grunatules. Sw. prod.

Flores monœci aut diœci. uasc. Filamentum basi simplex, mox tripartitum, ibiquè instructum squamâ sessili, simplici, interdìm glandulosâ; singulæ filamenti laciniæ squamulà propriâ unicâ aut duplici stipatæ, nunc simplices 1 -antherileræ, nunc 2 -3-fidæ, 2-3-antheriferr. FoEM. Calix ninimus, squamiformis, trilidus, interdùm nullus. Stylus crassus, breris, 5-parlitus; stigmata 5 reflexa; orariun 3-loculare, loculis 1-orulatis. Fructus globosus, capsularis, 3-coccus.

Arbores aut arbusculæ, quædam lactescentes. Folia alterna, exstipulacea crenata serratave, rariùs integra, glabra. Flores : masculi anentacci, axillares, simplices aut fasciculati; foeminei, nunc ad basim amenti masculi, pauci, sessilcs pedunculative, nunc in diversâ arbore laxè spicati aut racemosi, axillares aut terminales, simplices aut fasciculati, bracteis squamiformibus stipati.

oss. Species 8 descriptæ, quarum 5 antiltanæ, 2 brasilienses, 3 asiaticæ : quæilam prætereà (iı Herb. Mus.' et J.) incdilæ è Brasilià et Bueynos-Ayres; sed omnes sedulò recognoscendæe in genere adhùc obscuro. - An hasis filamenti simplex pro pedicelto habeuda; squama pro bracted; squamula pro calicibus; filameuti laciniæ 1-aut pluri-antheriferæ pro totidem floribus matsculis? Quod confirmarent imtheræ diverso tempore erumpentes in quibusdam speciebus mihi visæe, el gencrum vicinorum analogia. Pratereà squama in nounullis multilloræ, ut in E. glandulosa Sw. et E. cochinchinensi Lour. - Charact. ex sicco et ex Sw. Fl. 111g et seq.

- Non-ne congener Gussona Spreng. cui, ex auctore (Neuc Entdec. 2. 119. 
tab. 2. fig. \$-10) : flores monceci. Masc. amentacei ; squama intùs glandulosa , $\tilde{J}$-stdminifera. Fam. Calix 5 -fidus. Stylus stibnullus; stigmata 5 rellexa ; ovarium 5-coccum. - Caulis lignososus. Folia altcrua, gulaberrima, suprà lucida. Flores axillarcs, focminei ad basiı ameuli nasculi, longè pedunculali; pedunculi (columnula Spr. bracteis imbricatis (calix inferior squamosus Spr.) basi cincli. - Species 2 brasilienses.

COMIIIA. Lour.

Flores diœci. xasc. Amentacei, squamis imbricatis, 1-floris. Calix proprius nullus. Filamentun unum breve; anthera muliblecularis (non-ne potiùs filamentum apice pluriantheriferum, antheris adnatis ?). Focm. Racemosi ; calix 5-partitus, brevis, presistens. Styli 5 reflexi, breres; stimmata crassiuscula. Capsula 5-łoba, 5-locularis, loculis interiùs hiantibus, 1-spermis.

Arbuscula succo resinoso scatens. Folia alterna, intēgerrima, glabra. Amenta mascula, axillaria, brevia; racemi fœminei subterminales, parri, numerosi.

oвs. Species unica cochinchinensis. - Charact. ex Lour. 742 .

\section{STYLOCERAS.}

Flores monæci aut diœci. susc. Squama simplex antherifera, antheris sæpins 10 oblongis, inæqualibus, introrsis. FE.M. Calix breris 5-5-partitus. Orarium globosum, 2-aut-\{-loculare, superiùs quasi bicorne stylis 2 oblongis, incurratis, crassis, intùs glanduloso-canaliculatis; orula in singulis loculis solitaria, ex apice pendula. Fructus....

Arbores. Folia alterna, integerrima, glabra, lueida (laurocerasi). Flores axillares; munc in isdem spicis solitariis geminatisve, fœmineus unicus, terminalis, masculi plures, inferiores; nunc in diversis arboribus segregati, masculi tantùm spicati, fœminei solitarii, breviter pedunculati. Bractea ad basim pedunculorum multæ, imbricatx.

овя. Species 5 ex Americâ australi iuedita, lua in herb. Kunth, tertia in Herb. Mus. - Nomen à lormá stylorum. - Geuus à Cl. Kunth communicatum . 


\section{(54)}

Euphorbiaceum floribus diclinibus, numeroque et situ seminun; Excæcaria afline squamis antheriferis, propius tamen 'ricera et Buxo slylurum forma et tolo habitu. - Qtiænam fructús et seminum structura? In uná specic ( ex Dombey in Horb. Mus.) pericarpium edule, 4-spermum, seminibus castanciformibus.

MAPROUNEA. Aubl.-J. — Ægopricon. L. f.-Gœrt.-TV.

Flores monœci. Mssc. Calix 2-q-fidus. Filamentum exsertum, apice 2-antheriferum, antheris bilonis, cxtrorsis. Fo:n. Calix 5-lobus. Stylus crassus, brevis, 5-fldus; stigmata 3 leflexa ; orarium globosum, 5 -loculare, loculis 3-ovulatis. Fructus cápsularis, 5-coccus, coccis 2-ralribus; semina ossea, infrà scrobiculata.

Arbor. Fóliá alternā, integerrima, glabra . supernc̀ lucida, rcunsa. Flores : masculi minutissimi, squamis intérjectis, argregati in capitula paniculata, paniculis parvis, terminalibus, singula nvala, amentiformia, basi involucrata, involucro breviori 2-partito, 2-bracteato; fœmineus unicus ad basin cujusque capituli masculi, pedunculatus, 2-bracteatus.

овs. Species unica guianensis ( Aub. tab. 542). - Fructus baceatus', ex L. . ; ; capsularis ex Suith (Icon. exotic. ined. tab. 42), Gœrt. (2. 2636. tab. 158), et in speciminibus à me observatis. Non-ne igitur congener ptanta è Congo Egoprico affinis, sed discrepans præcipuè fructu capsulari ( $\mathrm{R}$. Br. Obs. liserb. Cong. 25 )?

OMPhalea. L. -J. - Onphalandria P. Br. - Duchola. Adans.

Flores monœci. Calix 4-partitus. yasc. Filamentum disco glanduloso impositun, supernè dilatatum, incrassatum, pileiforme, anbitu in lobos 2-3 fisso; antheræ 2-3, Joculis distinctis, in latere cujusque lobi (connectivum) quasi immersis. Fo£. Stylus brevis, crassus, in stigma obsoletè 5 -lobum desinens; ovarium obtusè 3-gonum, 3-loculare, loculis 1-ovulatis. Fructus carnosus, intùs $\mathbf{3}$-coccus, maturatione (ex Aubl. $\$ 4$ 1. tab. $\bar{j}_{2} S$ ) 5 -partibilis; semina magna, subglobosa.

Arbores aut srandentes frutices. Folia alterna, stipulacea, petio- 
lata petiolo supernè 2-grlanduloso, integra, crassa, nèrvis prominentibus subtùs reticulata. Florum panicula breves, in quibus famineus unicus terminalis, masculi plures, inferiores, bracteolati; singulæ stipulà longissimâ 2 -glandulosà stipatæ, suprà axim communem disposita in paniculan unicam, magnam, ramosam, termisalem.

obs. Species 3 guianenses ct antillanæ, quarum una inedita (Herb. J.).

Huc potiùs referenda videtur Hecatea A. P. T. (Vuy. 13 et 3o. tab. 5), structurà formâque staminum et pistilli omuinò congener, distincta tamen calice 5-lobo et dispositione florum, quorum peduncnli pluriès aul semel dichotomi, in dichntomiis a-flori flore fomineo, cæleris masculis terminalibus. Folia altcrna aut onposita, basi 2-glandulosa, paucinervia; bracteæ 2-ğlandulosæ, sub dichotomiis geminatim oppositæ. Species 2 arborescenles, madagascarienses.

\section{SECTIO VI.}

Frores monoeci in involucro communi foliaceo aut caliciformi. Masculi plures polyandri ant monandri, calice nunc 5- 4 -fido aut 4-5-partito, nunc nullo. Foemines 1-3, centrales aut laterales; calix nune 5-fidus aut 6-12-partitus, nune nullus. Styli 5 distincti ant in unum simplicem trifidumre coaliti; stigmata 1,3 aut 6 ; ovarium 5 -loculare, loculis 1-ovulatis. Fructus capsularis aut subcarnosus, 5-coccus.

Arbores, frutices aut herbæ, plereque lactescentes, caule interdìm scandenti, interdùm carnoso, cactiformi. Folia alterna, simplicia, rariùs 5-5-partita, rarissimè 5-5-phylla. Pedunculi áxillares 1-multiflori, aut terminales umbellati (involucris moltifloris habitis pro floribus in iuflurescentià).

DALECHAMPIA. Plum.-L.-J.-Kunth.

Flores monceci in involucro eodem pedunculato, 2-phyllo, foliaceo, basi appendiculato, appendiculis 4 stipuleformibus. masc. Involu- 
crum proprium, pedunculatun, 2-5-phyllum, multinorum, floribus (sxpiùs 10) perlicellatis, subumbellatis. Singulis calix 4-5-partitus; prefloratio valvala ; stamina numerosa, filamentis infrì connatis in stipitem brerem, pedicello continum. Interdins squamet pauca. his interjectæ, plures in umbellæ latere fasciculatx, apice pluripartila, resiniflua. foæu. Involucrum proprium, subsessile, 2-phyllum, 5-10run, floribus brevissimè pedicellatis. Calix 5-6-aut-10-12-partitus, laciniis intcgris, dentatis aut ciliatis. Stylus 1 oblongus; stigma simplex capitato-peltatum ant infundibuliforme; orarium 3-loculare, loculis 1-ovulatis. Fructus calice persistente cinctus, pedicello elongato insidens, capsularis, 5 -coccus, coccis globosis.

Frutices scandentes ct rolubiles. Folia alterna, longè petiolata, petiolo infrà 2-stipulaceo, nunc subintegra, nunc 5-5-lobata aut etiam 3-5-phylla, limbo 3-5-nervi, ad basim 2-appendiculato. Pedunculi axillares, sæpius bracteati, bracteis stipulæformibus. Omnes partes plerumquè hispidx

OBs. Species circiter 20 ab auctoribus descriptæ, omnes ex Americâ æquinocliali, præter unam tamen indicam, et alteram sinensem. Duæ prætereà ineditx, altera senegalensis (Herb. J. ), altera capensis (Herb. Mus. et Kunth.) - Foliola involucri vera folia sunt in extremis ramis subopposita, caulinorum instar integra lobatave, limbo 5-5-nervi, ad basim 2-appendiculato, petiolo 2-stipulaceo. Hinc inflorescentia minùs à cæleris Euphorbiaceis plerisque recedens.

\section{ANTHOSTEMA.}

Flores monœci, masculi plures, fœmineus unicus lateralis, in eodem insolucro profundè 2-lobo, lobis in tùs glandulà minutâ instructis. sasc. Involnesum proprium, multilobum, lobis (circiter $S$ ) inter se dissimilibus. Pedicelli numerosi, receptaculo plano impositi, inæquales, fasciculati, bracteis paleaceis interjectis ; singuli superiùs articulati cum filamento, quod basi caliculatum caliculo 5-4-fido, apice 1-antheriferum. Foex. Calix campanulatus, 5-4-dentatus, jufrà pedunculo incrassato continuus. Stylus crassus, brevis, 3-fidus; stig- 
mata 5 subbiloba; ovarium $\tilde{5}$-loculare, laculis $\mathbf{1}$-ovulatis. Fructus carnosus, 5-coccus.

Arbor lactescens. Folia alterna, integra, glabra, venosa. Pedunculi axillares, multiflori, ramosi, ad divisuras articulati.

085. Species unica senegalensis (in Herb. J.) - Nomen à staminibus singulis florem masculum constituentibus.

EUPHORBIA. L.-J.-Tithyalus. T.-Adans. - Euphorbiuy. Isnard. - Euphorbe.

Flores monœci in eodem involucro, fomineus unicus centralis, masculi plures ambientes. Involucrum commune (calix L.) regulare, aut sæpiùs irregulare linc fissum, campanulato-turbinatum, 4-5-fidum, laciniis integris fimbriatisve aut multipartitis, erectis aut inflexis ; quibus extcriores appendices (petala I.) nunc totidem alternæ, nunc pauciores, carnosæ, glandulosæ aut petaloïdeæ, integræ bicornesve aut rariùs plurifidæ, patentes aut reflexæ. Masc. Pcdicelli plures, singuli cum filamento apice 1-antherifero articulati (stamina floris unici polyandri. T.-L.), plerumquè infrà distincti bracteis interjectis paleaceis squamuliformibusve ( petala floris unici hermaphroditi. Adans. - Calices florum distinctorum? J.). FoEs. Pistillum longiìs pedunculatum, basi nudum aut rariùs caliculatum, caliculo integro trifidore. Styli 3 bifidi, rariùs connati in unum apice 3 -fidum; stigmata 6 , rariùs 3 biluba; ovarium 3 -loculare, loculis-orulatis. Fructus capsularis, pedunculo elongato insidens et eodem deflexo nutans, lævis aut verrucosus, glaber aut pilosus, 3 -coccus, coccis elasticè biralvibus, deciduis.

Plantx. Jactesccntes, herbacex aut fruticosie, crectæ aut rarius repentes, labitu admodùm rario. Etenim : caulis; nunc carnosus (in Euphorbı Isn.) cactiformis, angulatus, aculeis solitariis geminatisve, scrie simplici in angulorum jugo superpositis, aut tuberculatus; nunc sxpissimè (in Tithymalo T.) teres, ramusus. Folia in paucis nulla, in plurimis alterna, nuda, aut rariùs opposita et 


\section{(58)}

lunc plerumquè stipulacea, aut rarissimè terna verticillata. Involucra multiflora in influrescentià pro floribus simplicibus habita, pedunculata. Pedunculi, in carnosis subaphyllis, brevissimi, 1-5-flori, nudi; in foliosis, nunc axillares, nunc sxpiùs triminales, 2-5pluresve umbellati, singuli interdùm capitato-multiflori, plerumquè 2-j-4-cholomi, inter divisuras 1 -flori. Umbellæ et umbellula: basi cinctæ foliis (bracteæ auct.) numero pedunculorum et pedicellorum verticillatis, involucra et involucella polyphylla mentientibus.

OBS. Genus à plerisque olim pro hermaphrodito habitum, nunc rectiùs inter monoïca adnumeratum, staminum veram singularemque naturam primò indicantibus Jussieu (Gen. 586) et Lamarch (Enc.), posteriùs perfectè describentibus R. Brown (Gell. rem. 24) et Kunth (Nov. gen.). (Quod confirmant generum ejusdem ordinis omnium, et præsertim vicinorum, analogia, staminum diverso tempore erumpeutium filamenta articulata, paleæ interjectæ, caliculus sub pistillo in nonuullis observatus, idem filamentis subjectus in genere inedito R. Br. (loc. cil.), et in Anthostemate. - Interdùm, sed rariùs, involucra abortu tanlùm mascula.

Species circiter 500 ab auctoribus enumeratæ. - 100 europæanæ, quarum plures ex australibus atque orientalibus plagis. Tantus profectò respectivus specierum Europæ nunerus, quia regio multò magis botanicis indagala et cognita. - Asiaticæe, præter multas cum Europâ orientuli communes, 5o, pleræque indicæ. - Africanæ circiter zo, quarum 50 capenses; cæeteræ ex Africá boreali aut requinoctiali, aut ex insulis. - Americanæ $z_{0}$ quoque, quarum dimidia pars ex Anericà boreali, dimidia ex australi, pleræque tamen sub

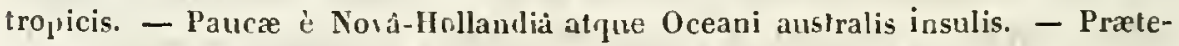
rè̀ specimina multa in herbariis innomisata, multa profectó inedita; sed ex his nonnisi circumspectè instiluen.læ noræ species, synonymiâ generis jàm nimiùm dıbià atque intricatà, et monographum severiorem reposcente.

Habitus et structura cum cimatibus variant. Pleræque Euphorbix boreales herbacea; australes frutescentes, magis succulentæ: in regionibus calidioribus omninò carnosæ.

Haworth (Synops. plant succul. 126-164) Euphorbiæ species 114 in generibus is (Euphorbia, Treïsia, Dactylanthes, Medusea, Tilhy-malus, Galarhaus, Esula, Anisophylllem) yuibusdan, ex ipso, recoznoscendis, distribuit, cx partium calicinarum (id est iuvolucri) uumero, forma et naturà, palearun præsentià aut defectu, llorum dispositione, caulis structurì. 


\section{$(59)$}

Necker (1153. 54. 55. 57.) ex Euphorbiis linnaanis instituit plura geners (Euphorbia, Keraselma, Athymalus, Tithymalus.), habitå involucri appendicum ratioue.

Ad Tithymalum T. referuntur Pithyusa Lob., Chamasice, Lathyris, Peplus c. B., Peplis Clus.

PEdilanthus. Neck. - Poit. - Kunth. - Timhymaloïdes. T. Crepidaria. Iaw. - Eupiorbie spec. L. et Jacq.

Flores monœci in eodem involucro, fœmineus unicus, centralis, masculi plures ambientes. Involucrum calceiforme, superiùs coarctatum, basi ventricosum et intùs glanduliferum, hinc hians atque auctum laciniâ fornicatà faucem obcludente. Stylus unicus; stigmata 3 bifida. Cetera ut in Euphorbiâ.

Frutices lactescentes, ramosi, inermes. Folia alterna, integra, subcarnosa. breviter petiolata petiolo ad basim utrinque glanduloso. Pedunculi plures, terminales, foiiis bracteiformibus stipati, singuli florem (id est involucrum) unicum rubrum sustinentes.

овs. Species 3, duæ antillanæ, tertia indica : quibus consocianda Euphorbia bracteata Jacq. (Hort. sch. tab. 270 ) et forsàn quoque $E$. cordellata Haw. (Misc. nat.). - Charact. ex Poiteau (Aun. Mus. 19. 388. tab. 19) et Kunth (2.63.)

\section{GENERA EUPHORBIACEA MINUS COGNITA.}

\section{MARGARITARIA. L. f.}

Flores diøci. Calix 4 -dentatus. Petala 4 calici inserta. susc. Stamina 8 receptaculo imposita; filamentis setaceis, longioribus; antheris subrotundis, parvis. Ovarii rudimentum 1-stylum. FOEM. Styli 4-5 filiformes; stigmata simplicia. Fructus globosus, sub integunento baccato, cartilagineo, 4-5-coccus, coccis nitidissimis, 2-valvibus.

obs. Species unica surinamensis. - Charact. ex L. suppl.

Genus vallè obscurum et imperfectum. An rami masculi (quibus folia opposita Evonymo similia; Hores paniculati, numerosissimi, ut in Spired arunco) 


\section{(6o)}

et fœminei (quibus folia semper alterua, flores solitarii axillares) verè inter se couspecifici aut etiam congencres, auctore ipso dubitante? - An ovarium in masculis sterile? An loculi in fœminis 1-aut 2-spermi ? - In specimine fomineo Herbarii Candoll. , folia alterna, 2-stipulacea, flores axillares, peclicellati, geninati ternative, bracteati ; calix 4-sepalus, post anthesim reflexus, persistens; styli 4-6, bifidi ; fructus 4-6-coccus, coccis lucidis, 2-spermis. Genus Ciccæ admodùm accedit ex hâc descriptione à $D$. Choisy communicatà, idcòque omni fide dignâ, sed non omninò cum characteribus Linnæi f. concordante.

\section{SUREGADA. Roxb.}

Flores diøci. Calix 5-scpalus. 1usc. Stamina plurima, filamentis linearibus, antheris ovatis, ercetis. FoEM. Stylus o ; stigmata 3 bipartita; ovarium ovoïdeum sexangulare. Capsula 3-cocca, coccis sæpissimè 1-spermis.

Arbor. Folia alterna, integerrima, glabra, venosa. Flores brevissimè pedunculati, foliis oppositi.

obs. Species unica ex Madras. - Charact. ex W. (Act. soc. cur. nat. berol. 4 . 206.) - An quædam affinitas cum Gelonio?

\section{HEXADICA. Lour.}

Flores monoci. мAsc. Calix 5-partitus, patens. Petala 5. Stamina 5, filamentis brevioribus, antheris bilobis, erectis. Foæu. Calix 6-partitus, persistens. Petala o. Stigmata 6 sessilia, concava, conniventia. Capsula globosa, 6-valvis , 6-locularis, loculis 1-spermis.

Arbor. Folia alterna, integerrima, glabra. Flores fasciculati, subterminales, masculi et fominei in diversis ramis.

oBs. Spccies unica cochinchinensis. - Charact. ex Lour. 61\%. - An affinis Glochidio aut quibusdam aliis generibus Phyllantho propioribus?

HOMONOIA. Lour.

Flores dioci. masc. Calix 5-partitus, basi extùs 5 -squamosus. Cololla o. Stamina numerosissima ( circiter 200), filamentis in fasci- 


\section{(61)}

culos 20 connexis, antheris subrotundis. Fors. Squama simplex, acuta, multifida. Calix, corolla et stylus o. Stigmata $\tilde{5}$, villosa, oblonga. Capsula 5-loba, 5-locularis, loculis 1-spermis, 5-valvis.

Arbuscula. Folia alterna, angusta, integerrima, tomentosa. Flores miuuti, amentiformes, amentis subterminalibus, linearibus.

ofs. Species unica cochinchinensis. - Charact. ex Lour. ( $(932)$. - An genus floribus amentaceis, interdùm uudis, Exccecarice affine? Non-ne staninibus polyadelphis et quibusdam aliis characteribus Ricinis, et præcipuè Crotoni salicifolio propius accedit?

\section{CLADODES: Lour.}

Flores monœci. Calix 4-partitus. Corolla o. Masc. Stamina 8, filamentis membranaceis, brevibus, antheris subrotundis. Foess. Stylus o ; stigmata 5 oblonga, reflexa. Capsula subglobosa, 5-loba, 3 -locularis, Joculis 1 -spermis, $\tilde{J}$-valvis.

Arbuscula ramosissima. Folia alterna, serrata, glabra, rugosa. Flores racemoso-spicati, terminales.

obs. Species unica cochinchinensis. Charact. ex Lour. ;05. - An affinis Alchornex ?

\section{ECHINUS. Lour.}

Flores diœci. sasc. Calix squamiformis apice inæqualiter multifidus. Corolla o. Stamina circiter 30 calice bréviora, filamentis capillaribus, antheris subrotundis, minimis. Foes. Calix 5-6-fidus, laciniis inaqualibus, patentibus. Corolla o. Styli 2 pilosi , breves; stigmata simplicia ; ovarium bilobum. Capsula villis subulatis, setosis echinata (undé nomen ), 2-cocca, coccis subglobosis, 1-spermis.

Arbuscula caule declinato. Folia sparsa, integerrima, orata tricuspidatave, reticulato-renosa. Pedunculi laterales pauciflori.

овs. Species unica cochinchinensis. - Charact. ex Lour. 277, qui hùc dubiẻ revocat Ulassium Rumph. (3. 42. tab. 23) arborem ingentem, foliis opposilis aut 4-verticillatis, fructu pisiforni i-spermo. $-\Lambda_{n}$ yæxdam affinitas cum Mappà ? 


\section{(62)}

COLLIGUAYA. Molin.

Flores monœci. Calix 4-fidus. Corolla o. MAsc. Stamina S. FoEM. Styli 3 ; capsula 3 -rgona, $\mathbf{3}$-sperma, elasticè dehiscens.

Frutex ramosus. Folia opposita, crassa, glabra, denticulata. Flores axillares, masculi amentacei, fœminei infrà siti.

obs. Species unica chilensis. - Charact. ex Molina Hist. nat. du Chili. 129. - Genus non procul à Sapio?

LASCADIUII. Raf.

Flores monøeci. Calix limbo integer. Corolla o. Masc. Stamina circiter 12 , filamentis brevibus, antheris crassis. Fowy. Styli 3 partiti; orarium 5-lobum. Capsula ovata, lævis, 3-sperma.

Frutex, totus lanatus, ramosus. Folia alterna, longè petiolata. Flores terminales, masculi plures umbellati, circa fœmineum centralem.

ors. Species unica ludoviciana. -- Charact. ex Rafinesque Fl. Ludov. 114. - Genus, ex ipso, Euphorbiaceum : sed quænam fructùs et seminis. structura?

SYNZYGANTHERA. R. P. - Didymandra. W.

Flores monœci. Calix inferus, brevis, 4-partitus. Petala 4 alterna, minuta. Masc. Filamentum apice bifidum et 2-antheriferum, hinc insertum. sub ovario 5 -stylo, sterili. Foes. Styli 5 brevissimi ; stigmata acuta. Bacca stipitata, orata, exsucca, 3-locularis, loculis 1 -spermis.

Frutex. Flores amentacei, in amentis distincti bracteis squamiformibus, masculi mixti fœmineis, quarum 2-4-adolescunt. Bacca abortu interdùm 1-sperma.

oвs. Species unica peruviana. - Charact. ex R. P. ( Prod. 125. tab. 3o.). - Ex Willdenow, flores omninò hermaphroditi, fæmineis mixti. - An genus veré Euphorbiaceum? 


\section{CONSPECTUS GENERUM (1).}

I. Loculi 2-orulati. Stamina definita, sub pistilli rudimento centrali, sessili, inserta.

Drypetes. Fl. diøci, fasciculati. Calix 4-6-partitus. ơ. Stamina 4-6 disco inserta. \&. Styli et stigmata $1-2$. Ovarium 1-2-loculare. Fructus drupæformis 1-2-spermus.

Thecacoris. Fl. diœci?, subracemosi. Calix 5-6-partitus. ơ. Stamina 5 , loculis antherarum distinctis. $q$. Styli et stigmata 3 . Ovarium 3-loculare. Fructus....

Pacursañda. Fl. monoci, spicati. Calix 4-scpalus, bracteatus. 0. Stamina 4, filamentis dilatatis. $q$. Styli et stigmata 3. Capsula 5-cornis, 3-cocca, 6-sperma.

Buxus. Fl. monœci, glomerati aut (in Tricera ) racemosi. Calix 4-sepalus, bracteatus. ${ }^{\text {r. Stamina } 4 \text {. }}$. Styli et stigmata 3. Capsula 5-cornis, 5-cocce, 6-spcrma.

Securinega. Fl. diøci. Calix 5-6-partitus. 0 . Glomerati. Stamina 5-6. ₹. Fasciculati. Styli subnulli. Stignata 5 reflexa. Capsula 5-locularis, 6 -sperma.

Savia. Fl. diœci. Calix 5-partitus. Petala 5-5 aut o. $\sigma^{7}$. Glomerati. Stamina 5. 9 . Solitarii. Styli 3 bifidi. Capsula 3-cocca, 3-sperma.

Amaxoa. Fl. monœci aut diœci, glomerati. Calix 5-partitus. ơ. Stamina 5. o. Stiginata 5. Capsula 5-cocca, 5-sperma.

Rıcheris. Fl. diœci, spicati. Calix 4-5-partitus. Petala 4-5. ơ. Sta-

(1) Conspectum hunc subjunxi, quo uti liceat veluti tabula brevius conumerante præcipuos sectionum et generum characteres. Scd horum, ut necesse erat, multi omissi, cæteri mutilati, descriptionesque minimć principiis methodi naturalis convenientes. 
mina 4-5.. . Stylus 1. Stigmata 5 revoluta. Capsula corticata, 5-locularis, 3-sperma.

Fluggea. Fl. diœci, fasciculati. Calix 5-partitus. ơ. Stamina 5. \&. Stylus 0. Stigmata 2-3 reflexa, biloba. Capsula subbaccata, 2-3-locularis, 4-6-sperma.

1I. Loculi 2-ovulati. Stamina definita centro floris inserta. Flores glomerati, fasciculati aut subsolitarii.

Epistxhium. Fl. monœci. ơ. Calix 4-partitus. Filamentum apice iucrassatum, 2-antheriferum. $q$ Calix 5-partitus. Stylus subnullus. Stigmata 3, biloba. Capsula 3-locularis, 5-6-sperma.

Grooon. Fl. monceci. ơ. Calix 5-partitus. Stamina 3 basi coalita. $q$. Calix 6-partitus. Stigmata 5 connata in massam ovoïdeam, magnam. Ovarium 3-loculare. Fructus....

Glochidion. Fl. monœci aut diœci. Calix 6-partitus. O'. Stamina 3-6 coalita. $\%$. Stylus subnullus. Stigmata 6 . Capsula depressa, umbilicata, 6-cocca, 12-sperma. Semina fenestrata.

Ansonema. Fl. monœci. Calix 4-6-partitus. o. Stamina 5, filamentis inæqualibus infrà coalitis. \&. Styli 0 . Stignata 6-10. Capsula depresøa, umbilicata, 6-10-locularis, 12-20-sperma.

Leptonema. Fl. diœci. Calix 5-partitus. $\sigma^{7}$. Stamina 5-6, filamentis tenuissimis, loculis antherarum distinctis. 9 . Styli $5-5$ profundè bipartiti. Capsula depressa, 3-5-cocca, 6-10-sperma.

Cıcca. Fl. monœci aut diøci. Calix 4-partitus. 0 . Stamina 4. 9. Styli 4-5 bifidi. Capsula subcarnosa, 4-5-cocca, 8-1 0 sperma.

Embica. Fl. monœci. Calix 6-partitus. 0 . Stamina 3 coalita. . Styli 3 dichotomi. Fructus carnosus, 5-coccus, 6-spermus.

Kirgarrena. Fl. monoci. Calix 5-6-partitus. $\sigma^{7}$. Stamina 5 filamentis inaqualibus, cualitis. 9 . Styli 3 bipartiti. Bacca 3-locularis, 6-sperma.

Puxlanthus. Fl. monœei aut dioci. Calix 5-6-partitus. $\sigma^{\pi}$ Sta- 


\section{(.65)}

mina 5 , rariùs plura, infrà connata. q. Styli 5 bifidi. Capsula 3-cocea, 6 -sperma.

Xreophyla. Fl. monœci, ad crenulas ramulorum folia simulantium. $\sigma$. Stamina 2-5 connata. $\%$. Styli 5. Stigmata lacera. Capsula 3-cocca, 6-sperma.

Menarda. Fl. monœcị. Calix 5-partitus. o7. Stamina 5. bipartiti. Capsula 5-cocca, 6-sperma.

Micraxthea. Fl. monœci. ot. Calix 6-sepalus. Stamina 3 cirea discum glandulosum. o. Calix 6-partitus. Styli et stigmata 3. Capsula j-cocca, 6-sperma.

Agreia. Fl. monœci. ot. Calix 6-partitus, intùs disco membranaceo 6 -lobo restitus. Filamentum columnare 3 -antheriferum. 9. Calix 6-partitus. Styli 5 bifidi. Capsula 3-locularis, 6-sperma.

Andracine. Fl. monœci. Calix 5-partitus. Petala 5 aut o. ó. Stamina 5 connata in stipitem pistilli abortivi. 9 . Styli 5 bifidi. Capsula 5-cocca, 6-sperma.

Cuevtra. Fl. diøeci. Calix 5-partitus. Petala 5. $0^{7}$. Stamina 5 connata in stipitem pistilli abortivi. $q$. Styli 5 bifidi. Capsula 5 -locularis, 5-sperma.

Briedelia. Fl. monœci. Calix 5-fidus. Petala 5 minuta. o7. Stamins 5 connata in pistilli abortivi stipitem impositum disco basim calicis vestienti. 9 . Styli 3 bifidi. Ovarium tubo 5-fido involutum. Fructus carnosus , 2-locularis, 2-4-spermus.

III. Loculi 1-ovulati. Flores, staminibus definitis aut indefinitis, sæpè corollati, fasciculati, spicati, racemosi aut paniculati.

Argytuannia. Fl. monoci. ot. Calix 4-partitus. Petala 4. Stamina 4 , sub pistilli rudimento infrà coalita. o. Calix 5-partitus. Petala o Styli 5 bis bifidi. Stigmata lacera. Capsula 3-cocea.

Ditaxis. Fl. monœci. Calix 5-partitus. Petala 5. 07. Stamina 10 , 
filamentis inæqualibus, connatis in stipitem pistilli abortivi $\subsetneq$. Stylus 3-fidus. Stignata 6. Capsula 3-cocca. :

Crozophora. Fl. monceci. o ${ }^{7}$ Calix 5-partitus. Petala 5. Stamina 5-10, filamentis innqualibus, connatis. 9 . Calix 10-partitus. Petala 0. Styli 3 bifidi. Capsula 3-cocca.

Croton. Fl. monœci aut rarissimé diœci. Calix 5-partitus. on: Petala 5. Stamina 10 aut plura libera. $\$$. Petala o. Styli 3 bifidi pluripartitive. Capsula 3-cocca.

Crotonopsis. Fl. monœci. Calix 5-partitus. o. Petala 5. Stamina 5 libera. $\subsetneq$. Petala 0. Stigmata 3 biloba. Capsula 1-locularis.

Adelia. Fl. diøeci. Calix 5-6-partitus. Petala o. o. Stamina plurima basi coalita. 9 . Stigmata 3 sessilia, lacera. Capsula 3-cocca.

Acrooton. Fl. monœci aut diœci. o. Calix 5-partitus. Petala o. Stamina plurima, receptaculo globoso inserta. ․ Stylus 3-fidus. Stigmata 3. Capsula 3-cocca.

Rotrlera. Fl. diøci aut? monœci. Calix 3-5-partitus. Petala o. o. Stamina plurima receptaculo inserta. $q$. Styli $2-3$ plumosi. Capsula 2-3-cocca.

Codieum. Fl. monœci. o. Calix 5-partitus. Petala 5 squamiformia. Stamina plurima. 9 . Cajix 5-fidus. Petala 0. Styli et stigmata 3. Fructus subcarnosus, 3-coccus.

Gelonium. Fl. diœci. Calix 5-partitus. Petala o. o. Stamina-12 aut plura. ․ Stigmata 2-3 lacera. Capsula 2-3-cocca.

Hisingera. Fl. diœci. ơ. Calix 4-sepalus. Petala o. Stamina 15-25. ९. Calix 6-sepalus. Petala o. Styli 2. Stigmata capitato-depressa. Bacca 2-locularis.

Mozinna. Fl. diceci. Calix 5-partitus. Corolla urceolata, 5-loba. o. Stamina 8-13, filamentis inæqualibus, infrà coalitis. \&. Stylus bifidus. Stigmata 2-4. Capsula 2-cocca.

Amperea. Fl. monœci aut ? diœci. $\sigma^{7}$. Calix campanulatus, 4-5-fidus. 


\section{(67)}

Petala o. Stamina 8, filamentis inæqualibus, liberis, loculis antherarum distinctis. \%. Calix 5-partitus. Petala 0. Stigmata 5-bifida, acuta. Capsula 5 -cocca.

Ricinocarpos. Fl. monoci. Calix 5-partitus. Petala 5. 07. Stamina plurima, filamentis infrì in stipitem unicun coalitis. + . Styli 5 bipartiti. Capsula 5-locularis.

Ricrous. Fl. monoci. Calix 3-5-partitus. Petala o. ox. Stamina plurima, filamentis connatis in stipites plures ramosos, loculis antherarum distinctis. o. Stylus 1. Stigmata 3 bipartita, plumosa. Capsula . 3-cucca.

Jaxipha. Fl. monœci. Calix campanulatus, 5-partitus. Petala o. 0. Stamina 10, filamentis inæqualibus, liberis, circa discum insertis. + . Stylus 1. Stigmata 3 in massam ragosam connata. Capsula 3-cocca.

Jatropha. Fl. monoci. Calix 5-partitus-lobusve. Corolla 5-partita

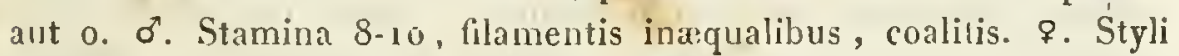
2 bifidi dichotomive. Capsula 3-cocca.

ELEococca. Fl. monœci aut? diœci. Calix 2-3-partitus. Petala 5. 8. Stamiua 10-12, filamentis inæqualibus, coalitis. 9. Stigmata 3-5. Fructus carnosus, 3-5-coccus.

Alecrites. Fl. monœci. Calix 2-3-partitus. Petala 5. 0'. Stamína plurima, filamentis inæqualibus, connatis. $q$. Styli 2 bipartiti. Ovarium tubo conformi involutum. Fructus carnosus, 2-coccus.

Axda. Fl. moneci. Calix campanulatus, 5-dentatus. Petala 5. o. Stamina 8 , filamentis inæqualibus infrà coalitis.' + . Stylus bifidus, stigmata 2. Fructus carnosus, foetus putamine osseo 2-fenestrato, 2-loculari.

Siphona. F! monœci. Calix 5-fidus-partitusve. Petala o. do. Columna sub apicc 5-1n antherifera. o. Stigmata 3 biloba. Fructús subcarnusus, j-coccus.

Mares. Fl. monoci. ó. Calix 5-dentatus. Petala o. Stamina 9-12. 
9. Calix 5-6-fidus. Petala o. Stylus 3-fidus. Stigmata 5 filiformia Capsula 3-cocca.

Hyenaxche. Fl. diœci. o Calix 5-7-sepalus. Petala o. Stamina 10-50. ㅇ. Calix polysepalus. Styli 244 . Stignata 4 fimbriata. Fructus suberosus, 4-coccus, 8-spermus.

Gatcia. Fl. monoci. Calix 3-partitus. Petala 7-11. 0'. Stamina plurima , receptaculo hemisphærico inserta.. 9 . Stylus 1 . Stigma 5-lobum. Capsula 5-cocca.

IV. Loculi 1-ovulati. Flores, staminibus definitis aut indefinitis, apetali, glomerato-spicati aut rarius subracemosi.

Archonnea. Fl. diœci. $0^{\pi}$. Calix 2-5-partitus. Stamina 8 , filamentis in annulum infrì coalitis. + . Calix $3-5$-dentatus. Stylus bipartitus. Stigmata 2. Capsula baccata, 2-cocca.

Conceveibun. Fl. dicei. ox. Calix 3-partitus. Stamina 5-4 basi coalita. 9 . Calix 5-fidus. Styli 3. Stigmata plumosa. Capsula 3-cocca.

Claoxyron. Fl. diøci. Calix 5-4-partitus. $\sigma^{7}$. Stamina 15 aut plura, loculis antherarum distinctis. ㅇ. Appendices 3 . Styli $2-5$ breves, plumosi. Capsula 2-3-cocca.

Macaranga. Fl. diøci. o7. Calix 4-partitus. Stamina 8-12. 9. Calix urceolatus. Stylus liguliformis. Stigma villosum. Fructus follicularis, (abortu) 1-locularis.

MIPPA. Fl. monœci aut diœci. $\sigma^{7}$. Calix 5-partitus. Stamina 5-10. 9. Calix 2-3-fidus. Styli 2-3 oblongi, plumosi. Capsula 2-3-cocca.

Catures. Fl. dicci. ơ. Calix 5-fidus. Stamina 5. 9 . Calix 5-partitus. Styli 5 laciniati. Capsula 5 -cocca.

Acalmpha. Fl. monœei aut dioci. o'. Calix 4-partitus. Stamina 8-16, loculis antherarum distinctis, vermiformibus. 9 . Calix 5 -partitus. Styli 3-laciniati. Capsula 3-cocca.

Mercurianls. Fl. monœci aut diøeci. Calix 5-partitus 0 . Stamina \$-12 aut plura, loculis antherarum distinctis, globosis. 9 . Styli 2 breves, denticulati. Capsula 2-cocca. 
Anabara. Fl. monœci. Calix 5-partitus. ơ. Stamina 10 basi connata in stipitem squamulis 4 cinctum. 0 . Stylus oblongus, proboscideus. Stigma 5-lobum. Capsula 5-cocca.

Plukxema. Fl. monœeci. Calix 4-partitus. ơ. Stamina 8 , basi connata in stipitem glandulis 4 barbatis cinctum. of. Stylus oblongus, proboscideus. Stirma peltatum, q-lobum. Capsula q́-cocca.

Trafia. Fl. monoci. ơ. Calix 5-partitus. Stamina 2-5. o. Calix 5-8-partitus. Stylus J-fidus. Capsula 3-cocca.

V. Loculi 1-orulati. Flores, staminibus definitis, apetali. Bractcie. magnæ, multifloræ, spicate, aut amenta.

Mrcrostacins. Fl. moneci. Calix 3-partitus. ơ. Stamina 3. \%. Stylus 5-partitus. Capsula 5-cocca.

SApicy. Fl. monœci. ơ. Calix 2-fidus. Stamina 2. \&. Calix 5-dentatus. Stylus 5-fidus. Capsula 5-cocca.

Strlungia. Fl. monœci. o. Calix tubulosus, dentatus. Stamina 2. 9. Calix 5-fidus. Stylus 5-fidus. Capsula 3-cocca.

Triadic.. Fl. diceci. Calix campanulatus 5-4-fidus. o7. Stamina 2. 9. Stylus 1. Stigmata 3. Bacca exsucca, 3-locularis.

Omalantuus. Fl. monœci. Calix 2-sepalus. ơ. Stamina 6-10, filamentis connatis. q. Stylus bifidus. Stigmata 2. Capsula 2-locularis.

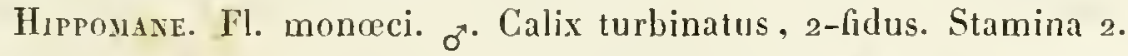
\%. Calix 3-partitus. Stylus 1. Stigmata 7. Fructus carnosus foetus nuce $;$-loculari.

Hura. Fl. monœei, amentacei. $\sigma^{x}$. Calix truncatus. Filamentum columnare pluriantheriferum. + . Stylus 1. Stigma 12-18-radiatum. Capsula 12-18-cocca.

Serastiaxia. Fl. monœci, amentacei. Squam $x$ 1-flor:e, squamulis intùs instructx. $0^{3}$. Stamina 5. . Stylus 3-partitus. Capsula 3-locularis.

Excecaria. Fl. monœci aut diœci, amentacei. ơ. Squamæ stami- 


\section{( 70$)$}

niferre. Filamenta 3 basi coalita, simplicia aut partita. $q$. Calix 3 -fidus aut 0 . Stỵlus 5-partitus. Capsula j-cocca.

Commı. Fl. diœci. o. Amentacei. Squamæ staminiferæ. Filamentum unicum, pluriantheriferum. \%. Racemosi. Calix 3 -partitus. Styli 3. Capsula 3-loba.

Struoceras. Fl. monøci aut diveci. ơ. Squamæ. 10-antheriferæ. 9. Calix 3-5-partitus. Styli 2. Fructus 2-4-locularis.

Mafrocxea. Fl. monaci. $0^{*}$. Calix 2-4-fidus. Filamentum 2-antheriferum. q. Calix 5-lobus. Stylus 5-fidus. Capsula 3-cocca.

Osphales. Fl. monœci. Calix 4-partitus. $\sigma^{2}$. Filamentum sụprà pileiforme, in ambitu 2-j-antheriferum. ơ. Stylus 1. Stigma subtrilobum. Fructus carnosus, 3 -coccus.

VI. Loculi s-ovulati. Flores apetali, monœei in inrolucro communi.

Dalechampia. Inrolucrum commune foliaceum, 2-phyllum, 4-appendiculatum. 6 . Inrolucrum proprium 2-5-phyllum, multiflorum, floribus stipitatis. Calix 4-ว-partitus. Stamina plura infrà connata. 7. Involucrum proprium 2-phỵllum, 3-florum. Calix 5-6 aut 10-12partitus. Słylus et stig̣ma 1. Capsula j-cocca.

Axthostema. Involucrum commune 2 -partitum. 0 . Involucrum proprium multilobum, multiflurum. Pedicelli receptaculo, bracteis interjectis . impositi, singuli articulati cum filamento caliculato, 1-2ntherifer\%.. . Unicus lateralis. Calix 3-dentatus. Stylus 3-fidus. Stigmata 5. Fructus 3-coccus.

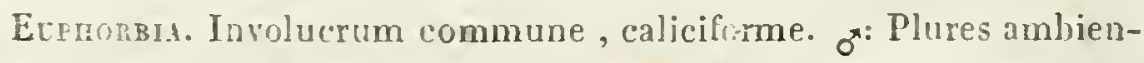
tes. Peenicelli, bractèis infrà interjectis, singuli articulati cum filaments) nudo, 1-antherifero. \&. Unicus centralis. Calix brerissimus ant 0 . Styli 5 bifidi. Capsula 5 -cocca.

Pedicaxturs. Insolucrum commune, calceiforme. $\sigma^{2}$. Plures ambientes. I'edicelli, bracteis stipati, singuli articulati cum filamento 
nudo, 1-antherifero. +. Unicus centralis. Calix o. Stylus 1. Stigmata 3. Capsula 5-cocca.

VII. Genera minùs cognita.

Margaritaria. Fl. diøeci. Calix 4-dentatus. Petala 4. o. Stamina 8. Orarii rudimentum. \$. Styli et stigmata 4-5. Frnctus subhaccatus, 4-5-coccus.

Suregad A. Fl. diceci. Calix 5-sepalus. 8 . Stamina plurima. + . Stylus o. Stigmata 3 bipartita. Capsula 3-cocca, 3-sperma.

Hexadica. Fl. monceci. ơ. Calix 5-partitus. Petala 5. Stamina 5. 7. Calix 6-partitus. Petala et stylus o. Stigmata 6. Capsula 6-locularis, 6-sperma.

Homonoï. Fl. diœci. c. Calix 3-partitus, extùs 3-squamosus. Corolla o. Stamina indefinita, polyadelpha. ?. Squama simplex. Calix, corolla et stylus o. Stigmata 5. Capsula 5-loba, 3-sperma.

Cladodes. Fl. monoci. Calix 4-partitus. Corolla o. 8 . Stamina 8. ?. Stylus o. Stigmata 3. Capsula 3-loba, 3-sperma.

Echinus. Fl. diœci. on. Calix squamiformis, multifidus. Corolla o. Stamina 30. 9. Calix 5-6-fidus. Corolla o. Styli et stigmata 2. Capsula echinata, 2-cocca, 2-sperma.

Colliguay. Fl. monoci. Calix 4-fidus. Corolla o. $0^{7}$. Stamina 8. 9. Styli 3. Capsula 3-gona, 3-sperma.

Lascadiur. 11. monoci. Calix integer. Corolla o. o. Stamina 12. 9. Styli 3-partiti. Capsula 3-loba , 3-sperma.

Synzyganthera. Fl. monceci. Calix 4-partitus. Petala 4. 0 . Filamentum 2-antheriferum. Pistilli rudimentum. 8 . Styli et stigmata 3. Bacca 3-locularis, 5 -sperma. 


\section{N D E X}

\section{PARTIS BOTANICA.}

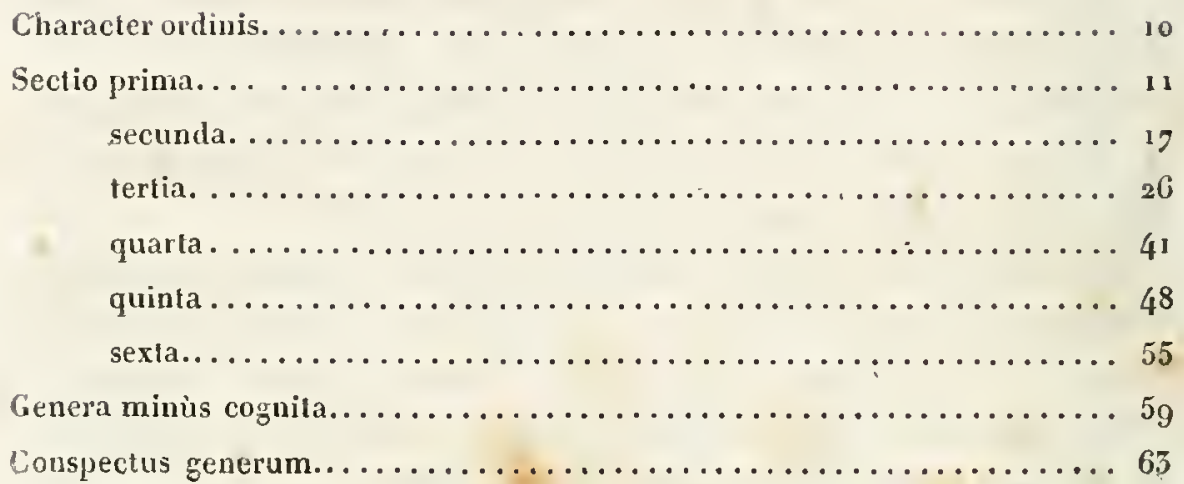




\title{
PARS SECUNDA,
}

\author{
SEU MEDICA.
}

Quod in ordinibus plerisque vcrè naturalibus, hoc maximè in Euphorbiaceis obscrvatur, medicarum scilicet virium convenientia: adeoque manifesta est, ut eam senserint veteriores etiam botanici , qui primi methodicam quamdam plantarum dispositionem prætentaverunt, sed.dubiè adhùc, et iter illud, in quo nunc firmiùs incedimus, suspenso quasi gradu explorantes. Omnes enim hanc Tricoccarum, ut vocant, familiam nocivam exitialemque arguunt, et stirpes, quxcumque huic referendæ videntur, suspectas habent : atque ipse jam Morisonius, multis non malè conjunctis in eâdem sectione, ipsam nomine purgatricium lactescertium necne designat. Progressu autem temporis, ut meliùs hujus ordinis innotuêre characteres, utque crevit continuis auctorum laboribus generum specierumque numerus, virtus simul eorum magis ac magis, quotiès explorata, totiès confirmata est.

Hæc Euphorbiacearum vis de quâ dicimus, in omnibus ejusdem natura est, excitans scilicet; vérùn ex eà non semper unus atque idem effectus. Natura enim, dùm cunctas ejusdem familix plantas communibus quibusdam connectit signis, singulas iisdem varie modificatis distinguit; quod de proprietatibus earum proindè ac de botanicis characteribus intelligi potest.

Quid de medicatione excitanti eveniat primò considcrandum. Si non admodìn vehemens et dosi modicà ingeratur, pleraque organa, quasi stimulo admoto, vividè magis exercentur. Sanguinis circulatio 


\section{( 54 )}

celerior atque plenior, presertim in capillaribus : hinc frequentes fluxus; aut in cute sudor; aut in utero mensium eruptio; aut in renibus copiosior urinæ secretio. Augetur simul vasulorum absorbentium suctus, quod atonicx congestionis resolutioni, hydropisve passivi curationi farere potest.

Si medicamentum acrius aut minùs parcum exhibeatur, loca ipsa quæ tangit, irritat. Hinc, si canali intestinorum admoveatur, nunc emesis, nunc catharsis, sæpè utraque. Tunc phænomena exstant quoque generalia quædam, sed minùs clara propter majorem localium intensitatem.

Si denique substantiæ excitantis et vis acerrima sit, et dosis copiosa, loca quæ in contactu cum ipsâ inflamnantur. Hinc phlegmasiarum diversa signa diversæque læsiones. Hinc sæpè quoque sympathica systematis nervosi perturbatio, qux lethifera etiam esse potest, spatio nonnunquàm temporis breviori quàm ut læsioni organorum suffecerit.

Itaque inter medicamina quæ sudorifica, hydragoga, emmenagoga, diuretica, emetica, purgativa vocantur, magna similitudo; tanta quidem, ut unum atque idem interdùm pluribus finibus respondeat : atque ex his multa etiam sunt qux à venenis dosi tantùm discrepent, quod manifestum fit in toxicologia libris corpora recensentibus pleraque eadem ac pharmacologia.

Quibus præmissis, vis Euphorbiacearum, quamris nunc leniùs, nunc vehementissimè operetur, sibi tamen constare semper invenietur; prasertim, si ratio habeatur multorum, quibus variantibus, vis hæe quoque variat, ut optimè clarissimus De Candolle edocuit; si hinc scilicet plantæ, quam explores, genus, species, pars, patria, sedulò notentur, indè vivi corporis cui applicatur status.

Lacteus scilicet succus est in quo principia acerrima abscondi videantur. Necesse igitur est magna proprietatum existat discrepantia varias inter ejusdem plantre partes plùs minùs hoc lacte imbutas ; major, diversas inter stirpes eodem alias instructas, alias rerò egentes. Dispares erunt quoque inter se quæ in plagis crcrerunt 


\section{$(75)$}

temperatis, ct qua sole tropicorum caluerunt. Hæc $\rho$ mnia in com parativa virium astimatione, inque experimentis agendis, seduld attendenda.

Euphorbiaceis paucis odor saporque aromaticus; plurimis odor nunc nullus, nunc nauseoșus virosusve, sapor sapiùs acriṣ et pungens. Quædam, ut Acidoton diversa:que Tragiæ aut Jatrophæ species, pilis horrent qui liquorem acrem excernunt, sensumquc cutipunctx, urticæ instar, imprimunt.

Cortex variarum Crotonis specierum tantìm aromaticus, indè in potibus gratè stimulantibus aut vulnerariis confıciendis usitatıs. Cascarillæ virtus similior, sed jam magis valida. Sic agere quoque videntur flores nonnullarum, Caturi spiciflori verbi gratiâ, ut corpori solummodò tonum addant.

Non pauca sunt quæ renum laborem stimulent, ut quidam Phyllanthi, folia Mercurialis annue, radix Ricini communis, etc. Multas prætereà contra lyydropem valere auctores testantur, seu indè absorptioni, seu urine secretioni faveatur. Phyllanthi iidem emmenagogi. Cortex plurium Crotonum, lignum Crotọnis tiglii et Buṣi, folia ejusdem et Ciccæ distichæ, Luphorbiaque multa, ctc., memorantur ut sudorifica, aut contra syphilitidem commendantur : ut emetica autem, radix Euphorbiarum, Commir succus, Anda, Mercurialis perennis, etc. È purgantibus; inter plurima quæ in loc ordine exstant, conmemorare satis est folia Buxi et Mlercurialium, suc; cum Euphorbiæ, Commix, Huræ, semina Ricini, Crotonis tiglii, Andx, Jatroph $x$, etc.

Multæ barum parcà etiam dosi nocivæ; aliæ autem adeó venenosæ, ut his nunquàm medicina uti audeat, quemadmodùm, exempli gratià, Hippomane. Sic vis excitans in Euphorbiaceis gradatin ab operatione innoxiâ aut utili, ad periculosam exitialemve transit.

Venena ex hoc ordine desumpta pleraque inter acria collocanda esse videntur. Şæè tamen quidda an accedit nạrcotici; cujus rei exemplum in Phyllantis variis et nonnullis aliis piscem, si aqua injiciantur, 


\section{$(76)$}

menispermi cocculi instar, inebriantibus : quod et in homine ipso diversis exemplis confirmatur.

Vis Euphorbiacearum resina alque imprimis princinio volatili, quæ in his continentur, tribui potest. Hinc harum tincturæ alcoolica vehementiores; hinc nónnumquàm ex ipsis raporibus manantibus periculum; hinc notabilis virium, post admotum calorem, imminulio : sicque intelligi potést quomodò quadam ex his, anteactî coctione, nunc pro topicis emollientibus , nunc pro alimeutis in usu esse potuerint. Exemplum scilicet pre omnibus insigne radix Janiphæ mąnihot, quâ nullum venenum forsàn acrins, sed quâ câdém 'igni subjectâ pauci cibi salubriores, frequentioresve.

In seminibus, perispermo crassiori oleum inest fixum, innocuum; principium autem nocivum, et, ut videtur, volatile embryoni. Itaque, hoc ablato, nuclci in quibusdam, ut Omphaleà diandrà, tutò eduntur; oleumque ex ipso expressum nunc lene est, nunc acre, prout, in eo parando, embryo intactus necne relictus est.

Inter alia elementa quæ ịn Euphorbiaceis chemica analysis invenit, duo hic pracipuè notanda, alterum scilicct quod vulgò Cahuchu seu Caonulchouc dicitur, alterun quod Tournesol.

Calsuchu, singularis hæc materia, quæ, quoniàm calore modico fusa facilè formam quamlibet accipit et servat, neque aëre neque aquâ vitiatur, mollis omnique acritudine destituta dirersas humani corporis partes contactu suo minimè lædit, iislemque variè flexuosis admodum elastica sese accommodat, et hinc maximum prestat arti chirurgicx in conficiendis instrumentis adjumentum; hac, inquàm, è Siphonià elasticî́ extrahitur, sed invenitur quoque in succo pluriun Euphorbiacearum, ut Excacariæ a aallochæ, Hippomanis mancanilla: Huræ crepitantis, Sapii aucuparii, Pluknetix volubilis, Jatropharum, Mabearum, Omphalearum (De Candolle), Euphorbiarumque quarumdam (Tussac).

Tournesol, succus arti tinctorix utilis, sed multo magis chemicx, quoniàm puniceus naturâ, paratione autem, additis quibusdam 
alcalinis, crruleo-violaceus, statim ad colorem nativum redit, si quidpiam acidi addatur; paratur ex Crozophorà tinctoriâ seu Crotone tinctorio L., sed et in quibusdam aliis exstare videtur, ut in aliis Crozophoris, Crotone tricuspidato et C. quinquecuspidato, Argythamnix, Ditaxis, Claoxyli speciebus.

Substantiæ qua:dam singulares, ut quâ Stillingiæ sebiferæ semina involvuntur, pulvisque coccineus quo fructus Rottleræ tinctoriæ conspersi, hic prætermittentur, quoniàm in speciebus unicis occurrunt, neque ideo characterici in ordine possunt vocari.

Nunc enumerandæ sunt species omnes quibus aliqua vis ab auctoribus tribuitur, seu confirmetur horum testimoniis virium in Euphorbiaceis analogia, sive contrà infirmetur. Antè autem animadvertere decet, è tam numerosis hujus ordinis speciebus paucissimas tantùn species expertas haberi, et in his ipsis non semper partes quæ maximè valerent, ut semen, fuisse exploratas, et earum deniquè quæ exploratæ fuerunt vim nativam interdùm præparando, ut coctione, mutari potuisse.

\section{ACALYPIIA.}

A. cupameni, herba indica. - " Radix trita et cum aquâ calidâ - assumpta, cathartica est. Folia trita et cum aquâ epota ventrem "laxant." (Reed. เo. 161.)

\section{ACIDOTON.}

A. Łrens, frutex jamaïcensis. - Nomen à setis quibus instruitur urentibus, ex Sw. et Sloane.

\section{ALEURITES.}

A. ambinux, arbor moluccana, quæ in insulà Borbonicâ crescit, qúoque importata. "Nucleus ejus sapidissimus, aphrodisiacus, et - pauld nimis indigestus. "(Commers. mss.)

Camirium Rumphii, arbor javanensis et moluccana, certò congener. A Amboïnenses quidam nucleos crudos comedunt cum pauxillo 
" piperis mistos; sed non multi simul sunt edendi ed quìd incbrient.

- Si torieantur, securissimum est.... Oleum decoctum ad pisces fri* candos ab hominibus vilibus usurpatur. " (Rumph.)

ANDA.

A. gomesii, arbor brasiliensis.

lix Marcgravio (110) : "Barbari illius cortice utuntur ad capien-

" dos pisces; aquâ enim in quà maceratur omnes animantes sopo-

" rantur.... Fructûs duæ castaneæ comestæ purgant bilem atque

" pituitam absque molestià, omnique etati et sexui, imò et prægnan-

" tibus conveniunt. Possunt quoque ex his cum saceharo pauxillo,

" semine anisi et cinnamomo tabellæ fieri, quæ sunt gratissimum

" medicamentum iis qui abhorrent ì purgantibus. Dosis autem duæ

"castanea."

Piso (lib. Iv. ch. 25, p. 72 ) vim majorem seminibus tribuit. Ipso enim testante, "valide purgans hoc est operationis. Quamobrem "agris morbo fractis haud tutò exhibetur, nisi opportunè à manu "medici correctorium accipiat.... Unum siquidem semen atque " alterum mandueatum alvum ducit; quibusdam simul et romitum " excitat. Olim magnates purgans hoc et salutare remédium cæeris " omnibus præferebant."

Nuperiùs Bern. Gonıs in observationibus botanico-medicis de quibusdam Brasilia plantis ( 1 em. acad. Lisb. 5. 1), de hàc disseruit, actis quibusdam experimentis. "Semina, inquit, absque torminibus " aut aliâ molestià mediocriter operata esse comperi. Hıc tamen dissi- mulandum non est mihi viderc contigisse juvenem qui, duo triave " semina recenter lecta edens, postei tormina passus est; hinc tamen " nilhil aliud, nisi matura tantùm, sicca et optimè contusa, ut benè " vertant, exhibenda esse conficio. His sub cautionibus tutum sua"veque semper hoc fore remedium confido. Adhùc quid jucundius? "Hæc semina sicca arellanas sapiunt. quapropter ea mandueare non *. tar?et. Quoniàm insuper olcun et mucilaginem in se recondunt, - Lacili eun saccharo in omulsionem verti possunt : quid tunc ad 
- solvendos pueros, et eos qui à remediis abhorrent, prestantius?

"Hàcce sub formà illa exhibui in memoratis periculis. Pro delica-

- tioribus, et, ut tormina omninù vitentur, huic compositioni non-

" nilıil aromatis accedat oportet... Hisc semina perdurant diù

- incorrupta. Abhinc duos annos ea serro, nec utcunque rancida de-

- preliendo. Dosis duo triave semina. "

Quædam addit auctor de oleaginusâ seminum naturâ, undè utilitas in usu domestico, et pracipuè in picturâ, pcrcipi posset.

BRIEDELIA.

B. spinosa, frutex indicus. - Ex Roxburgh, cortex astringens est, cujus magna vis. Foliis libenter vescuntur pecora, et indè vermes eorum intestini necari feruntur.

- BUXUS.

B. sempersirens, arbuscula europæana. - Foliis odor ingratus, et sapor amarus, nauseosus, præsertim humidis. Decoctis vis sudorifica (Duhamel), purgansque, ex quibusdam, velıemens. Dosis autem unciæ $\frac{1}{2}$ aut $1 \frac{1}{2}$ (Peyr. 434) : ex aliis (Puyzh. Gouan. Haller) drachma unica in pulvere satis est. Narrat Hansray hæc in Persiâ pabulum camelis præbere gratum, sed nox lethiferum. Interdùm in cerevisià conficiendâ pro Hunulo substituuntur.

Ligni radicisque scobis (unciæ 1-4) in aquâ vinove infusa, sudorem potenter ciet, et hinc quasi ligni guayacini succedanea in morbis syphiliticis rheumatismoque chronico commendata est. Ex eâdem oleum empyreumaticum, fœtidum distillatur. - Hæc omnia medicamenta nunc obsoleta.

CATURUS.

C. spiciflorus, arbuscula indica. - "Doctor Pryon notat qudd flo- res specificun præbeant remedium in diarrhæâ et omni morbo ex - laxitate vasorum orto, si cum aquâ coquantur, vel ir conservâ adhi-

" beantur. ( (Burm. Ind. 505.) 
CICCA.

C. disticha, fruticula indica. " $\mathbf{E}$ foliis cum aquâ communi de" coctum conficitur quod sudores movet et variolos expcllit. " Hac Reed (3. 58), additque radicem, cujus succus lactescens acris, ad ciendum vomitum alvumque laxandam adhiberi, sed quibusdam aliis commixtam; foliaque cocta, ad sudorem. Fructùs bacciformis intcgumentum carnosum, saporis subacidi refrigerantisque, jucundè et tutò comeditur, sicut et in C. racemosa $\vec{a}$ Lour. (680). De seminum ri, profectò catharticâ, tacent auctores.

Tricarium, cochinchinensis arbuscula, quæ Ciccæ affiuis, drupam quoque fert esculentam. (Lomr. 680.)

GLUYTIA.

C. collina, arbuscula indica. - Capsularum cortex dicitur admodùm venenosus, testante Roxburgh.

CODIOEUM.

C. variegatum, frutex moluccanus. - Hujus varietates nonnullix velut distinctæ species describuntur à Rumphio, quo testante, "om" nium cortex et radices calidæ sunt naturæ, oris ac faucium ardorem " excitantes, qui per totam persentitur dicm.." Sed precipuè varietatis sub nomine $C$. sylvestris nemorate radix " ab Uliasserensibus et "Nussalauta populis adhibetur tanquàm purgans vulgare, cujus frus" tulum semidigitum longum sumitur ac masticatur cum siri pinungâ " (arecâ cathecu), ejusque deglutitur succus; faucium verú ardorem " excitat notabilem, etc. "Folia autem " modicè sunt refrigerantia ac "saporis dulcescentis, teneraque in olus coqui possunt. "(Rumph. 6. chap, 29. 51.)

COMMIA.

C. cochinchinensis, arbuscula. - "Gummi albi, tenacis, ex arbore

" manantis virtus emetica, purgans, desobstruens. Prudenter admi" nistrata valet in rebelli hydrope et obstructionibus. "(Lour. 740 
CROTON.

C. tiglium, frutex indieus, zeilanensis, sinensis, moluccanus. - Cuilibet hujus planta parti magna vis inesse videtur, radici scilicet, ligno, foliis, sed precipuè seminibus et olen ex his expresso.

Radix drastica est et in Amboinà Bataviàque hydrope laborantibus velut specifica adhibetur paucorum granorum dosi.

Lignum ejus "leve, spongiosum, pallidum , vestitum cortice cine- reo saporis pungentis et caustici odoris ingrati, ", anave dicitur. Dosis ejus parcior sudorem movet, copiosior purgat utràque parte; sed ris multò major recenti quàm sicco.

Folia sic acria sunt, ut indè "os, labia, fauces inflammatæ intu" mescant, et ardor usque ad anum percipiatur. " (Murr. 4. 150.)

Seminum, quæ grana molucca aut tgglia vulgò nuncupantur, usus frequentior et jamdiù notus; sed in Europâ, casibus nonnullis ex imprudenti medicinâ ortis, onınind obsoleverat. Nunc tandem renovatur à Britannis, quibus rerum indicarum, nunc imprimis, cognitio familiarior et facilior comparatio.

Semina hac aquæ injecta pisces interimunt. Decem aut riginti fructus confracti et cum melle misti, equos modicæ staturæ, citâ ex his diarhhâ vehementissimâ, interdùm necaverunt; et tùm signa reneficii crant ventris tormina, ciborum inappetentia, æger anhelitus, os spumans, dentes frendentes, pulsus arteriarum, presertim morte jam propiori, parvus et contractus. (Orfil. 2. 113.) Vehemens semper è seminibus sine ullà præparatione datis, ventriculi intestinorumque inflammatio. Itaque in Indiâ, ubi medicamentum hoc purgans in usu est, non adhibentur nisi tosta primò, quo facto removetur testa, nucleus in pulverem redigitur et paulisper lenitur acrimonia.

Oleum cx his èlicitur, cui color luteus, odor vix ullus, sapor acris; quæ tamen variare possunt, seminibus plùs minùsve torrefactis. Cùm xther et terebenthinum oleum totum hoc dissolvant, purius sinceriusque obtinebitur, si digerantur in his menstruis se- 
mina, quàm si è tostis et conpressis, ut fit in Indià, exprimatur. Elementa autem hujus, ex doctoris Nimuo experimentis, sunt : olei fixi vi omni catharticà destituti partes 55,45 autem principii cujusdam acris, purgativi, quod, in alcoole athereque sulfurico et pinguibus volatilibusque oleis solubile, naturæ resinaceæ videtur, possitque nomine tiglina insigniri.

Utuntur aut oleo integro aut tincturâ ejus alconlicâ, in quâ tiglina tantùm suluta continetur. Dusis, guttæ una aut altera. Operatur autem ceterurum drasticorum modo; eo tamen commodius, quod facillinè administrari possit. Satis est enim interdùm si linguam tetigerit. Valcbit igitur cum maniacis aut aliis æoris quibus diflicilè potus copiosior ingereretur. (Hxe omnia excerpta è doctoris Paris Pharmacologiâ. London medic. journ. $n^{\circ}$ 208.)

Vim olei tiglini nuperrimè expertus est medicus alter britannus, C. Dendy, qui mulierem juniorem tres jam hebdomades constipatione pertinaci laborantem, in quâ curandà usitata omnia remedia, vel valentissima, nihil omninò profecerant, symptomatibus jam admodium ingravescentibus, medicamento hoc adhibito, celerrimè sanavit. (Lond. medic. reposit. $n^{\circ} 112$.)

Inò hoc oleum non tantùm ori, sed ipsi umbilico appositum, catharsim ciet. (Ex Herm. mm.)

CRoton moluccanum Lour. (non L.), arbor cochinchinensis. - Virtus seminum purgans, emetica, desobstruens, eadem ferè " qua. C. tiglii, sed minùs vehemens; ideò apud medicos cochinchi" nenses crebriùs usu venit. Lenior et innoxia fit, si semina pelliculâ - interiori libera ità contundas in linteo, ut huic totum oleum ad" hæreat, massamque istam coquas et exsiccatam leviter torreas. " (Lour.)

Свотом cascarilla, frutex americanus. - Cortici ejus, qui in pharmacopais vulgatus sub nomine Cascarille, corticisve eleutherani, odor suavis, magis, dùm comburitur, fragrans; sapor amarus, undè sensus acritudinis in ore diù persistens. In hoc, ex 
analysi D. Tromsdorff, continentur oleum volatile, resina, principium amarum, mucilago. Infunditur aque, vino, alcooli; hoc infusun ceteris potentius. Pulvis quoque aut extractum ejus parantur, et aquam de eor stillatitian indicat codex medicamentarius.

Cascarillee vis tonica et excitans. Doses ejus paree (pulveris grana 6-12, tinctura guttæ 50 ) facultates digestivas stimulant, copiosiores totam œconomiam. Hinc euim cursus sanguinis celerior, calor corpori additus, sapè etian diaphoresis aut hæmorrhoidum lluxus, etc. Suadebatur itaque, si tonicis opus esse judicaretur, in diarrlıa, febribusque adynamicis aut intermittentibus. ut corticis peruriani succedanea, ipsique interdùm consociabatur. (Barb. 2. 12.-Alib. 1. 72.) Nunc minus in usu est.

Hanc quidam medici virosam narcoticamque suspicati sunt (Peyr. 44j) . quod confirmant vertigines et ebrietas quibus interdùm laborant qui pulveris ejus plìs justo addunt tabaco, ut fumus ejus fiat ad sugendum gratior. (Murr. 4. 155. - Desc. 1. 15.)

Свотом balsamiferum, frutex antillanus. - Martinicenses, " qui" bus petit baume sive balsamum pumilum vocatur, ex spiritu vini a adusti cum hâc plantà destillato liquorem conficiunt spirituosum " mensisque dicatum, cui nomen imposuêre eau de mantes. " (Jacq. Amer. 255.) Succus spissus et odorifer ex omnibus partibus fruticis incisi manat : similique scatent Ćroton origanifolium, ided copahu domingense nuncupatum, $C$. niveum et $C$. aromaticum.

Plures preterea Crotonis species apud Brasilienses coutra morbos syphiliticos nunc magno in usu esse, profectò ut sudorificas, retulit mihi D. Aug. de Saint-Hilaire (1).

(1) Idem in plurimis Euphorbiaceis observatis vim plùs miuùsve excitantem et frefuentem acritudinem confirmavit. Hæc, ut sperauus, nelius patebunt in expectatis celeberrimi peregrinatoris operibus, quæ hoc modo, ut butanicx plurima, sic quxdam et medicina discenda poterunt exisibere. 
CROZOPIORA.

C. tinctoria seu Croton tinctorium, vulgò Tournesol, herba europæana australis. - Sapor acris; virlus emetica, drastica, corrosiva. Hanc medici nullo in usu habent; veteres tamen, Plinius, Cæsalpinus, Boerhaavius, jure Ricino Euphorbiæque comparaverunt, affirmantque, seminibus ejus in pulverem contritis curnque oleo ingestis, catharsim optimè cieri. Sućcus ejus spissatus, sub nomine lacmi vulgatus, vi eâdem ac fructus valet. Quem Bergius, cùm gustu exploravisset, ore deindè non colluto, œsophagi irritationem, cardialgiam, vertiginem expertus est. (Gouan. 357.)

DRYPETES.

$D$. állua et $D$. crocea, arbores fruticesque antillanæ. - In priore, fructûs drupaformis pulpa saporis expers, perispermum paulisper acre. Idem in posteriore faucium ardorem ciet, sinapis instar acerrimæ. (Ex Puiteau.)

ELEOCOCCA.

$E$. verrucosa seu Dryandra cordata, arbor japonica; et $E$. vernicia seu Vernicia montana, arbor sinensis.-Amba magni commodi propter abundans oleum è seminibus expressum, in illà lychnis, in hâc lignis telisque illinendis, utile; sed in neutrâ, rei cibariæ, quia scilicet acrius.

EMBLICA.

E. officinalis, arbor indica. - Fructus qui myrobalanus emblica offic., drupæformis, sapore manifestè acido et astringente. "Siccatus " autem pro miti purgante habitus est, sed veriùs astringendi poten" tiâ pollet. Decoctum indè paratum contra dysenteriam aliaque alvi "profluvia in laude fuit." (Murr. 4. 127.) 
Inter species hujus generis numerosissimas, pauce sunt que non succo turgeant lacteo, acri : sed in quibusdam carnosis, cactiformibus abundat presertim, è quibus extractus concretusque servatur sub nomine gümmi Enphorbii, de quo hìc primùm agetur.

Forma ejus, massula irregulares, friabiles, sæpius perforatæ; color extùs pallidè luteus aut rıfescens, intùs albus; odor nulhıs; sapor mox pungens urensque nec tutò exploratus. Elementa, resinx partes 60 , olei volatilis et aquæ 8 , cæteræ, malatum calcis et potassa, ceræque et lignosi. Aqua paucissimas solvit, alcool plurimas, tincturaque ex eo acerrima.

Euphorbii nociva vis pluribus exemplis patet quàm ut omnia hic referantur (vid. Murr. 4. 88 ). Ex lıoc deglutito atrocissima ventris tormina, hypercartharses cum romitionibus frequentissimis, singultus, ardor ventriculi et faucium, sudores frigidi, animi deliquia, mors sæpè, consecuta sunt. Cùm cuti vultûs atque imprimis telæ narium mucosæ applicatum, phlegmasiæ ulcerationesque supervenêre. Hujus semiunciâ cani valido ingestà, mox gemitus et ad vonıendum conatus; posterâ die virium et sensuum defectio, mors ; in cadavere, intestina omnia admodum inflammata. Euphorbii pulverulenti drachma 2 tela cellulari femoris admotæ, membri partiumque vicinarum inflammationem lethalem attulère, sed servato sensuum motûsque usu, intestinisque et pulmonibus illæsis. Euphorbium igitur in animantibus sicut in homine operatur, phlegmasiam localem acerrimam ciet, undè sequitur sympathica systematis nervosi perturbatio, sed non absorbetur. (Orf. 2. 52.)

Usus ejus apud veteres, ad catharsim sternutationemque ciendam, frequentissimus, nunc quasi omninò obsolevit; et rectè quidem : plùs enim pharmacopæo paranti nocebat quàm proderat xgrotanti. A quibusdam tamen conmendatur, sed topicè tantùm, seu ad vesicationem in unguentis epispasticis, ut pommato vulgò dicto de Grandjean, seu " in carie ossium ad separandam vitiosam par- 
" tem, sive exfoliationem cjusdem quam vocant perficiendam. (Murr. 4. 95.)

De quâ specie oriatur Euphorbium, ambigitur adhùc; forsànque indiscriminatim è pluribus extrahitur, inter quas precipuè inclarescunt Euphorbia canaricnsis, E. officinarum athiopica, et $E$. antiqnortum indica et arabica, cujus pretereà (ex Reed. 2. 82) cortcx radicis contritus et sumptus cum aquâ purgativus est. His addenda forsàn $E$. cereiformis africana, cujus è cortice quomodolibet fracto lac virosum copiosè effluit, succusque concretus pro mercimonio importatur. (Moris. 3. 3亿5.)

Quædam species inter alias hic breviter notandæ, ut :

$E$. virosa, xthiopica. - Nomen vim indicat.

E. nereifolia, indica. - " Lac ejus desumptum rehementem caussat . "faucium ardorem.... Adhibetur ad purgationes vehementiores....

"Oculos tangens, illos quàm naximè inflammat et tumidos reddit." (Rumph. 4. 89.)

E. tribuloïdes, canariensis. - Sudorifica.

E. tirucalli, indica. - Ex lacte ejus oculis admoto ophthalmia vehemens, et interdùm cæcitas. Ejusdem, cuilibet farinæ misti, drachmam singulis diebus sumunt Indi in syphilitide, et indè, nisi morbus nimiùm inveteraverit, sæpè curantur, narrante Sonnerat. Lac etiam coctione spissatum, ad catharsim aut emesim ciendam, servatur ; sed è remedii violentiâ periculum. (Encycl. )

In Euphorbiis plurimis caule tereti nec carnoso, è quibus multæ herbaceæ in regione plùs minùs à tropicis remotâ habitant, succus exstat, multò quidem minùs acer et copiosus, sed ejusdem naturæ. Hinc vis illis semper stimulans, variis autem modis manifestata, prout in variis seu spcciebus, seu ejusdem speciei partibus, exploratur. Nunc enim sxpissimè purgatio etiam nimia, uunc vomitus, nunc sudor movetur, his ingestis, vel, iisdem applicatis, phlogosis aut vesicatio. Inter multas quadam tantùm hic memorandæ :

E. lathyris, herba europæana, vulgò Épurge. - Semina, qux vulgò Cataputio minoris dicuntur, vi drasticà valent, quæ experi- 


\section{$\left(s_{7}\right)$}

mento et in animalibus confirmatur et in homine. Unum enim aut alterum rustici sæpiủs, ad alvum solvendam, mulieres plura, ad provocandum abortum, sumere narrantụr. (Fid. Murr. 4. 100.)

Foliorun ejus succi unciæ $\&$ cani valido ingestæ, conatus ad vomendum primó, alvi dejectiones, debilitatem, posterà die convulsiones et mortein attulêre. Pulmones in cadarere lividi, sanguine congesto deńsi, intestinum rectum maculis quibusdam rubentibus notatum. (Orf. 2. 54. )- Ejusdem granis 20 feli exhibitis, succussio capitis, tussis, sternutamenta, tremor et motus totius corporis convulsivi, mox dejectiones, xgra et sibilans respiratio, vani ad vomendum conatus, corpus immobile, oculi clausi ; denique, post vomitum concitatum, curatio. (Sprôgel exp. circ. venen. 12.)

Cortex radicis cauliumque in pulverem redactus ct dosi granorum 15-5o sumptus, cartharsim ciet, cui vomitus quoque, sed rariores accedunt. (Lois. Desl.)

E. peplus, herba europæana. - Mulieri tertianâ laboranti grana 20 radicis ejus in pulverem redacti ingesta fuêre, et sine nauscà : indè dejectiones tres, absque colicis. (Lois. Desl.) - "In Alsatiâ in " medicinam recipitur, ejusque cortex in hydrope drachma pondere "propinatur." (Hall. 2. 10.)

E. pithyusa, frutex europæanns australis. - Radicis cortex in pulverem tritus agris triginta et sex purgandis propinatur. Hinc alvi dejectiones plùs minùs copiosx in omnibus, in quibusdam prætereà vomitus, sed multò rarior. (Lois. Desl.)

E. sjlvatica, herba europeana. - Radicis caulisve pars corticalis trita, sæpiùs catharsim, interdùm romitum, non rarò utrumque ciet. (Lois. Desl.)

$E$. hiberna, herba europeana. - "Aded acris dicitur, ut etiam " manu comprehensa alvum ducat. "(Hall. 2. 8.)

E. ipecacuanhoc, suffrutex ex Americâ boreali. - Harum regionum medici cortice ejus utuntur, non secùs ac speciebus Rubiacearum Violacearumque emeticis. (A. Rich.)

E. gerardiana, herba europæana. - Radicis cortex ægris viginti 
et duo sủb formã pulverulentà exhibitus, catharsim, simulque emesim ferè totiès, civit. (Lois. Desl.)

E. Cyparissias, herba europæana, quæ Esula minor offic.-Hujus succi unciis 5 cani modico ingestis, dejectiones nonnullæ, secundà ac tcrtiì dic major ac major tristitia, usu tamen sensuum et motuum adhuc servato, denique mors. Naculx tantìm quxdam rubentes in intestino recto observantur, cæteris organis illasis. (Orf. 2. 55.) "In homine, ab hujus remedii usu, delapsa et renovata cutis ficici, " et oculus inflammatus, cæcitasque secuta est, cùm ad clausi oculi " palpebras succus admotus fuisset ; et fœmina à sumptâ radice iutra " triginta minuta occisa." (Hall. 2. 8.) - Refert quoque Lamotte clysma ex hâc herbâ paratum lethiferum fuisse. - Quidam tamen eà minùs infeliciter usi sunt. Scribit enim Murray (4. 104.) radicem ejus à granis 6 ad 20 in pulvere, imò à scrupulo uno ad drachmam, alvi fortiùs movendi causâ, concessam fuisse, usitatamque hoc fine olim apud rusticos, undè nomen Rhabarbari rusticorum acceperit. Eamdem prætereà doctor Loiseleur-Deslonchamps in morbis riginti exploravit, sed prudentiùs (dosi gran. 4-30), et in plerisque vomitus simulque alvi dejectiones, has tamen illis frequentiores, observavit.

E. palustris, frutex europaanus, qui Esula major offic. - Vis, usus, dosisque, perindè ac præcedentis. "In Russià autem succus " ejus recens ingeritur pondere circiter 5 drachmarum, et, hujus " defectu, ridix sicca ad idem pondus, cui aqua calida infusa, ut " alrum purget. Violentiùs quidem hoc efficit, et plerumquè vomitum " mitem ciet, nunquìm autem tormina creat, et effectum suum, "uno quasi impetu, absolvit. "(Murr. 4. 105. ex Pallas.)

E. helinscopia, herba europreana. - Sub nomine Esulc et eîdem de causà in Suecià petitur. "Succus ejus corrosivus, exulcerans instar " cantharidum.... Editur ab ovibus, sed facit diarrhæam. " (L. Fl. suec.)

E. esula, herba europæana.- Mulier, radicis ejus granis jo deglutitis, post semi-horam obiit, tcste Scopoli, qui vidit etiam, Esulâ abdomini imprudentcr applicatà, gangrænam mortemque mox sequi, 
sicut et ophthalmiam creitatemque, cum ejus lacte palpebra oculi clausi illita fuisset. (Orf. 2, 56.)

$E$. verrucosa, herba curopana. - Hìc et Reussi et rustici nostri alpicolas ad eatharsim cicudam utuntur. (Vill. Dauph. pref. 6.) Memorantur prætcreà seu venenosæ seu purgatrices species, inter indigeuas E. platyphyllos, E. characias, E. amygduloüdes, E. exisua; inter exoticas, E. mauritanica, $E$. portulacoïdes, E. retusa; et $E$. canescens ab Hispanis infusa in aquâ adrersùs syphilitidem adhibetur.

Yerùm aded constans est ct indubitata specierum gencris hujus vis : ut cunctas que ralere eà dicuntur referre liat omnind supervacaneum, quoniam sic omnes, ut itì dicam, forent enumerandre. Nonnullæ quidem sunt quæ in noxiæ videantur, sed temperatî tantìm, non planè sublatà acritudine, ut, exempli gratià, E. dulcis: qux quin nomen mereatur multùm abest, cæeteris tamen paulù mitior, ideòque tutiùs adhibenda, indicante Gilibert.

Narrat Loureiro folia cujusdam Euphorbiæ, quam ideù specifico nomine edulis distinguit, pro oleribus apud Cochinchinenses in usu csse.Quid autem mirum, cum precipua vis in principio volatili existere rideatur, et cum co dissipari coctionis calore debeat? Quod confirmat Egrptiorum usus memoratus à Forskal, quo teste, caules Euphorbix antiquorum succo tàm exitiali scatentes, in terrâ tamen coneoctas pabulum equis suppeditant.

\section{EXC五CARIA.}

E. agallocina, arbor ex indicis insulis. - Si fructus ore manducentur, primò nullum notabilem exhibent saporem, sed demùm parùm exurunt.... Si incidatur arbor, " copiosum fundit lac albi" cans, spissum, ingratum ac nauseosum.... Nocet presertim ocuc lis, si illos adtingat, quos adeù inflammat, talique dolore tumidos " reddit, ut illorum usum quis amitteret, ni cito auxilio illis succur" rerctur. Hoc nautæe nostrates experti sæpiùs fuère cum suo damno, " qui emissi ad lignum cædendum pro foco, ac in littore has ar- 
" bores obvias videntes, securibus suis fortiter incidebant. Sed mox

" prosiliente lacte oculi ipsorum ità infestabantur, ut tanquàn furi" bundi per littus decurrerent, quorun et quidam visum suum penitùs "perdiderunt." (Rumph. 2. 238.) Hinc arbori excæcantis, generique Excacarix nomen inditum. Ligni ejusden, cum uritur, funus nocet. (Ex Leschenault mss.)

$E$. camettia, arbor indica. - "Lignum et radix incisa succum " acrem lacteum fundunt. Ex arboris foliis in aquà coctis balneun " conficitur anti-arthriticum. Eodem decocto, si ulcera antiqua et "verminosa laventur, vermes necantur, ac ulcera potenter mundan"tur." (Reed. 5. 89. )

11 PPOIINE.

H. mancinella, arbor antillana et guianensis. - Arboris liujus exitialis magna fama, dissentientibus tamen de periculi magnitudine narratoribus. "Tota arbor in omnibus suis partibus lacte scatet can" didissimo, copiosissimo valdèque caustico, hinc venenatissimo. c Guttula ejus cuti manûs imposita (volam excipio) brevi eamdem, " ignis instar vivi, in vesicam lymphâ plenam attollit. " (Jacq. Amer. 251.) Quod quidem expertus est D. Tussac, qui de hâc arbore disseruit (Jour. bot. 1815. 1. 112) : guttæ nonnullæ hujus succi manui admote ampullas moverunt, quas consecuta sunt acerba pertinaciaque ulcera, quie nonnisi mensibus aliquot elapsis sanata fuêre. - Nigritæ qui ramulum tantùm Mancanillæ fiderat, facies manusque quasi ustæ intumuerunt, teste Castera. - Memoratur denique agittas boc veneno inficere soliti olim esse Americani.

Fodem succo abındat integumentum carnosum fructùs, qui colore et odore pomum parvulum europaum referente nescios infitat. Arbitratur autem Jacquin (loc. cit.) plures nunquìm comedi posse, obstante nucis interioris asperrimâ superficie, ct monente faucium ardore pronptissimo. Sed ipsi contradicunt quadam exempla, eademque vim Hippomanis non tam formidulosam testari videntur. Dicitur, verbi gratiì, miles quidam, plurimis horum fructuùm cumestis, unâ hori 
elapsâ, in grave periculum incidisse. Venter admodìm tumefactus erat, fervor intestinorum urens, standi impotentia ; mox etiam labrorum, succi contactu, ulceratio, sudorque gelidus. Foliorum Ricini decoctum aquosum emesin catharsimque movit. Hinc symptomata paulatim mitiora, dolorque, post horas viginti quatuor, quasi omnind desierat. Narrat idem auctor (Peyssonel) mulierem gravidam tres hujus arboris comedisse fructus qui vix nocuerunt. (Orfil.)

Umbram ipsam Hippomanis et aquam pluviatilem ex ipsâ defluentem lethiferas plerique memoraverunt; negat autem Jacquin. (loc. cit.) "Per trihorium, inquit, ipsi mihi periculum cum " sociis facienti nihil mali evenit. Tìm etiam pluviam trans hanc " arborem cadentem corporeque nudo exceptam, innocuam sum ex" pertus. Noxia fortassè fuit, ubi rupti ventis vel imbribus rami - foliave lac simul distillaverint pluviæ immistum. "

Huic experimento, ex quo tributum umbra. Hippomanis veneftcium mera fabula videatur, non tamen omninò fides, adhibenda. Namque isti vapores maligni, si reverâ existuıt, à principio volatili deriventur necesse est. Itaque, secundùm variam coli temperiem, manare aut deesse poterunt; secundùm varios venti flatus, huc aut. illuc ferri; ità ut idem sub arbore nunc impunè nunc periculosè recubet; aut linc sedens nihil mali, indè etiam ultra umbram situs multùm mali, experiatur. Nonne pariter aqua trans arborem stillans, secundùm calidiorem frigidioremve ipsius temperiem, venenata aut innoxia esse poterit?

$11 \mathrm{URA}$.

H. crepitans, arbor americana. - Stillat ex hujus cortice succus lacteus acris, qui, oculis admotus, ophthalmiam concitare queat, undè cacitas per aliquot dies consequatur. - Narrat Aublet (885) seminibus vim drasticam inesse, quam ob causam amande à purger les perroquets vulgò nuncupentur : quumque quidam imprudentius semina hæc unum aut duo in emulsione servis nigritis, 
ad ipsos purgandos, porrexissent, miseros à vita periculo non procul abfuisse.

\section{HY ENANCIIE.}

H. globosa, arbor capensis. - Lambert refert fructum ejus colligi redigique in pulverem quo spargantur ovinæ carncs, quibus comestis, hyæna interimuntur, ut in nostris urbibus à nuce romicâ canes erratici.

JANIPIIA.

J. manihot, frutex americanus. - Radix ejus tuberosa, magna? molis, quippè qux libras usque triginta pendens, succo lacteo turget venenatissimo. "Potatus enim vehementer inflat corpus, ventri" culum afficit dolore, cum ructu, nauseâ et tenesmo : hine mox " oculi obfuscantur; vertigines perpetuique dolores capitis accedunt; - tandemque extremorum frigus, animi deliquium et ipsa mors suc"cedit. "( Pis. 48.)

De succi hujus vi memorantur doctoris Fermin experimenta quxdam in animalibus, qux, ante semi-horam, dosi modicâ haustâ, expiravcere. Symptomata autem erant ad vomendum conatus, anxietas, convulsivi motus, salivæ urinæque et fecium copiosa excretio. Cìm ejusdem stillatitii guttæ 35 servo, capite propter reneficii crimen damnato, ingestæ fuissent, subiti ululatus, violentæ corporis distorsiones, dejectiones, post decimam tantùm horæ partem, mors : nulla in intestiuis inflammationis signa.

Cùm autem in hâc radice maxima pars amyli misceatur principio isti nocivo, hoc autem admodum volatile, rel ferventis aqux calore dissipetur, inter stirpes alimentarias homini utilissimas adnumeratur, frumentoque æquiparari potest. Itaque radulà redigitur in pulverem, qui, prelo subjectus, cribro deindè succernitur, et aquà lotus imponitur lamina ferrex, cui subjicitur ignis. Farina sic parata manioc vocatur, aut, si ex agglutinatâ placentæ fiant : panis cassavi. Aqua autem quâ pulvis lavatur feculam deponit purissimam, quæ vulgò tapioka. Minuta lujus fabricæ descriptio, variæ- 
que artes tùm parandi manihot, tìm servaudi paratum, eoque aut in cibis, aut in potibus, aut in medicamentis utendi, legi possunt in diversis operibus, ut Marcgravio (65), Pisone (52), Aublet (Suppl. 65), et variis de agriculturà aut de chemià tractatibus : verùm hic, utpotè minùs ad argumentum nostrun spectantes, pretermittentur.

JATROPHA.

J. curcas, arbor ex Americâ calidiorc, Africâve boreali. - Semen, quod pignon d'Inde, nux barbadensis seu americana vulgò nuncupantur, valdè acre et venenosum. Ex analysi chemicâ (Pelletier et Caventon, Journ. pharm. 1818. $11^{\circ} 7$, et Ess. anal. sur la graine du Médicinier cathartique), præter alia nonnulla, oleum et quoddam peculiare acidum continet.

Perispernum lenius videtur, embryo adnodùm nocivus, idque principio volatili tribuendum, ut in multis Euphorbiaceis; quod jampridem constabat. Piso enim de hoc semine : "Validè purgant tres " aut quatuor nuclei comesti, et quidem nimis, si pellicula interior " non separetur; ideòque semper adimenda. "Et infrà : " Nuces " purgatrices nonnilil antè torrendæ sunt, ut leniùs operentur. » Seminis autem perispermo non destituti vin recentioribus experimentis comprobavit doctor Orfila (2.97). In canibus quibus ingesta sunt hujus farinæ 1-3 drachme, observabantur primo ad vomendum conatus, et interdùm querelæe, mox standi et etiam sentiendi impotentia ; postque mortem, dẹcem circiter elapsis horis, supervenientem, canalis digestiyus intùs et extùs inflammatus, calorque membranæ cjus mucosæ interdùm atro-rubens. Ejusdem 2 drachmæ canis femori pelle spoliato applicatæ, necem posterà tantùm die, sensibus quoque anteà extinctis, attulère : huic canalis digestivi inflammatio nulla, sed magna femoris spoliati vicinique abdominis. Unde patet semen hujus Jatrophre admodìm exitiale esse, quod non absorptioni debeatur, sed intense inllammationi quæ contactum ejus conscquitur, et sympathicæ nervosi systematis perturbationi; vehcmentiùs autem operari stoniacho quàm telæ cellulari admotum. 


\section{( 94 )}

Observantur ex oleo seu ingesto seu applicato effectus similes; multù autem celeriores, violentioresque ex acido jatrophico : cui quidem tribuenda videtur vis olei; hoc enim in saponem redicto, evanescit.

$J$. multifida, frutex antillanus. - Semine ejus, quod propter vim vulgò avellana purgatrix dicitur, multìn olim Hispani utebantur. Sed posteà, casibus niseris hunc usum sæpiùs consecutis. è plerisque materiæ medicæ operibus rejectun est. Unum quidem semen ad purgandum satis est... Dicuutur quoque hujusdem plantæe folia decem aut duodecim leviter cocta, catharsim sine nauseà torminibusve ciere. (Encycl.)

$J$. gossypifolia, frutex ex Americâ calidiore. - Incolæ foliis ejus decoctis alvum strictam laxant; inque truncis sapè tumores excrescunt quibus vis purgans et ptarmica, ex P. Br. Addit tamen auctor semina ab avibus edi.

$J$. glandulosa, suffrutex arabicus. - Dùm pungit, succum emittit laeteo-aquosum magnæ acritudinis. Recentioribus tamen ejus stipitibus furunculo impositis, tumor emollitur et dolor sedatur. (Forsk. 16j.)

J. urens et $J$. napcifolia, frutices ex Americâ calidiore. - Diversæ horum partes hispidæ pilis urentibus, quibus si pungaris, diù senties; ideòque viatori pediti molestissimæ.

J. stimulosa, herba virginica. - "Radix filipendulo-tuberosa, - tuberibus subcylindraceis, edulibus. "(Michx. 2. 216.) Nonne, Janiplı manihot instar, tantùm post coctionem?

\section{MHERCURIALIS.}

M. annua, herba europæana. - De hujus vi dissentire auctores inter se videntur, cùm alii mucilaginosam et emollientem, alii contrà purgativam nocivamque affirment. Oribasius olim, ad eatharsiu ciendam $\{$ decoctum ejus cum vino exhibebat. Pueros vermibus laborantes pulnento cum Mereuriali annuâ parato purgari diù mos fuit (Gouan. $5_{77}$ ) ; rusticique ferrarienses eodem cibo, ad alvum sollicitandam, utebantur : teste Brassavolo. (Murr. 22j.) Seriùs, in pharmacopæis 
sirupum aut clysmata ex hảc melli consociata laxativa conficiebantur. Linneus illam non purgantem tantìn, sed lypnoticam dicit, emollientemque negat (M. m. 247) ; pradicat denique ut diuretican Desbois-Ruclıefort (2.16).

1I. indica, frutex. - "Folia recentia in jusculo cocia leniter pur"gant absque ullo symptomate præcavendo." (Lour. 771.)

$M$. perennis, herba europaana. - Oribus nociva ct homini, ex Linnaro (Fl. suec. 360). Testante Sloane, apud quosdam, eâ imprudenter esâ, romitus ruhementes supervenêre, diarıłıa immodica, calor capitis urens, sopor altus diuturnusque, et convulsiones quas semel mors consecuta est. Non tutó igitur, quamvis uonnulli suaserint, hoc purgativo medicina utatur. In quibusdam locis, salivatio quoque cum eà cieri videtur.

Terisimile est nociras partes, qux, ex pracitatis, absque ullo dubio in Mercurialibus continentur, coctione partim dissipari : atque ità intelligitur quo modo veteribus pro olere hujus generis species in usu esse potuerit, recentioribusque topicum emolliens suppeditare. Sic applicatá, non ullà vi peculiari profectò prodest, sed solùm aqua quà imbuitur prasentià, sicut tot alia quæ in lande fuerunt cataplasnata.

OMPIIALEA.

O. triandra, arbor domingensis. - Fructus ejus inter nutritios numerantur à Pouppé-Desportes (Pl. us. de St.-Dom. 244) ; nuclei , nostræ avellanæ iustar cujus nomen in hàc insulâ obtinent, eduntur; et pectorale continent oleum quod amygdalum dulcem in linctibus supplere possit, ex Descourtils (2.55). Addit tamen idem auctor hos nucleos, sicut flores, astringentes esse et diureticos.

O. diandra, frutex antillanus et guianensis. - "Caules secti - lympliam aquosam gustu insipidam effundunt, qua pota sitim "compescit." (Aubl. 8/5.) Teste eodem, lobi seminis carnosi, crassi, oleaginosi, eduntur ; sed tantìn detracto embryone, ne catharsis cieatur. Hàc quidem ultimà notâ Omploalea cum cæeteris 
Euphorbiaceis concordat, cùm ferè omncs aliæ partes innocuæ videantur.

PEDILANTIIUS.

P. tithymaloüdes, frutex antillanus, qui vulgd Dictamnus real Havanensium. (Ex Iumb.) - " Iæc planta omnibus partibus, lacteo a acri et vellicante succo imprægnata, brevi resiculas in cute excilare - valet, ità ut usum intrinsecum generi humano nocivum esse cre" diderim. "(Commel. 1.3ı.) - Plantæ totius, præcipuè caulium, a saturatum decoctum à medicis curacaviensibus pro potu ordinario - dosique arbitrariâ præscribitur lue venereâ laborantibus. Eodem in - Continente utuntur Americanæ in menstruorum suppressione. (Jacq. Amer. 150.) - Poiteau refert eamdem etiam apud Domingenses sub nomine Ipecacuanhe notam, sed ejus usum non ab ipso observatum.

\section{PHYLLANTHUS.}

P. niruri, herba indica. - Folia infusa medicamentum præbent inter diuretica potentissimum, ex Commers. mss. Quod confirmat Loureiro (666.), quo teste, "urinam et menses moret, nec satis " tutò. "

P. urinaria, herba indica. - "Virtus totius herbæ diuretica, " emmenagoga. " (Lour. 677.)

P. conami, frutex americanus. - Ramis ejus foliisque contusis inque aquas injectis pisces inebriantur. (Aubl. 928.)

$P$. virosa, indica. - Nomen vim indicat . quæ ut præcedentis in usu est. "Cortex enim quàm maximè astringens, piscibus obnoxius." (Klein in W.)

Nymphanthus squamifolia Lour., arbor cochinchinensis, quæ species Phyllanthi, à congeneribus operandi modo differre ridetur, si fides Loureiro (664), ex quo, "foliorum, florum et fructuum virtus "resolvens, emolliens, anodina. Usus præsertim in affectionibus "pectoris, renum et vesicæ." 
PLUKNETIA.

P. corniculata seu Sajor-Baguala Rumph. Circa ædes plantatur, cùm ejus folia gratum ac delicatum præbeant olus cum Calappi lymphà coctum.

$$
\text { nicines. }
$$

R. communis, vulgd Palma-Christi, arbor herbave europæana australis, iudica, africana, etc. - Semina hujus, quæ vulgò Cataputire majoris dicuntur, oleo abundant, quod nunc in usu frequentissimo est. Constat autem partibus illius seminis diversis, diversas inesse vires, lenissimas scilicet perispermo, acres et nocivas cæteris : undè fit ut semen totum atque oleum ex toto elicitum admodùı periculosa sint, ideóque è medicorum praxi rejecta; perispermum verò separatim et oleum $\mathrm{cx}$ ipso expressum innoxia, ideòque usitatissima. His olim minùs cognitis, Ricini diversa laus fuit inter venena, aut drastica, aut cathartica, aut denique laxativa adnumerati, prout semen integrè aut partim sumebatur, atque oleo extracto è seminibus, nunc prelo plùs minùsve gravi subjectis, nunc cum aquà concoctis, plùs minùsve principii acris indè inerat.

Quidam seminis integumcntis, id est, testæ et pelliculæ interiori, magnam vim tribuunt, quod duplici exemplo confirmant : altero, hominis qui superpurgatus grave in periculum incidit, semine Ricini cum testà comesto; altero, fœminæ quæ, eodem eso sine testì, nilil mali experta est. (Bergius, Mat. med.) Sed antequàm indè quidquam certò concludi possit, opus sit, ut mili ridetur, probè compertum Labere nonne vir suum semen dentibus triverit, nonne contrà focmina suum nullatenis tritum degluticrit. Addunt tamen iidem anctores, " si testa unguibus separetur, inflammationem digitorum cum " insigni tumore enasci q quod non videtur à fragmentis exiguis subtùs " unguem detrusis dependerc, quippè quæ sub exploratione non visá "sunt, sed ab acri latente. "(Murr. 4. 202.).

Minimè autem dubia vis nociva embryonis, quam Serapio olim, 


\section{$\left(9^{8}\right)$}

J. Bauhin, Hermann, Geoffroy, indicaverunt, et posteà Jussieu ( $\left.39^{2}\right)$ pluribus exemplis, Deyeux certis experimentis, confirmavêre. Huic tribuendxe tot ab auctoribus commemoratæ, ex usu Ricini, superpurgationes. Quam ob causam "semen paucis adhuc retrò annis apud - auctores medicos nequitiæ notà distinguebatur, et inflamnare œso"phagum ventriculumque, purgare violenter, febrem syncopenque * excitare ferebatur; hine mentionem ejusdem potiùs fecerunt, ad " alios ab usu ejusdem arcendos, quàm ad eumdem alliciendos....

" Hoc etiamnùm suspectum est in locis plantæ naturalibus (Africâ), " adeù ut rarò ab incolis suspensâ manu, id est, unum vel alterum " semen commansum, drastico scopo ingeratur... Hæcce experi" menta sine dubio ad errorem ansam dedêre, quờd tota stirps veneno " imbuta esset et tactu, adeò quin halitibus umbràque suâ infesta, etc." (Murr. 4. 199-200). Doctor Orfila (2.49) quibusdam experimentis vim seminis ejusdem exploravit; quod canibus ingestum, post virium defectionem, dejectiones paucas, stuporem plùs minùsve altum aut vertigines, mortem deniquè, posterî plerumquè die, attulit. In cadaveribus auten, intestinorum, sed præcipuè recti, membrana interior inflammatoriis quibusdam maculis aut ulcerationibus notata occurrit; itì ut Ricini semina locum cui applicantur irritare, et deindè absorpta systema nervosum turbare videantur.

De oleo Ricini sic parato, ut embryo ferè intactus relinquatur, quale apud nostros pharmacopicos venire solet, pauca hic subjiciam, guia tùm lenius et principio Euphorbiacearum acri quasi destitutum, minùs ad materiam meam attinet. Quando puram est, color ejus glaucescens, odor et sapor vix ulli, consistentia limpida viscosaque, gravitas ceteris oleis fixis major ; frigore vel intenso non congelatur, totunque alcoole dissolvitur. Dosis cjus media uncia 2, non semel hausta. Si malè paratum aut nimis vetustum est, rubere nauscosum olcre et acre sapere potest $\cdot$ : sed puriorem ad statum redit, expositum ferventis aqux calori, quo principium ejus acre volatile dissipatur. Arbitraiur etiam D. Solimani fore ut Ricini olsum, iterùm atque iterum lotum in aquà acido sulfurico leviter imbutà, 
alimentarium evadere possit. Laxat olcorum fixorum more; sed quasi stimulo quodam superaddito: valetque adversis coustipationem, diversas colicæ species, ut pictorum (1), dysenteriam; sed ante omnia, contra vermes intestinos non tantìm lumbricos, sed et ipsum tæniau commendatur. (Barb. 3. 197. - Alib. 1. 5,5. - A. Rich. 1. 216.)

Radix Ricini dinreticum efficax predicatur ( P. Br.), sed insolitum. Folia verú cocta topicum emolliens prestant, profectò qui: tùm aquosa. Eadem tamen contra hemicraniam fominæ fronti per noctem applicata cæeitatem peperisse dicuntur, licet arte dein sublatam. (Hist. de la suc. r. de méd. 2. 302.)

Ricini comnunis nonmulla varietates, et ejusdem generis species quædam exstant, quibus semina similia, vi eàdem absque ullo dubio predila et indiscriminatim in locis natalibus usitata; ut, exempli gratià, Ricinus inermis americanus, testante Odier (Journ. med. 49. 455 ), et $R$. viridis indicus, de quo Rumphius (4. 94): - Antiquis temporibus 5o ejus ossicula contrita atque cum pauco - liquore assumpta vulgare exhibebant purgans : cùm verù ventricu"lum vehementer commoveret, in desuetudinem abiit. "

SAPIUM.

S. ancuparium, arbor americana. "Tota manat succo glutinoso - et abundanti, qui ex quâlibct læsà parte guttatim stillat, ferturque " venenatus." (Jacq. Amcr. 249.)

Refert D. Tussac (Journ. bot. 1813. 1. 117), cùm quidam hortulanus raporem aquosum è Sapii nescio cujus taleâ manantem

(1) “Dans la colique de plomb, les douleurs cessent dès qu'on a surmonté - la constipation. La principale indication étant de procurer les évacuations - alvines, tout traitement esl bon lorsqu'il atteint ce but, et le traitenent empi" rique des frères de la Charité n'a rien de spécifique. "(Ratier, Propos. de méd. Thèse, $1819, n^{\bullet} 206$.) 


\begin{abstract}
$(100)$
tersisset linteolo, et idem posteà admovisset naribus, aliquot horis elapsis, nasum ejus mirum in modum tumefactum et phlegmasiam erysipelatosam circà obortam esse.
\end{abstract}

SIPHONIA.

S. elastica, arbor guianensis. - Refert Aublet ( 872 ) hujus semina seduld colligi serrarique apud Guianenses, seque ipsum sine ul!o incommodo plurima comedisse. Non-ne autem ablato anteà embryone?

\title{
STILLINGIA.
}

S. sylvatica, herba carolinensis. - In morbis syphiliticis specifica habetur.

TRAGIA.

T. volubilis, frutex americanus. - Capsula foliaque setis urentibus hispida (ex Sloane), ut et in $T$. urente et $T$ cannabinâ. Duas species sub nomine Schorigenam Reedius describit ut diureticas.

XYLOPHYLLA.

$X$. ceramica, frutex indicus. - Fructus ejus canes enecat, ex Rumphio. 


\section{INDEX ALPHABETICUS.}

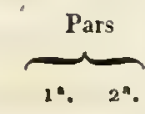

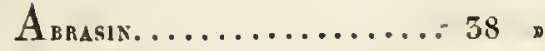

ACALYPHA.........., 45 7

Acalypha...... $15 \quad 19454548$ "

ACIDOTON............ 52 77

ADELIA.............. 51 D

Egopricon............. 54

AGYNEIA. . . . . . . . . 24 n

ALCHORNEA........... 42 "

ALEURITES............ 58 78

Altora................ 25 p

AMANOA............. 15 ,

Ambinux.............. 58 ,

AUPEREA........... 55 ,

ANABENA. ........... 46 ,

ANDA.............. $3_{9} \quad 78$

ANDRACHNE.......... 24 ,

ANISONEHIA......... 19 ,

Anisophyllum.......... 58 n

ANTHOSTEUA.......... 56 ,

Arachne.............. 25

Arbor vernicis........... 38 o

Arbre d'huile............. 58 ,

Ardinghelia............ 21 ,

ARGYTHAMNIA......... 26 ,

Aroton ................ 28 ,

Ateramnus............. 27 ,

Athymalus............. 59 ,

Aveilana purgatrix........, 94

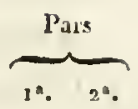

Bernardia............. $3_{1}$ n

Bois cassant............ 43 ,

Bois violon ............. 45 n

Bradleïa............... 18 ,

Breynia................22

BRIEDELIA . . . . . . . . 26 26

Bromfeldia........... $3_{7}$ "

Brunsvia............. 30 ,

Buis. ............... 1379

BUXUS ........... 13

Cahuchu.............. ఐ $\quad 76$

Camirium............. $38 \quad 77$

Caoutchouc.............. $40 \quad 76$

Cascarilla.............. $28 \quad 82$

Cassave............... $9^{2}$

Castiglionia............ 57 ,

Cataputia major.......... $₫$

- - - minor........... 86

Cathetus...............22 "

Caturus.............. $45 \quad 79$

Cauda felis............. 45 "

Chamøsyce............. 59 "

Cheramela.............. 20 ,

Cheramelier.............. 20 "

CICCA................. 20.80

Cinogasum............. 28 ,

CLADODES............. 61 ,

CLAOXYLON............ 45 


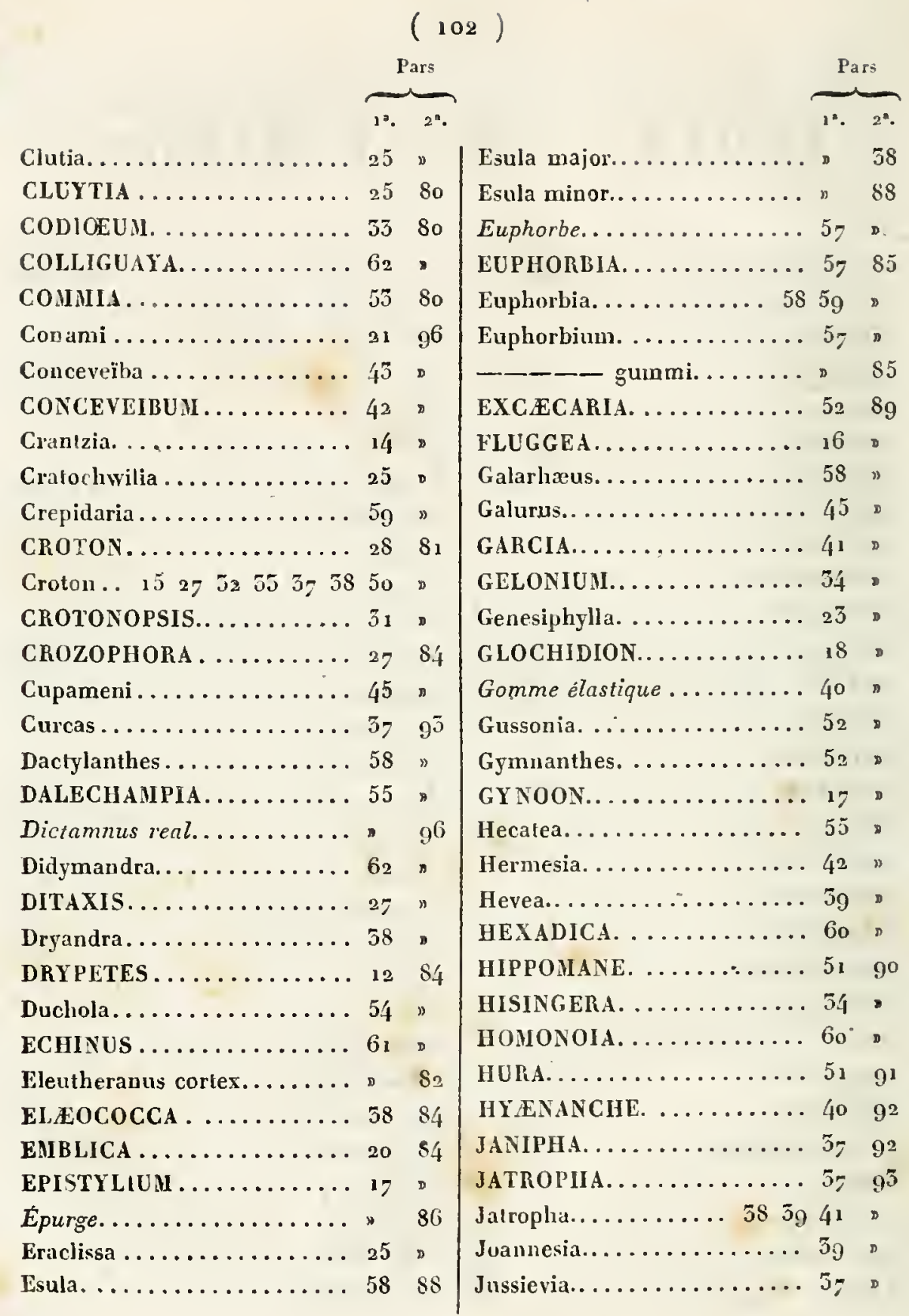




\begin{tabular}{|c|c|c|c|c|c|}
\hline & & ars & & Pal & \\
\hline . & $1^{a}$. & $2^{4}$. & & $1^{\circ}$ & $2^{2}$. \\
\hline Keraselma.............. & 59 & b & Omphalandria. ........... & 54 & 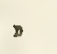 \\
\hline KIRGANELIA. . . . . . . . & 21 & , & OMPIIALEA $\ldots \ldots \ldots \ldots$ & 54 & $9^{5}$ \\
\hline Lacmus. ................. & , & 84 & Omphalea .............. & 17 & 》 \\
\hline 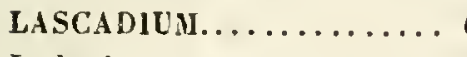 & 62 & $”$ & PACHYSANDRA . ....... & 15 & $"$ \\
\hline Lathyris. ............... & 59 & , & Palma-Christi. ............ & , & 97 \\
\hline Limeum................ & 25 & D & Panavæ lignum........... & ه & 81 \\
\hline LEP TONE.UA . . . . . . . & 19 & D & Panopia ................ & 45 & 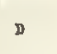 \\
\hline Loureira................ & 55 & D & PEDILANTHUS $\ldots \ldots \ldots \ldots$ & 59 & $9^{6}$ \\
\hline 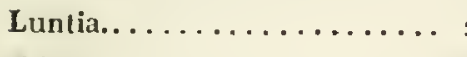 & 28 & ๑ & Peplis................ & 59 & 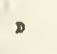 \\
\hline 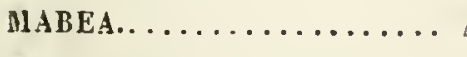 & 40 & D & Peplus. .............. & 59 & 2 \\
\hline 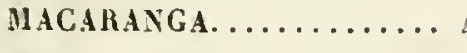 & 43 & D & Pharnaceur. ............. & 23 & $"$ \\
\hline Mallolus................ & 33 & \$ & PHYLLANTHUS. .......... & 21 & $9^{6}$ \\
\hline Mancanilla.................. & 51 & b & Phyllanthus. 1619202125 & 24 & n \\
\hline Mancenillier.............. & 51 & 90 & Phyllaurea............. & 53 & 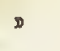 \\
\hline Manioc................ & 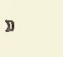 & $9^{2}$ & Pignon d'Inde............ & 00 & $9^{5}$ \\
\hline 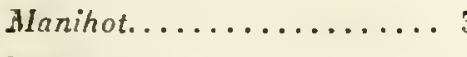 & $5 z$ & $9^{2}$ & Pithyusa.............. & 59 & $\rrbracket$ \\
\hline MAPPA.................. & 44 & 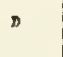 & PLUKNETIA. . . . . . . . . & 47 & 97 \\
\hline MAPROUNEA.......... & 54 & $\nabla$ & RICHERIA............. & 16 & $"$ \\
\hline MARGARITARI $\ldots \ldots \ldots \ldots$ & 59 & 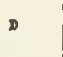 & $\operatorname{Ricin} \ldots \ldots \ldots \ldots \ldots \ldots$ & 36 & 97 \\
\hline Medicinier. ............ & 37 & $9^{\overline{3}}$ & Ricinelle ............... & 45 & $n$ \\
\hline Medusea.................. & 58 & $\triangleright$ & RICINOCARPOS........ & 56 & • \\
\hline MENARDA.............. & 25 & D & Ricinocarpos........... & 50 & $n$ \\
\hline Mercuriale................ & 46 & $\triangleright$ & Ricinoïdes. . . . . . . . & 28 & $"$ \\
\hline MERCURIALIS ......... & $4^{6}$ & 94 & RICINUS............. & 36 & 9 \\
\hline MICRANTHEA.......... & 24 & $\gg$. & Ricinus............... & 44 & , \\
\hline MLUROSTACHYS.......... & 48 & $n$ & ROTTLERA............. & 33 & D \\
\hline MOZINNA............. & 55 & D & Sablier................... & 51 & v \\
\hline Myrobalanus............. & 20 & 84 & Sajor................... & 47 & 97 \\
\hline Niruri................. & 21 & $9^{6}$ & SAPIUM............ & 49 & 99 \\
\hline Nux americans........... & D & $9^{j}$ & SAVIA.............. & 15 & 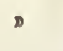 \\
\hline — birbadensis........... & 》 & D & Schorigeram............ & 47 & 100 \\
\hline Nynuphantus............... & 22 & $9^{6}$ & SEBASTIANIA. ........ & 51 & , \\
\hline OHALANTHUS............ & 50 & 》 & SECURINEGA........... & 14 & , \\
\hline
\end{tabular}




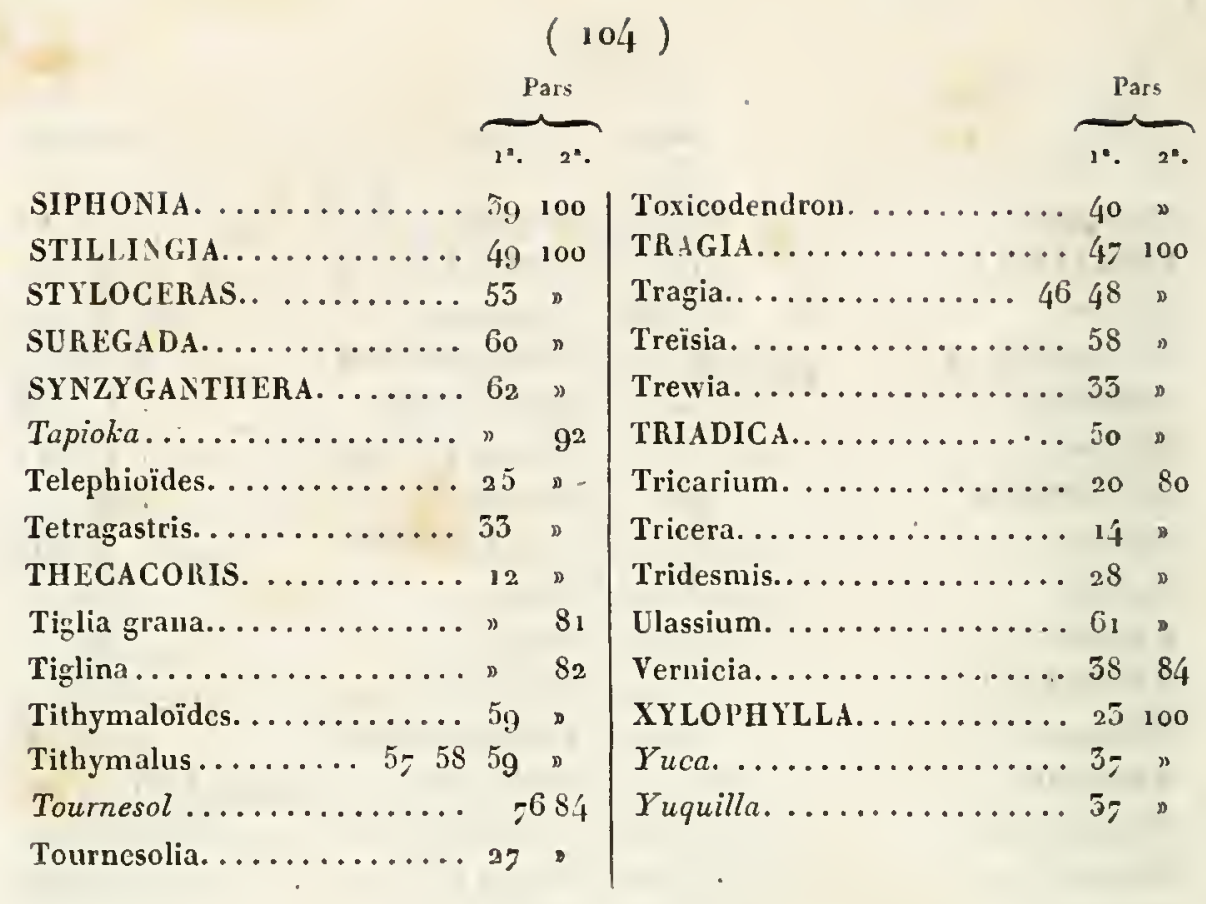




\section{EXPLICATIO TABULARÚM (1).}

\section{T A B U I/A I'.}

\section{THECACORIS madagascariensis.}

1. Flos masculus in præfloratione.

2. Idem in anthesi. a. Calix. 6. Stamina. o. Glandulx. $d$. Pistilli rudiuncotum.

3. Antliera debiscens.

4. Flos fuemineus.

5. Orarium verticaliter sectum. a. Discus. 6. Loculus. c. Ovula.

6. Ovarium transversè sectum.

4. PACIISAXDRA procumbens. Michx.

2. Flos masculus, a. Bractea. 6. Calix. o. Stamina.

2. $I d c m$ apcrtus supernè. a. Filamentum. 6. Anthera. $c$. Pistilli rudimentum.

3. Flos fomineus (ferè s. $\mathrm{N}$.).

4. Idem laciniis calicinis patcotibus. a. Calix. 6. Pistillum. $c$. Bractex.

5. Pistillum, ovarin verticaliter secto. $a$. Loculus. 6. Orula. c. Stigmata.

3. A. BUXUS sempervirens. $\mathrm{L}$.

1. Glomerulus flurum in preflurationc. a. Ramus. - b6. Fulia. (Alterum sectum, ut lanina duplex in $6^{\prime}$ perspiciatur.) c. Bractex. d. Flures masculi. $f$. Flos fomineus.

2. Flus masculus in prafloratione.

3. Idem apertus supernè.
4. Stamen in pratloratione. a. Extrorsim. 6. Introrsùun.

5. Glomerulus florum in anthesi, a. Bractex. 66. Flores.

6. Flos masculus in antlesi. a. Bractea. b. Calix. c. Filamenta. $d$. Antheræ. o. Pistilli rudimentum.

7. Ftos frenineus (s. w.). a. Bractex. 6. Calix. c. Ovarium. d. Styli. o. Stignata.

8. Fructus (M. N.). a. Bractex florumque masculorum reliquix. 6. Capsula.

9. Idcm post dehiscentiam, verticaliter apertus. a. Placentarium. 6. Sarcocarpium. co. Endocarpium, seu pars coccorum. d. Semen.

10. Capsula transversé secta.

11. Semen.

12. Idem verticalitersectum, a. Testa. 6. Arillus, c. Perispernum. $d$. Embryo.

13. Embryo.

4. B. TRICERA lavigata. Sw, FI. - CRANTZIA levigata. Sw. Prodr.

1. Florum racemus (ferè M. v. ).a. Axis. 6. Bractex. c. Flores masculi. $d$. Flus foemineus.

2. Flos mascnlus. a. Calix. 6. Stamen. c. Pistilli rudimentum.

3. Flos fuenineus. n. Calix. 6. Orarium. c. Stylus. $d$. Stigma.
(1) Cum Euphorbiacearum plerarumque flores sint admodum exigui, hic plis ninus aucti pxlibentor. Quantỏ auten singoli amplificati sint nutare necrssarium non existimavi, quonian in his tabulis genericos characteres exponentibus, partiun forma et situs alicujus momenti est, nultó minoris maguitudo. Lit- teræ . v. magnitudinem naturalem significant : quoties enim ifsam figura nun snperat aut eâdenı minur est, hìc indicatur. Fructus Aleuritis cx iconibus ineditis conmersionanis desumptus est : catera cx naturá. plerumqué è speciminum siccorum analysi.

$$
\text { 1'́ }
$$




\section{T A B U LA I I'.}

SECURINEGI nitida. W.

1. Flures masculi. a. Florum glomerulus. 6. Ramus. c. Foliun.

2. Flos masculus in prafloratione (sectiscalicinis laciníis et staninibus duobus, ut catera melius perspiciantur) ) a. Cálix. b. Stamioa. c. p'istilli rudimentum. $d$. Glandula.

3. Flores fruminei, a. Ramus. b. Folium. c. Flo. rum fasciculus. d. Bractex.

4. Flos fremineus. $a$. Bractex. 6 . Pedunculus. c. Calix. $d$. Discus.e. Ovarium. f. Stignata.

5. Orarium verticaliter sectum. a. Loculus. 6. Oruła masshla o' suspensa.'

6. Idcm transversè sectum.

7. Coccum post dehiscentiam.

8. Semen.

9. Idem rerticaliter sectum. a. Testa. 6. Perispermum. O. Embryo.

5. SATlA sessiliflora. W.

1. Calix floris masculi.

2. Flos masculus, calice ablato. a. Discus. 6. Stamina. c. Rudimentum pistilli. d. Petala.

5: Flos fremineas.

4. Orarium rerticaliter sectum. a. Discus. 6. Loculus. c. Pars massie te quà orula $d$ pendent.

5. Orarium transtersé seclum versis apicem ( ita $u t$ in singulis loculis massa tantim perspiciantur).

6. Idem verticaliter sectum propiús basi (ita ut in singulis loculis orula gemina perspicisotur?.

6. AMAYO 1 bracteata. Rich. herb.

1. Glomerulus forum masculorum in praflorationc. a. Bractex. 6. Flures.
2. Flos masculus, a. Calix. 6. Stamina. e. Pistilli rudinentum. $d$. Glandulx.

5. Pistillum.a. 1bincus. 6. Orariun. c. Stigmata.

4. Orarium verticaliter sentum. $a$. Loculns interior. 6. Ovula massula $c$ suspensa.

5. Idem transrersé sectum.

- i. FlCGGEA leneopyrus. W. - PHYLLANTIfL's leucopyrus. Kan.

1. Flos uasculus in prafloratione.

2. Idem in anthesi. a. Calix. b. Stamina. c. Piktilli rudimentum. $d$. Glandulx.

3. Flos fremineus.

4. Ovarium transrersè sectum.

5. Idem verticaliter sectum.

6. Fructus.

7. Idcm rerticaliter sectus. a. Semen alterum fertile. 6 . Alterum sterile.

S. Spmicn.

9. Idem varticaliter sectum. a. Testa. 6. Perisperuum. Embryo.

10. Embrỵo.

B. FLLGGEA xeracarpa. J. berb.

1. Flos focmineus.

2. Pistillun rerticaliter sectum. a. Discus. b. Loculus. c. Ovula.

5. Capsula verticaliter secta. a. Loculus. 6. Semen steclum.

4. Senzen (introrsin et à latere risum).

5. Idem rerticaliter sectum. $a$. Testa. b. Caritas inanis fencstrata. c. Perispermun, $d$. Embryo.

\section{TA B U LA I II"}

\section{EPISTYLIUM axilHare. Sw.}

1. Flos masculus in prafloratione.

3. Idcm apertis. a. Calix. 6. Stamina, c. Glandulx.
3. Apex flamenti incrasidus, autherifer risos superai $(a)$ et à Jatr.re (b).

4. Flus frunicues, a. Calix. 6. Orarium, c. Stigmata. 
5. Orariun transversé sectun. a. Calix, b. Glandula. c. Orariun cum loenlis.

6. Idcm vesticaliter sectunı. a. Loculi. b. Orula.

\section{GYYOOX rigidum.}

1. Flos masculus in prafluratione.

2. Idem . calicin is laciuiis duabus sectis. a. Calix. 6. Stanina.

5. Flos formineus, a. Calix. b. Pars superior sligmatum.

4. Idem, calice secto. a. Ovarium, b. Stiguata.

5. P'istillum rerticaliter sectum, aa. Stigmata dișjuncta. 6b. Loculi, cc. Orula.

6. Orarium transversé sectrim.

10. A. GLOCHIDION ramillurum. Forst. - BRADLEI A glochidion. Gert. (1)

1. Flos masculus, a. Calix. 6. Stanina.

2. Authera. a. Introrsim. 6. Extrorsing.

5. Flos fomineus superné. a. Orarinas. 6. Stigmata.

4. Idem sultus. a. Calix. b. Ovarium.

5. Capsula verticaliter secta, a. Loculus. 6. Scmina.

6. Eadem dehiscens, transrersé secta.
7. Semen è latere. $a$. Testa fenestrata in $b$.

S. Idcm introrsiu. $a$. Testa. 6 . Fenestre.

9-10. Idtm introrsiom ct extrorsinu, testá ablatà, iti ut cavilas embryonilera pateat a. Fenestrx. 6 . Cntyledunes. c. Radicula.

11. Ltemverticahiter sectum. $a$. Testa. 6. Cavitas iuteroa, inanis, lenestuata. c. Perispermum. d. Embryo.

B. GIOCIHDION zillanicum. - BRADLEIA zeilanica? Grert.

1. Flus urasculus in prefluratione.

2. Stamina.

5. Flos fomineus, a. Calix. 6. Ovariun, c. Stigmata.

4. Ovariun t!rasiersé sectum.

5. ldem verticaliter sectun, a. Pars ovarii superior carnosa. bb. Loculi et ovula.

6. Fructus. a. Calix. 6. Capsulı.e. Curuna é stigunatibus persistentibuis.

7. Idcm verticaliter sectus. a. Placentarium, b. Seuscn.

8. Sempn. a. Semen pelliculâ restitum. 6. Idem pelliculat denudatum, ut leste fencstrx appareant.

TABULA IV".

11.

AXISONENA reticulatum. - PHYLLAN- $1: 2$. TIIUS reticulata. Poir.

1. Flos masculus. a. Pedunculus. b. Calix. c. Glandula. d. Stamina.

2. Flus foemineus. $a$. Calix. $\ell$. P'istillum.

3. Idcm, ovario verticaliter secto. a. Calix. b. Glandulie. c. Stigmala. d. Loculus. c. Placentariun. $\pi$. O ula.

4. Capsula.

5. Eadem transversè secta.

26. Eadem verticaliter srcta. a. Placentariun i cujus apice pendeot semina superposita, duo integra 6 , duo sectar.

7. Semen. $a$. Integrum. 6 . Verticaliter sectum.
LEPTONEMA venosun. - ACALYPHA venosa. Poir.

1. Flos masculus, a. Pedunculus. 6. Calix. c. Stamina.

2. Stamen in prafloratione, a. Filanentum. b. Connectivum. 5 . Anthera.

3. Flos fanincus. a. Bractea. 6. Calix. c. Ovarium. $d$. Styli.

4. Fruetus superné (nondim maturus).

5. Idem, ablato pericarpio. $a$. Calix. 6 . Dissepinenta.c. Massula è summis loculis pendentes, sub quibus funiculi $d$ excurrunt. cr. Ovula.

6. Idem transversè sectus. a. l'cricarpium.

(1) Figura $1-4$ i specimine lorsteriano herbarii musxi parisiensis; cxlerx è specimine lurbar. Lessert. 
66. Locnli. ce. Orula. d. Massulax.

13. A. CICCA disticha. L.

1. Flus masculus, $a$. Pedunculus, $b$. Calix. Glandule. $d$. Stamina.

2. Flos femineus. a. Pedunculus. 6. Calix. c. Orarium. d Styli.

3. Pistillum transrersè sectum. a. Calis. b. Glandul.e. c. Orarium.

4. Orarium resticaliter sectum. a. Loculus biovulatus.

B. CJCCA antillana ( 1 ).

1. Flos masculus in prefloratione.

2. Iden apertus, a. Pedunculus, 66. Calix. c. Dis. cus. $d$. Stamina.

3. Flos freminens. a. Bractex. b. Pelunculi. c. Calix. $d$. Discus. e. Orarium. $f$. Styli.

4. Ovarium transversè sectum.
5. Illem rerticaliter sectum. a. Loculus. 6. Orula.

6. Fructus.

7. Semen.

14.

KIRG ANELIA phigllantoides. Desf. - PHYLLANTHUS kirganelia. W.

1. Flos masculus, a. Pedunculus, b. Calix. $c$. Glandulx. $d$. Stamina.

2. Flos fomineus, a. Pedunculus. b. Calix, c. Discus. $d$. Pistillum.

3. Orarium rerticaliter sectum. a. Discus. 6. Pistillum. c. Orula.

4. Fructus.

5. Idem transversè sectus.

6. Senen.

7. Idem verticaliter sectum. a. Testa. b. Perispermum, c. Embryo.

8. Embryo.

TAB ULA $\mathrm{V}^{\mathrm{s}}$.

15.

EMBLICA officinalis, Gort. - PHYLLANTHUS emblica. L.

1. Flos masculus. a. Calix. 6. Stamina,

2. Antheræ.

3. Flos foemineus. a. Calix. b. Orariunı. c. St sli. 4. Idem, calice et stylis ablatis. a. Basis calicis.

b. Tubus membranaceus ovariun ocingens.

5. Orarium rerticaliter sectum. $a$. Orarium. 6. Orula. c. Locules.

6. Orarium transversé sectum.

16. A. PHYLLANTHUS lanceolata. Lamck.

1. Flos masculus in prafloratione.

2. Idem in anthesi. a. Calix. 6. Glandula, c. Stamina.

3. Flos foemineus, a. Calix. b. Glandula, c. Pistillum.

4. Fructus.

5. Flos fumineus post occasum capsule. a. Calix. 6. Glandulæ. $c$. Placentarium.

6. Capsula transversè secta.

7. Coccum. a. Semina.
S. Semęn.

B. PHYLLANTHUS tristis, - P. rhamnoïdes? Retz.

1. Flos masculus. a. Bractere. b. Pedunculus. c. Calix.

2. Idem sectus. a. Pars calicis. 6. Stamina.

5. Flos formineus, a. Calix. 6 . orarium. e. stylus. d. Stigmata.

4. Orarium rerticaliter sectum. a. Orula.

5. Capsula rerticaliter secta. a. Pericarpium. b. Placentarium. c. Loculus. e. Semina pelliculà $d$ partìm restita.

6. Semen à facie et à latere. $a$. Fenestra.

7. Idem transversè sectum. S. Idem verticaliter sectum. - a. Testa. b. Cavitas inanis fenestrata. o. Perispermum. d. Embryo.

XYLOPIYLLA latifulia. Sw.

1. Ramulus floriger.a. Stipula. bb. Ramnli dilatati.c. Flores.

2. Flos masculus, a. Calix. 6. Glandulx. c. Stamina.
(1) Spccies hac in herbariis $J .$, Rich. et aliis occurrit sub nomine Margaritarice, cum generis hujus characteribus minimè tamen conveniens. 


\section{$(\log )$}
5. Flos focunineus, $a$ Calix. 6. Glandılæe, $c$. Ora- rium. d. Stigmata.
4. Ovarium verticalitcr sectum. a. Loculus. b. Orula. c. Ovariuns. d. Glandulix.
5. Capsula.
6. Coccum, a. Semiua.
7. Scmen.
S. Iden rerticaliter sectum. a. Perispermum. 6. Embryo.
9. Embrỵo.

\section{TABULA VI"}

18. MEXIRDA cryptophila. Cumm, mss.

1. Flos masculus in pratluratione.

2. Idem in antletsi, a. Prdunculus, 6. Calix. c. Stamina. $d$. Glandulax.

3. Flos fomineus. a Calix. t. Discus. c. Orarium. d. Styli.

4. Orarium rerticaliter sectum, a, Ovula.

5. Idem transversè sectum.

6. Capsula.

7. Calix (a) persistens cum placentario ( $b$ ).

8. Coccura.

9. Semen.

\section{AGYYEIA impubes. L.}

1. Flos masculus, a. Calix. 6. Discus. C. Stamina.

2. Flos femineus, a. Calix. b. Orarium, c. Stigmata.

3. Capsula debiscens.

4. Placentarium. a. Calix. 6. Placentarium cui semen $c$ adhuc affixum.

5. Semen.

6. Idem transtersé sectum.

so. ANDRACINE telepbioides. L.

1. Flos masculus. a. Calix. b. Petala.c. Squamulæ. d. Stamina. e. Pistilli rudimentum.

2. Flos formineus. a. Calix. b6. Squamulx.o. Styli ct stigmata. $d$. Orarium.

5. Idem post occasum capsulx. a. Calir. 6. Squamula. c. Placentarium.

4. Capsula transversé secta. aa. Loculi, 6. Semina.

5. Semen.

6. Idem rerticaliter sectum. a. Testa. b. Perispermum. c. Embryo.

CLUYTIA puichella. W.

1. Flos masculus in prafloratione.

2. Idem in antbesi. a. Calix b. Petala. c. Appendics. $d$. Glandulx. $e$. Filamenta coa. lita. $f$. Pistilli rudimentum. $g$. Anthere.

3. Stamina in prafloratione. a. Glandula. 6. Antheræ. c. Pistilli rudimentum.

4. Flos fomineus. a. Bractex. b. Pedunculus c. Calix. d. Petala. c. Appendices. f. Pistillum.

5. Pistillum. a. Appendices glandulos $x, 6,0$ rarium. c. Styli.

6. Ovarium transverse sectum.

7. Fructus.

8. Coccum.

9. Semen à facie et à latere, a. Testa, 6. Funiculus. 0 . Arillus.

10. Idem verticaliter sectum, a. Testa. 6. Perispermum, c. Embryo.

\section{TABULA VII"}

22. BRIEDELI A retusa. - CLUYTIA retusa. W.

1. Flos masculus in prafloratione.

2. Idcm in anthesi. a. Calix. 6. Petala. $c$. Discus. d. Stanina. e. Pistilli rudimentun.

3. Flus fonincers. a. Calix. 6. Petala. c. Tubus. d. I'istillun.

4. Pistillum. a. Pasis calicis. 6. Tubus, c. Stgli.

5. Fructus rerticaliter sectus. a. Pars calicis. b. Pericarpiun. c. Loculus. d. Semen integrum. e. Semen abortirum.

6. Fructus transversè sectus.

ARGYTHAMMIA candicans. Sw.

1. Florum racenulus, $a$. Axis. $b$. Flos fomineus. c. Flores masculi. add. Bractex.

2. Flus masculus, a. Calix. 6. Pctala, c. Stamina, 
3. Idem apertus superné. a. Calix. b. Petala. c. Stamina. d. Pistilli rudimentum, e. Clandulie.

4. Idem, ablalucalice.

5. Stamina cum pistilli rudimento.

6. Anthere (in prafloratione). a. Introrsum. b. Extrorsum.

7. Flos famineus. $a$. Calix. 6 . Pistillum.

8. Pistillon a. Squanula. 6. Ovarium. c. Styli. 9. Cuccum.

20. Semen.

11. Idem verticaliter secium. a. Testa. b. Perispelmum. c. Embayo.

24. DITAXIS fasciculata. Vahl (iu IIerb. J.).

1. Racemulus florum, $a$. Bractea. $b b$. Flores mas culi. $c$. Flos fumineus.

2. Flus masculus in prafloratione.

3. Idem, calice aperto. a. Pelala. 6. Calix.

4. Stanina. a. Columna if filamentis connatis. b. Anthcra. c. Pistilli rudinientum.

5. Flos formineus, petalis ablatis, calice reflexo. a. Calix. b. Glandulx. c. Ovarium. d. Stylus. e. Stignuata.

6. Orarium verticalliter sectum, a. Ovulum.

7. Illcm transrel'si sectum.

8. Capsula.

9. Coccum.

10. Semen.

25. CROZOPIIORA tinctoria. - CROTOX tinctorium. L.

1. Calix floris masculi in prefloratione.

2. Petala ejusdem.

3. Stamina.

4. Flus fo'mineus, a. Calix.6. Orarium. c. Styli.

5. Squamulat lurfuracea.

6. Pilus stellatus.

7. Ovarium transversé sectum.

8. $1 d c m$ verticaliter sectum.

9. Capsula.

10. Siruen.

11. Idcm verticalitor sectum. a. Testa. b. Perispermum. c. Embryo.

\section{TABULA VIII.}

26. A. CROTON penicillatun. Vent.

1. Flos masculus in plixfloratione.

2. Prefloratio petalorum. a. Petala. b. Glandula.

3. Præfloratio staminum. a. Stamina quxdam, catcris ablatis. b. Glandula.

4. Flos masculus in antbesi. a. Pedunculus. 6. Calix, c. Petala. $d$. Stamina.

5. Idcm, calice ablato. a. Glandulx. 6. Petala. c. Stamina.

6. Flos fremineus. a. Calix. 亿. Pistillum.

7. Idem, ablato calice. a. Ovarium. 6. Styli. c. Glandulae. d. Appendices.

8. Stylus rl stigmata.

9. Capsula transrcisé secta.

10. Semen.

11. Idem verticaliter sectum. a. Testa. 6 . Perispermun. c. Lubryo.

B. CROTON castaneifolium. L.

2. Flos masculıs. a. Calix. b. Petala. c. Stamina tt pistilli rudimentum.

Flos fumineus, a. Calix, 6 . Pelala. c. Ovarium. $d$. Styli et stigmati.
3. Pars capsule. a. Calix. 6. Coccum. c. Placen. tarium.

4. Semen.

5. Idcm. a. Testa verticaliter secta, b. Nucleus.

6. Nucleus rerticaliter sectus. a. Perispermum. b. Embryo.

C. CROTON quinquecuspidatum. Ilerb. nus.

1. Flos masculus. a. Calix. b. Petala. c. Glandulx. $d$. Stamina et pistilli rudimentum.

2. Capsula.

3. Flos licninens post occasum capsula. a. Calix. b. Glandulx. $c$. Placrontarium ¿̀ quo semen $d$ nondum maturum pendet.

4. Cuccun.

\section{CROTONOPSIS linearis. Michx.}

1. Flos masculus, a. Calix. b. Petala. c. Stamina. 2. Flus fomineus, a. Bractua.bb. Calix́, c. Squamulx. d. Ovarium. c. Siliguata.

$\therefore$ S.quamula furfuracea. 
4. Fructus rerticaliter sectus, a. Pericarpium. 6. Semen.
5. Semen verticaliter sectum, $a$. Testa, b. Perispermuru. c. Embryo.

\section{TABULA I $\mathrm{X}^{2}$.}

aS. ADELIA bernardia. L.

1. Flos masculus in prafloratione. aa. Bractex. 6. Calix.

2. Idem apertus. a. Calix. 6. Stanina.

5. Stanen.

4. Flos fomineus. a. Bractea et calix. 6. Orarium. $c$. Stigmata.

5. Orarium verticaliter sectum. a. Loculus. 6. Orulum.

6. Idcm transverse sectum. a. Calix. b. Ovariuns.

7. Coccum.

8. Idem sectun a. Pericarpium. b. Semen.

9. Semen rerticaliter sectum. a. Testa. b. Perispermum. c. Embrģo.

29. A. ROTTLERA ricinoides. - CROTON ricinoïdes. Pers.

1. Flus masculus in præfloratione.

2. Idem in antbesi. a. Pedunculus. 6. Calix. c. Stamina.

5. Antluera in apice filamenti.

4. Flos fensinens. a. Calix. 6. Ovarium. c. Styli.

5. Idem rerticaliter sectus. aa. Orula.

6. Fructus.

7. Idcm rerticaliter seclus. a. Placentarium. 6. Semen. o. Loculus.

S. Semen.

9. Nucleus verticaliter sectus. a. Perispermum. 6. Embrro.

B. ROTTLERI scabrifolia.

1. Flos masculus. a. Calix. 6. Stamina.
2. Flos fremineus in proflorationc.

5. $I d c m$ maturior.

4. Idem rerticaliter sectus. a. Loculus. 6. Semen.

5. Fructus dehiscens.

6. Semen pelliculà inrolntum.

7. Ideon, ablatâ pelliculà.

8. Idcon rerticaliter sectum. a. Testa. b. Perispermum. c. Embryo.

9. Embryo.

C. ROTTLERA indica. W. goett. - TREWIA indica. W. spec.

ı. Flos masculus, a. Calix. b. Stamina.

2. Flos fremineus, ablatn calice. a. Orarium: b. Stylus. c. Lacinix styli plumosx.

5. Orarium verticaliter sectum. a. Orulum. b. Loculus.

4. Idem transversè sectum.

3o. CODIECM variegatum. - CROTON rariegatum. L.

1. Flos masculus in prefloratione.

2. Idcm in antlesi. a. Calix. b. Petala squamifurmia, c. Glandula, d. Stamina.

5. Flos fumineus. a. Calix. 6. Ovarium. c. Styli,

4. Ovarium rerticaliter sectum, $a$, Squamulæ. b. Loculus. O. Uvulum.

5. Idem transrerse sectum.

TABULA $\mathrm{X}^{2}$ 。

51. A. GELONIUM multignum.

1. Flos nuasculus in prxfloratione.

2. Idom in anthesi. a. Calix. 6. Stamina.

5. Receptaculum. a. Glandula.

4. Anthera, a. Extrorsins. b.Introrsim. c. Transversè secta.

5. Flos fuemineus, a. Calix. 6. Orarium. o. Stig- mata. $d$. Discus.

6. Ovarium transversè sectum.

7. Fructus.

8. Idem verticaliter sectus. $a$. Loculus. 6. Semen. 9. Sinien.

10. Idem rerticaliter sectum, a. Testa. b. Perispermum. c. Embryo. 
B. GELONIUM Lilarim. Roxb.

1. Flos masculus. a. Calix. b. Stamina.

2. Flos feemineus. a. Calix. b. Discus. $c$. Ovarium. d. Stignata.

5. Idem maturior.

4. Ovarium transversè sectum.

5. Fruclus (M. N.).

6. Semen (M.x.).

7. Idcm, integumento extcriori ablato.

8. Nucleus $b$, cum parte integumenti $a$. (s. s. j.

9. Idem verticaliter scctus. a. Perispernum. b. Embijo.

10. Embryo.

\section{AMPERE $\Lambda$ ericoïdes.}

1. Flos masculus, a. Ramus. b. Folium. c. Bractex. $d$. Flos.

2. Idcm magis auctus. a. Calix. b. Stamina.

5. Flores fominei. a. Ramus. b. Folium. c. Bractex. dd. Calix. c. Capsula. f. Stigmata. g. Placentariun floris altcrius cunı calice persistens.

4. Capsula, loculo aperto, a. coccum bivalve.
6. Placentarium. c. Semen.

5. Capsula transrerse sccta. a. Calix. b. Pars pericarpii.

6. Semen. A.Extrorsim. B. Introrsím. aa. Testa. 66. Arilius.

53. J IX゙IPIIA manihot. Kunth. - IATROPHA manihot. L.

1. Flos masculus.

2. Idem, calice inverso. a. Calix. 6. Discus. c. Stamina quinque longiora. $d$. Quinque breviora.

3. Antluerx introrsim et extrorsim risa, staninum breviurum $a a^{\prime}$, et longiorum $6 b^{\prime}$.

4. Pistillum. a. Discus. b. Ovarium $c$. Stigmata.

5. Idem adultius.

6. Idem transverse sectum.

7. Fructus, parte pericarpii exteriori ablatá (s. s.).

8. Coccum.

g. Semen, a. Arillus. b. Testa.

10. Idem verticaliter sectum. a. Testa. 6. Perispermum. o. Lumbryo.

\section{TABULA X I'.}

54. A. JATROPHA curcas, L.

1. Flos masculus. $a$. Calix. $b$. Corolla. c. Glandula. $d$. Stamina.

2. Flos lemineus, a. Calix. 6. Corolla. c. Glandulae, $d$. Pistillum.

3. Ovarium transverse sectam.

4. Fructus (M. s.).

5. Semen.

6. Idem dissectum. a. Arillus. 6. Rapha rasa: $c$. Cbalaza. $d$. Testa. $e$. Nucleus.

7. Nucleus.

8. Idem verticaliter sectus. a. Perispermum. 6. Embryo.

B. JATROPII napaifolia. Desrouss. Enc.

1. Filos nasculus in profloratione.

2. Stamina.

3. 4. 5. Anthera : introrsim (3); cxtrorsim (4); transverse secla (5).

6. Flus masculus verticaliter sechus. a. Calix. 6. Stamina. c. Pistilli rudimentup.
7. Flos foemineus. a. Calix. 6. Ovarium. c. Styli et stignata.

S. Ovarium transrersè sectum. a. Discus. 6. Rudimentum filamentorum. $c$. Ovarium.

9. Idem verticaliter sectum. a. Loculus. 6. Ovulum.

35. ELAOCOCCA verrucnsa. - DRYANDRA cordata. Thunb.

1. Flos masculus in prxfloratione ( $x_{.} x_{.}$).

2. Idem in anthesi (fore s. x.). a. Calix. 6. Petala, c. Stamina.

3. Idcm, calice ablatu, apertus. a. Petala. 6. Stamina.

4. Ovariun. a. Pedunculi articulatio. 6. Ovariuns.

5. Idcm transversè sectum.

6. Idem verticaliter sectum. a. Placentariuns. b6. Loculi. $c c$. Orula.

7. Fructus (s. s. miuor).

S. Idem naturior, stuprrè visus.

9. Idem verticaliter scctus, aa. Sarcocarpium. 
6b. Endocarpium. o. Placentariun. d. Semen.

10. Semen. a. Arillus. b. Chalaza.
11. Nucleus.

32. Idem verticaliter sectus, a. Perispermum. 6. Einbryo.

TABULA XII".

36. ALEURITES ambinux. Pers.

1. Flos masculus. a. Calix. 6. Petala. c. Stanina.

2. Petalum introusim.

5. Stamina. a. Receptaculum. b. Discus. o. Anthera.

4. Stamen. a. Introrsìm. 6. Extrorsum.

5. Receptaculum staninum verticaliter sectum.

6. Flos liomineus, a. Calix. 6. Petala.

;. Idem, calice secto. aa. Calix. b. Petala. c. Tunica ovarii superius in $c^{\prime}$ fissa. d. Styli.

S. Pistillum, tunicà ablatâ. a. Discus. 6. Orariunt. c. Styli.

9. Orariun transrersè sectum.

10. Idem verticalitcr sectum. a. Loculus. 6. OvuJum.

11. Fructus (1) (dimid. s. v.).

12. Idem verticaliter sectus. aa. Sarcocarpium. 66. Cocca in cobiantia.

15. Coccum.

14. Idem dehiscens. aa. Valvæ. 6. Scmen.

15. Semen.

16. Idem verticaliter sectum. a. Testa, b. Perispermiun. c. Embryo.

5-. ANDA Gomesii. - JOANNESIL principis. Vell. - Gom.

2. Putamen (dimid. s. x.).

2. Idem transversè et verticaliter sectum, a. En- docarpium, in $a^{\prime}$ fenestratum. 6. Dissepimentum. co. Loculi. $d$. Semen.

3. Semen.

4. Idcm, testà sectâ.a. Testa. b. Chalaza. c. Nucleus.

5. Nucleus rerticaliter sectus. a. Pcrispermum. 6. Enbryo.

58. A. SIPHONiA calucbu. Rich. - S. elastica. Pers. - HEVEA guianensis. Aubl.

1. Flos masculus verticaliter sectus. a. Calix. b. Culumna. c. Antherx.

2. Flos fo'mincus, a. Calix , fissurâ circulari 6 infrà deciduus.

3. Pistillum. a. Basis calicis. b. Orarium. o. Stigmata.

4. Orarium transversé sectum.

5. Idom verticaliter sectum. a. Loculus. b. Orulum.

B. SIPIONIA brasiliensis. W. (in Lerbariis).

1. Calix floris masculi.

2. Stamina. a. Antberis. 6. Columna.

5. Anthera. a. Extrorsùm. b. Introrsum.

4. Flos fumineus.

5. Pistillum. a. Ovarium. 6. Stigmata.

6. Orarium, parte superiuri integumentorum ablatd, $a$. Basis ovarii. b. Ovula pendula.

\section{TABULA XIII".}

39. MABEA piriri. Aubl.

1. Pedunculus forun masculorum. a. Bractea biglandulosa. 6. Pedunculus trifidus. c. Flores.
(1) Figura 11-16 desumptx ex Commersonii iconibus ineditis, in mus. hist. nat. paris. bibliothecd serratis. Frucıs ideus sub nouniue Camirii cordifotii descriptus drlineatusque reporitur in Gortnero (11, 19f, tab. 125). Is autim anplum loramen in extima seminis tunica (id est, ut opinor, in endocarpio) a
Rumphio Commersonioque indicatum, nullum invenit, nihilque aliud esse censet a quản amplissinam expana sionem substantix illius lungosx, juxta umbilicos a seninum in Tithymaloìdeis adeó frequentis et usita* tx. " In quo plané ipsi assentior. 
2. Flos masculus, a. Calix. 6. Stamina.

3. Idem verticaliter sectus. $a$. Receptaculum. b. Anthera.

4. Flus formineus, a. Calix. b. Stylus. c. Stigmata.

5. Orarium rerticaliter sectum, a. Calix. b. Placentariuns. oc. Loculi. $d d$. Ovula.

6. Idem transversì sectum, a. Calix, b. Orariuns.

7. Fructus (feré s. x.).

8. Idem, coccis duobus ablatis, a. Placentarium. b. Coccum.

9. Semen.

40. GARClA nutans. Rorl.

1. Flos nasculus in prafloratione ( $x_{,} x_{.}$). a. Pedunculus, b. Calix.

2. Idem in anthesi. a. Petala. b. Stamina.

3. Idem verticaliter sectus. $a$. Glandula. b. Receptaculum. $c$. Stamina.

4. Pistillun. a. Ovarium. b. Stigma.

5. Idem verticaliter sectun. a. Orarium. b. Stylıs. o. Stigna. $d$. Loculıs. e. Ovulum.

6. Idem transversè sectum.

41. ALCHORNEA latifolia. Sw.

1. Flos masculus in præfloratione.

2. Idem apertus. a. Calix. b. Stamina.
3. Staminum pars, a. Filamenta connata. $b$. Antheræ.

4. Flos fremineus. a. Calix. b. Pistillum.

5. Orarium transwersè sectun.

6. Ovarium verticaliter sectum.

42. A. CONCEVEÏBUM cordatum. Rich. Ilerb.

1. Flos masculus in prefloratione.

2. Anthera in prafloratione. a. Introrsum. b. Extrorsind.

5. Flos masculus in anthesi.a. Calix. 6. Stamina.

4. Flos foemineus. a. Pedunculus cun calice. b. Ovarium. o Stigmata.

5. Ovarium transiersè sectum.

6. Fructus verticaliter hinc sectus, a. Pericarpium. b. Loculus. $c$. Semen.

B. CONCEVEÏBUM oratum. Rich. Herb. COXCEVEÏBA guianensis. Aubl.

1. Flos fomineus, a. Pedunculus. b. Glandula calicinze. c. Calix. d. Ovarium. e. Stylus et stigmata.

2. Ovarium transversè sectum.

5. Idem verticaliter sectum.

4. Fructus.

5. Idem, pericarpio ablato. a. Dissepimenta. b. Semina.

\section{TABULA X IV:}

43. CLAOXYLON parvillorum. - ACALYPII |4 4. spiciflora. Enc.

1. Florum masculurum fasciculus. a. Bracter. b. Pedunculus. c. Flores.

2. Flos masculus, a. Calix. 6. Stamina.

3. Pars staminum 6 , receptaculo $a$ verticaliter secto.

4. Anthera. a. Filanentum. bb. Loculi.

5. Fominex spicx pars. aa. Bractex. bb. Flures.

6. Flos foemineus. a. Calix. b. Appendicula. c. Ovariun. d. Stigmata.

7. Ovarium transversè sectum.

8. Capsula, loculo alteru verticaliter secto. $a$. Calix. b. Pericarpium. o. Loculus. d.Semen.

9. Semen verticaliter sectum. $a$. Testa. $b$. Nucleus.

o. Nucleus verticaliter sectus, $a$, Perispermum. c. Embryo.
MAPPA glabra. - RICINUS tanarius? L.

1. Florum masculorum glomeruli. aa, Bractex. bb. Flores.

2. Flos masculus in prafloratiune.

3. Idcm in anthesi. a. Calix. 6. Stamina.

4. Anthera. a. Supernè. $b$. Infernè.

5. Flos famincus, a. Bractea. 1. Calix.c. Pistillum.

6. Pistillum verticaliter sectum. a. Orarium. b. Stylus. c. stigmata. $d$. Loculus, c. Oruluni.

7. Orarium transversè sectun.

8. Capsula. a. Calix, b. Stignatum reliquia. c. Echini.

9. Semen.

10. Idem verticaliter sectum. a. Pellicula. b. Testa. c. Perispermum. d. Embryo. 
๕ă. CATURUS spiciflorus. L. - ACALYPHA hispida. Burm.

1. Flos masculus in prefloratione.

2. Itlem apertus. a. Calix. b. Stamina.

5. Stamen. a. Filamentum. b. Connectivum. cc. Antheræ loculi.

4. Flos femineus (1),a. Bractca, 6. Calix. c. Ovarium. d. Stÿli.

5. Idem transversè sectus. a. Calix. 6. Ovariun.

46. ACALYPHA alopecusoïdea. J acq.

2. Flos masculus in prafloratione.

2. Idem in anthesi. a. Calix. b. Stamina.

3. Stamen. a. Filamentum. 6. Anthera loculi.

4. Flos fomineus, a. Bractea, 6. Calis. c. Orariun. d. Styli.

5. Orarium transrersè sectum.

6. Capsula , loculo verticaliter secto. $a$. Pericar- pium. 6. Loculus. c. Semen.

7. Semen. a. Testa. 6. Arillus.

8. Idcm verticaliter sectum. $a$. Testa. $b$. Perispernum. c. Embryo.

47. MERCURI ALIS annua. L.

1. Flos masculus, a. Calix. 66. Stamina.

2. Stamen. a. Filamentum. 6. Connectirum. co. Anthera loculi.

3. Flos fomineus. a. Calix. b. Filamenta sterilia. o. Ovarium. $d$. Styli et stignata.

4. Capsula, loculo altero secto. a. Pericarpium.

b. Loculus. e. Senea.

5. Eadcm transversè secta.

6. Semen verticaliter sectum.a. Arillus. 6. Testa. o. Perispcrmunı, d. Embryo.

7. Embryo.

\section{TABULA X V•.}

48. ANAB ENA tamnoïdes. - PLUKNETIA occidentalis. Leandro (in berb. mus.)

1. Flores masculi, a. Bractex, b. Pedunculi. c. Flores.

2. Flos masculus, ablato calice. $\boldsymbol{a}$. Squamulx. 6. Stanina.

5. Anthera. a. Supernè. b. Suhtùs.

4. Stamina, filamentis plerisque sectis. Squamula. ๑. Filamenta. c. Pistilli rudimentuou?

5. Flos founeus. a. Calix. 6. Ovarium. o. Loculus. $d$. Orulum. $e$ stylus. $f$. Stigma.

6. Orarium transversè sectun.

7. Fructus. aa. lntegumentum exterius. b. Endocarpium seu cocca.

8. Cocca.

9. Semen. a. Posticè. 6. Anticè. c. Scctum.

49. A. TRAGIA volubilis. L.

1. Flos masculus. a. Bractea. b. Pedunculus. c. Calix. d. Stamina.

2. Flos fremineus. a. Calix, b. Pistillum.

5. Capsula infernè risa.
4. Eaden supernè.

5. Eadem, coccis duobus ablatis. a. Calix persistens. 6. Placentarium. o. Coccum.

6. Coccum sectum. a. Pericarpium. 6. Semen placentario adnexum.

B. TRAG]A cannabina. L. f.

1. Flos masculus, a. Bractea, b. Pedunculus. c. Calix. d. Stanina.

2. Capsula infernè visa.

3. Eudem supernè. aaa. Calix, bbb. Cocca. co. Semina.

MICROSTACHYS bicornis. - TRAGIA bicornis. Vahl (in herb. J.).

1. Spica masculæ pars. a. Bracteæ, b. Flores.

2. Flos masculus in prefloratione.

5. Idem in anthesi. a. Calix. 6. Stanuina..

4. Flos fomineus.a. Bractea. Lb. Calix. o. Ova. rium. d. Stigmata.

5. Capsula.

6. Coccum.

7. Scmen. a, Arillus. b. Testa.

(3) Flos formineus certè Caturi spicifori; masculus dubié. 
8. Idcm, testá verticaliter sectâ. $a$. Testa. 6. Nucleus.

9. Nucleus verticaliter sectus. a. Perispermum. 6. Embryo.

51. SAPIUM aucuparium. Jacq.

1. Pars spicx. a. Rachis. $A$. Florum nasculorum glomeruli. a. Bractex. b. Florcs. $B$. Flus. l'cemincus, a. Bractea, 6. Stglus. c. Stigmata.

2. Flos masculus in prefloratione. $a$. Bracteola.

6. Pedicellus. D. Calix.

3. Idem apertus, a. Calix. 6. Stamina.

4. Anthera.

5. Flos fremineus, a. Calis. b. Stigmata, c. Placentariun. $d d$. Ovula.

6. Orarium transversè sectum.

\section{TABULA XVI.}

52. STILLINGIA sebifera. Michx. - GROTON sebiferum. L.

1. Pars spic $x$ masculx. aa. Rachis. 66. Florum gloneruli.

2. Bractea. a. Pars cjus squamulosa. 66. Pars glandulosa.

3. Flos masculus. a. Bracteola. 6. Pediccllus. c. Galix. d. Stanina.

4. Idem, calice secto. a. Basis calicis. 6. Stanina.

5. Anthera transrersè secta.

6. Flos fomineus.a. Calix. 6.0 rarium. $c$. Stylus. d. Stigmata.

7. Ovarium, integumentorum superiori parte ablatá, $a$, Ovarium. bb. Loculi. c. Placentarium. $d d$. Ovula.

S. Fructus. a. Bracteolæ. b. Pedunculns. c. Capsula.

9. Semina è placentario pendula.

10. Semen rerticaliter sectum. $a$. Materia sebosa. b. Testa. c. Perispermum. d. Embryo.

53. OMALATTIIUS leschenaultianus.

1. Pars spicx mascula. a. Rachis. b. Bractea. cc. Flores.

2. Flos masculus in pirflorationc. a. Calix. 6. Stamina.

3. Idem apertus. aa, Calix. b. Stamina.

4. Idem verticaliter sectus, a. Calix. b. Staminum pars.

5. Anthera. a. Extrorsim, 6. Iutrorsum.

6. Flos lin minens. a. Calix. 6. Ovarinn. c. Styli. d. Stigmata.

7. Osarium trausversè sectum.

S. Idem verticaliter sectun. aa. Locnli. 66 . Ovula. o. Placentarium.
9. Pars capsulx. a. Pedunculus. 6. Placenta. rium. c. Pars interiol ossca pericarpii. d. Semen.

10. Eadem, valví alterâ ablatà. a. Placentarium. b. Pericarpium. cc. Semina.

11. Semen. a. Testa. b. Nucleus (abortirus).

54. HIPPOMANE mancinella. L.

1. Florum masculorum glouerulns. a. Spic $x$ rachis. $b$. Bractea. c. Flores.

2. Flos masculus. a. Calix. b. Stamina.

3. Flos femineus. a. Calix. b. Stylus. c. Stigmata.

4. Ovarium transversè sectum.

5. Fructus (ar. $x_{4}$ ).

6. $\operatorname{Nux}$ (M. N.).

7. Eadem transrersè secta.

S. Semen.

9. Nucleus.

10. Idem rerticaliter sectus. a. Perispermum. b. Enbryo.

55. EXCACARIA lucida. Sw. 0. - GYMNANTHES lucida. Sw. Prodr.

1. Anentum masculum in profloratione.

2. Idem in anthesi.

3. Flus masculus. a. Filanentum. b. Squama. cco. Squamulx. ddd. Antherx.

4. Flus formineus, a. Biactex. 6. Pedunculi. c. Caliculus. d. Ovarium. c. Stigmata.

5. Ovarium verticaliter sectum. $a$. Loculi. b6. Uvula.

6. Fructus.

7. Coccum.

s. Semen. 


\section{TABULA XVI I*}

\section{STYLOCERAS kunthianum.}

1. Spica florum (M. s). a. Bractex. 66. Pedunculi. co. Flores masculi. d. Flos immineus.

2. Flus masculus. a. Squama. b. Anthera.

3. Idem introrsum risus. a. Antheræ.

4. Antlrera iutrorsim.

5 Pistillum.a. Orarium. bb. Styli.co. Stigmata.

6. Orarium transrersé et verticaliter sectum. aaaa. Loculi. 6. Ovulum.

7. A. MAPROUNEA guanensis. Aubl. - EGOPRIGON betulioum. L. F.

1. Capitulum florum masculorum. a. Pedunculus. 6. Inrolucrum. $c$. flores.

2. Flos masculus. a. Calix. b. Stamen.

3. Antheræ. a. Altera iotegra. b. Altera transversí secta.

4. Flos fremineus, a. Calix. b. Pistillum.

5. Idem verticaliter sectus. a. Loculus. 6. Ovulum.

6. Fructus.

7. Idem transversè sectus.

8. Semen. a. Introrsum. b. Extrorsum.

59. OMPHALEA triandra. L.

1. Flos masculus in prxfloratione.

2. Idcm verticaliter sectus. a. Calix. b. Stamina. $d$. Receptaculum in $c$ glandulosum.

5. Antheræ. a. Loculi antheræ.

4. Flos formineus. a. Calix. 6. Pistillum.

5. Ovarium verticaliter scctum. a. Placentarinm. bb. Ovula.
6. Idem transtersè sectum.

7. Fructus (y. ...).

8. Idem terticaliter sectus. aa. Sarsocarpium.

b. Endocarpium seu cuccum. c. Loculus.

d. Semen.

9. Semen verticaliter sectum. $a$. 'Testa. $b$. Nucleus.

10. Nucleus.

11. Idem verticaliter sectus. a. Perispermum. b. Embryo.

59. DALECHAMPIA pentaphylla. Lamck.

1. Flores in invulucro conmuni. aa. Appeodices stipulalormes, b6. Iavolucrum com. mune. c. Flores masculi. $d$. Flores freminei.

2. Flos masculus in prafluratione. a. Pedicellus. b. Galix.

3. Idem in anthesi.a. Pedicellus. 6. Galix.o. Stamiua.

4. Florum masculorum umbella. a. Involucrum pruprium. 6. Flores.

5. Eadem, fuliolis involucri reflexis, a. Involucrun proprium. 6. Flores.

6. Eadem ex altero latere. a. Iovolucrum proprium. b. Flores. cc. Squamulx resiniflux.

7. Flores feminei. aa. Invulucrum proprium. bl6. Flores.

8. Flos foemineus, a. Galix. 6. Ovarium. o. StyJus. d. Stigma.

9. Ovarium transversè sectum.

Iv. $I d c m$ verticaliter sectum. a. Calix. b. Ovarium. $c c$. Ovula.

\section{TABULA XVII ${ }^{\circ}$.}

60. ANTḦOSTEMA senegalense.

1. Flurum capitulum. a. Involucrum commune. 66. Involuerum proprium mascularum. cc. Flures masculi. $d$. Flos focmineus.

2. Id m ex altero latere. aa. luvulucrun commune. $b$. Glaudula. $c$ I nrolucrum ptopiem masculorum. dd. Flures masculi.e. Flos iopmineus.

3. Fluram masculorum capitulum verticaliter sectum.a. Pars invulucri. 6. Receptaculum. o. Bractex, $d$. Flores.

4. $A$. Flus nasculus. B. Idem. a. Pedicellus.

6. Filamentum caliculatum. $C$. Anthera.

a. Dehiscens. 6 . Transverse secta.

5. Flos ficmineus. a.Pedunculus, b. Calix.o. Stigmata.

6. Ovarium transversè sectum.

7. Pistillum verticaliter sectum. a. Basis cali- 


\section{( 118$)$}

cis. 6. Ovarium. o. Loculus. d. Orulum. e. Stylus. $f$. Stigmata.

8. Frurtus (s. N.).

9. Coccum sectum. a. Pericarpium. 6. Semen.

61. EUPHORBIA palustris. L.

1. Involucrum multiflorum. aa. Involucrum. 66. Flores masculi. c. Flus foemineus.

2. Involucrum, fintibus ablatis, hinc (in 0) fissum. aa. Lacinix calicinx. 66. Appendices glandulosa.

3. Flores, invulucro aperto. aaa. Involucrum. bb. Bractex.cc. Floses masculi. d. Flos fomineus.

4. Flus masculus. a. Bractea. b. Pedicellus. c. Articulatio. d. Filamentum. e. Anthera.

5. Flos femineus. a. Pedunculus. b. Caliculus. c. Orarium. d. Styli et stigmata.

6. Pistillurn verticaliter sectum. $a$. Ovarium. $b$. Styli et stigmata. $c$. Loculus. $d$. Ovulum. $e$. Arillus.
7. Idem, orulo resupinato. a. Loculus. b. Orulum. o. Stigmata.

8. Fructus sulitis (lerè $4 . x_{0}$ ).

9. Idem supervè.

10. Placentarium (cum situ seminis rerticaliter secti). $a a^{2}$. Reliquire involucri et pedicellorum. b. Peduncultis lloris frminei. o. Placcotarium. $d d$. Placentæet funicnli, e. Arillus. $f$. Radicula et plumula. $g$. Cutyledon alter. h. Perispcrmum. $i$. Testa.

11. Fructus transversè sectus.

12. Coccum.

13.1 dem post dehisceatiam.

14.. Semen. a. Testa. b. Arillus. c. Rapha. d. Chalaza.

15. Nucleus. a. Chalaza.

16. Nucleus verticaliter sectus, $a$ : Perispermum. b. Embryo. 


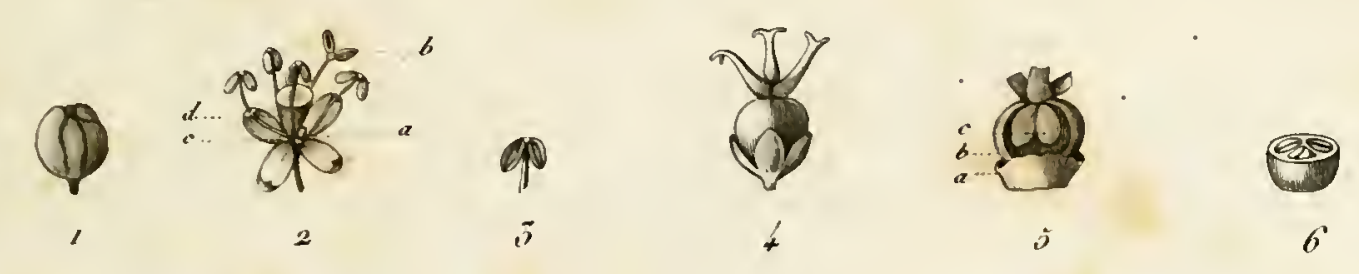

2
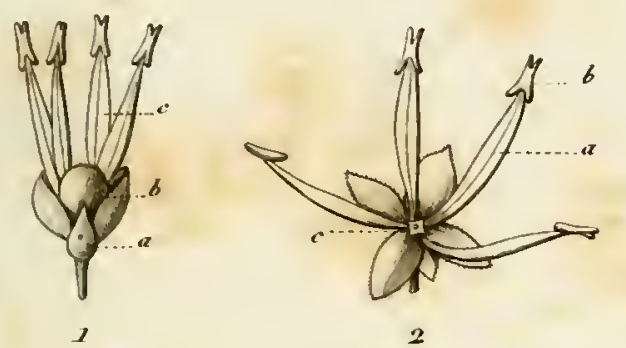

2
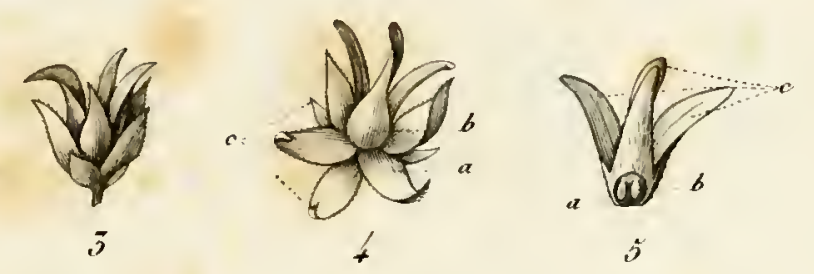

$\overrightarrow{3}$

A
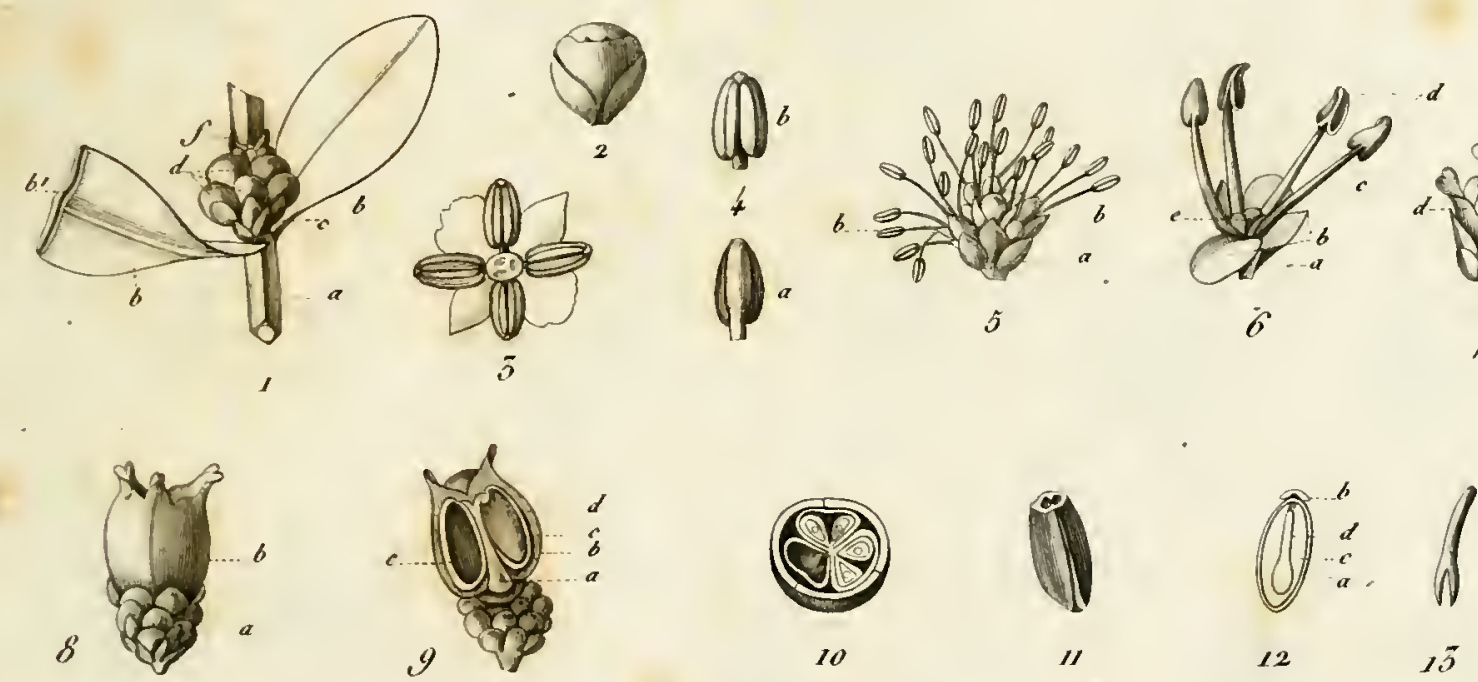

B
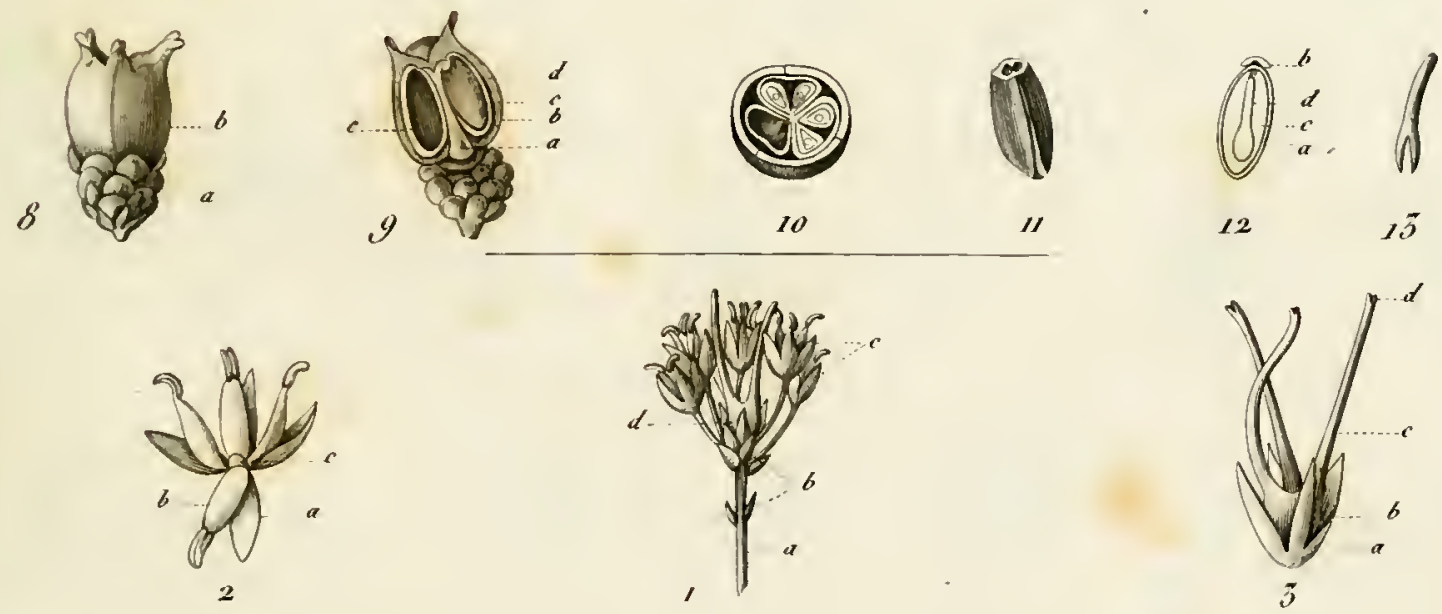

1. THECACOKAS modagascarionsis. 2. PACIISANIRA procumbens.

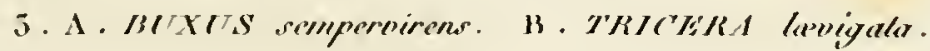




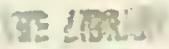

if iI

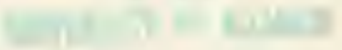


1.
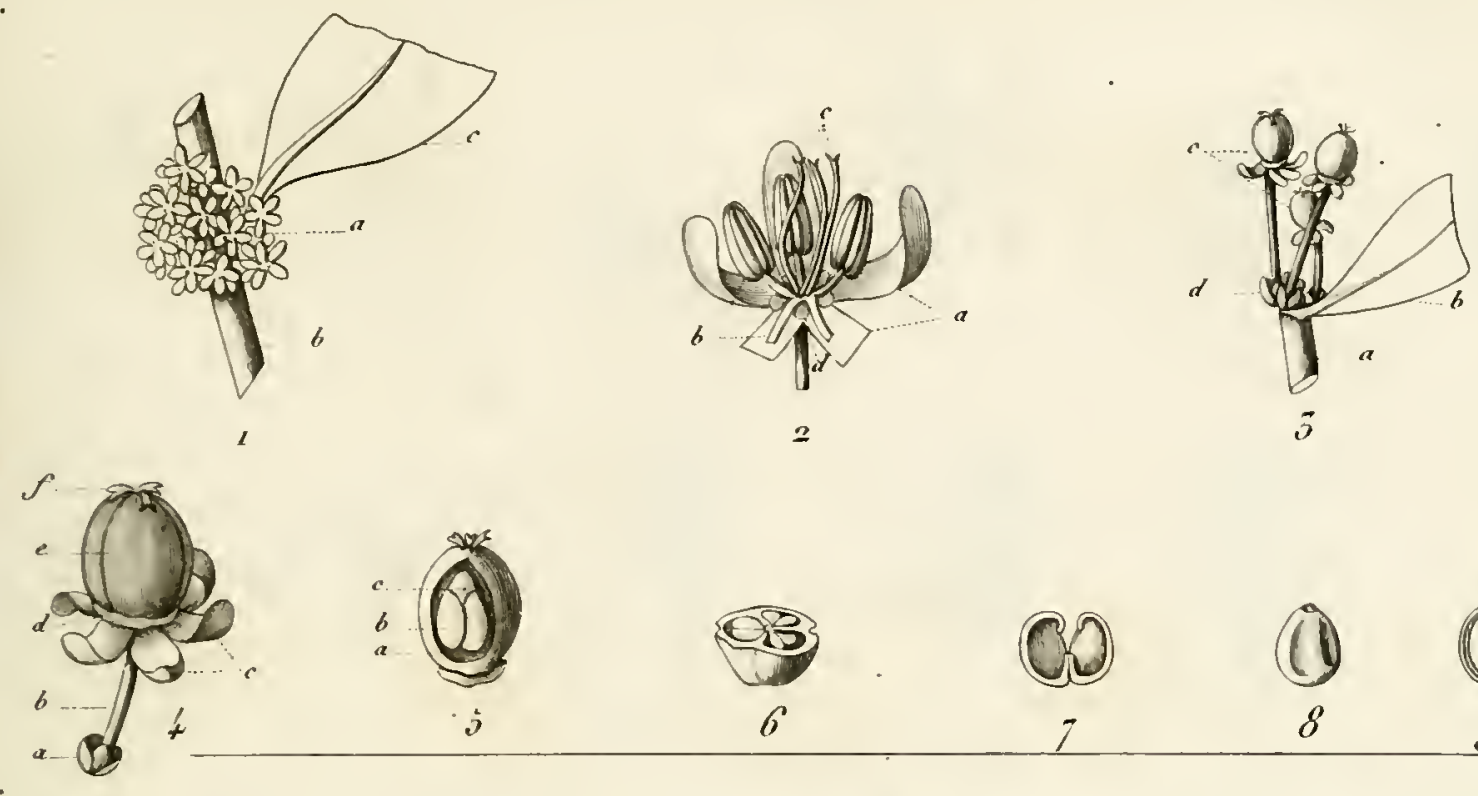

(1)

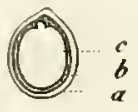

7

g 9

5.
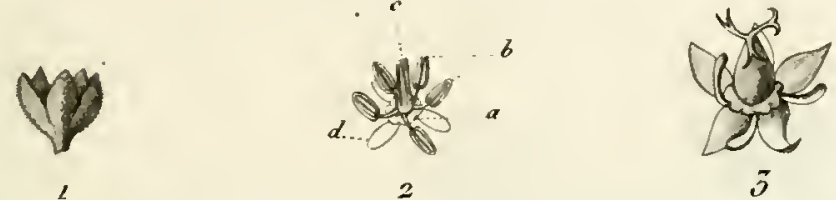

3
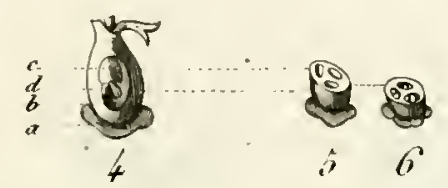

6.
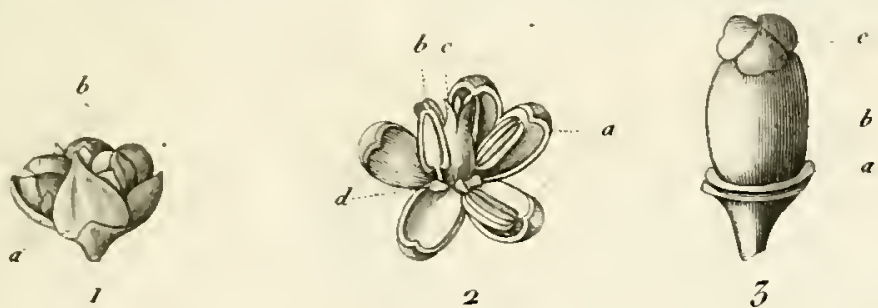

3
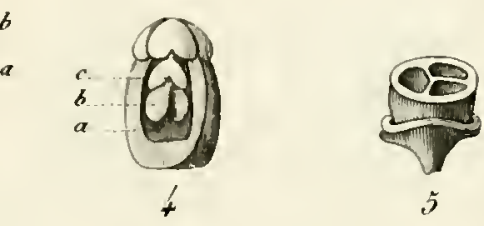

$7 \cdot 1$
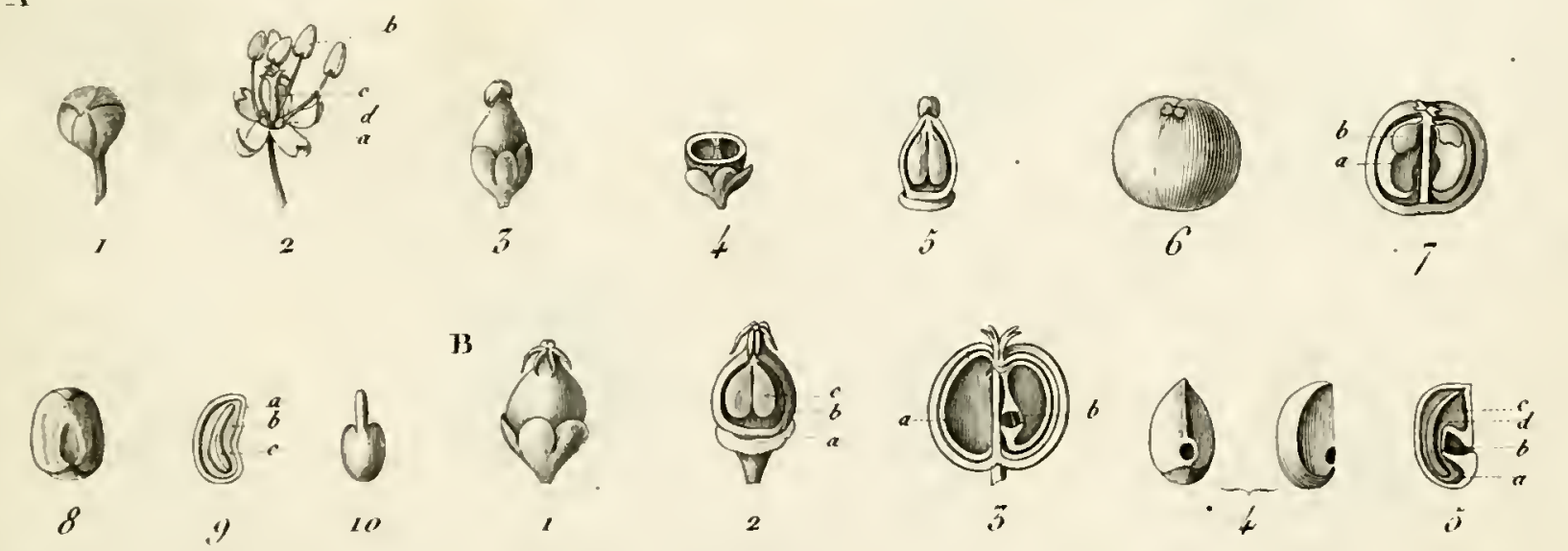

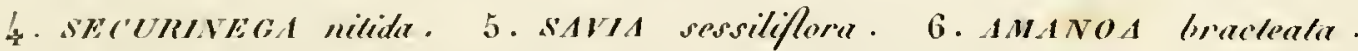
Plee pore siculp?

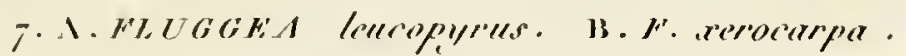


18 L L

ㅊ $P$

(1. $1+1$ 
H . I.

8.

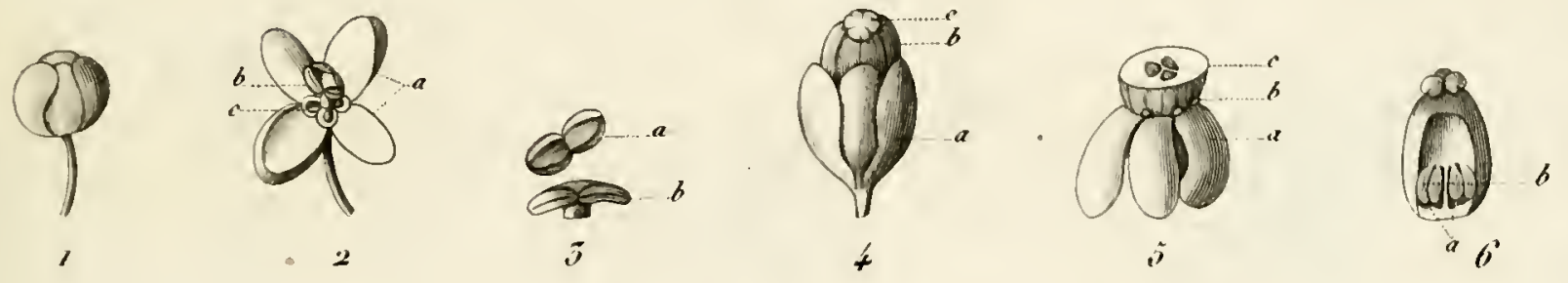

9 .

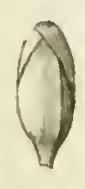

,

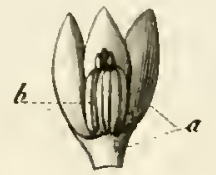

2

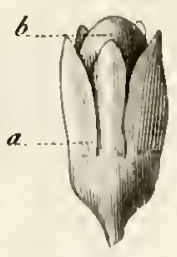

5

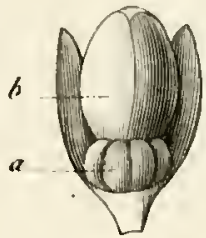

4

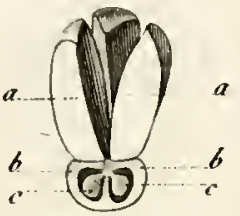

j

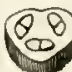

6

10.1 .

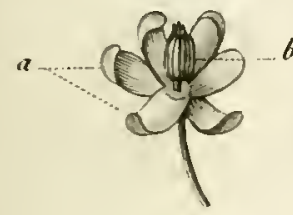

z

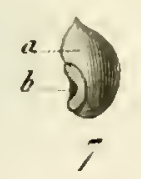

B.

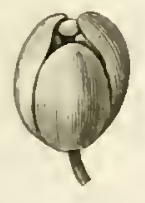

1.

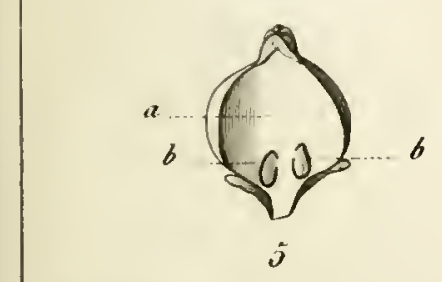

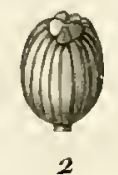

$a \int_{9}^{6}$

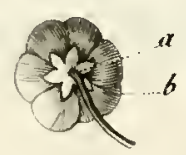

4

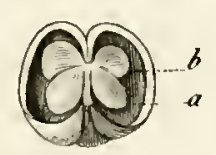

j
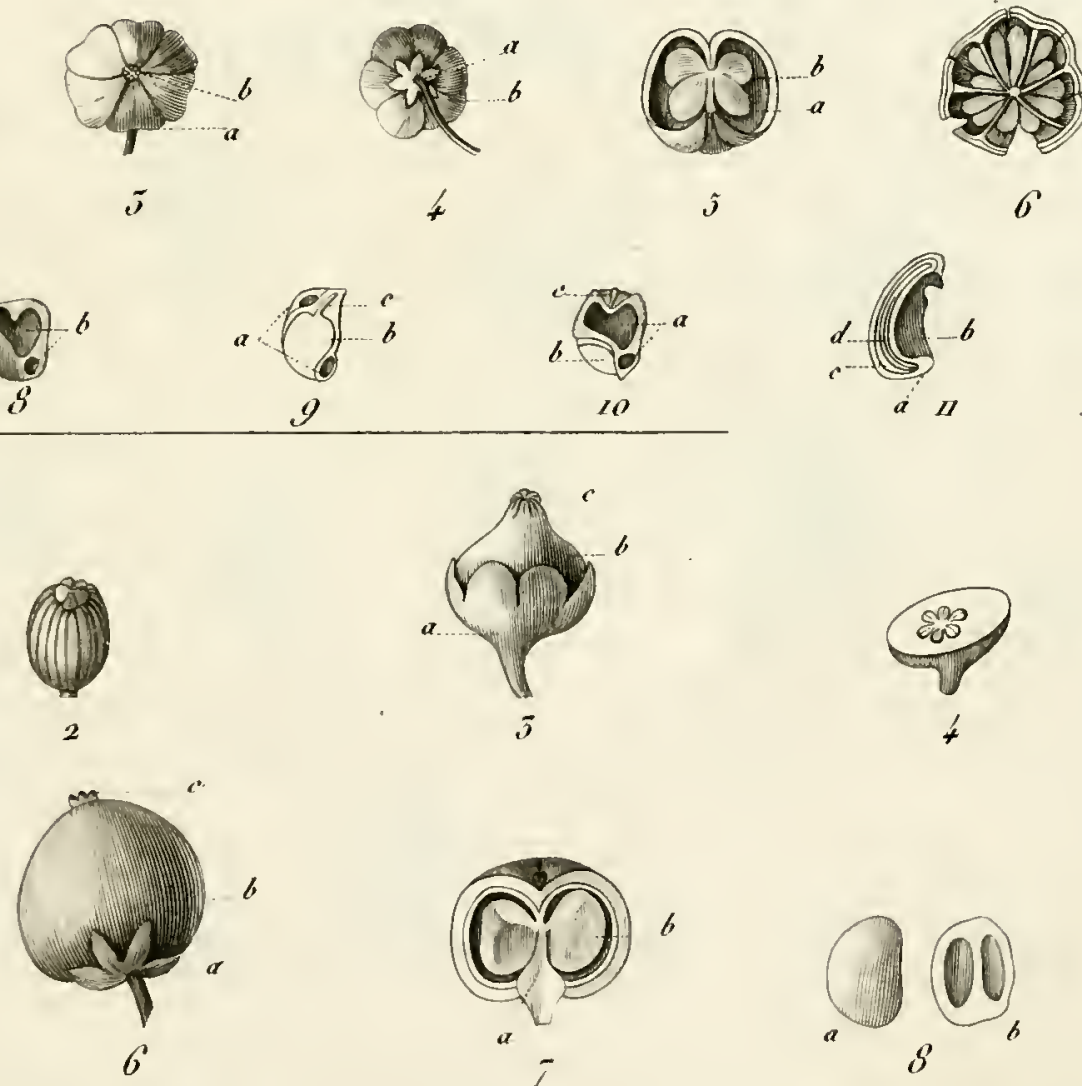

8. HPISTYYII/I axillare .

9. GSVOON rigidum .

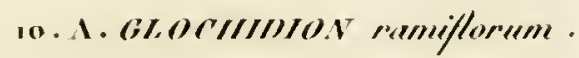

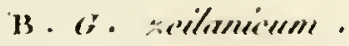

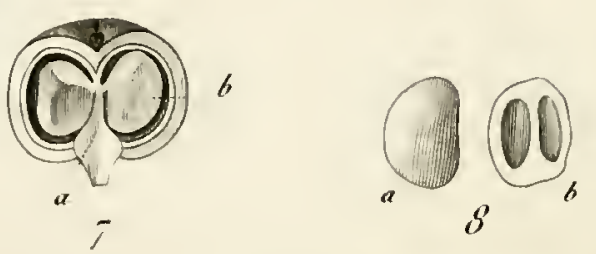



n
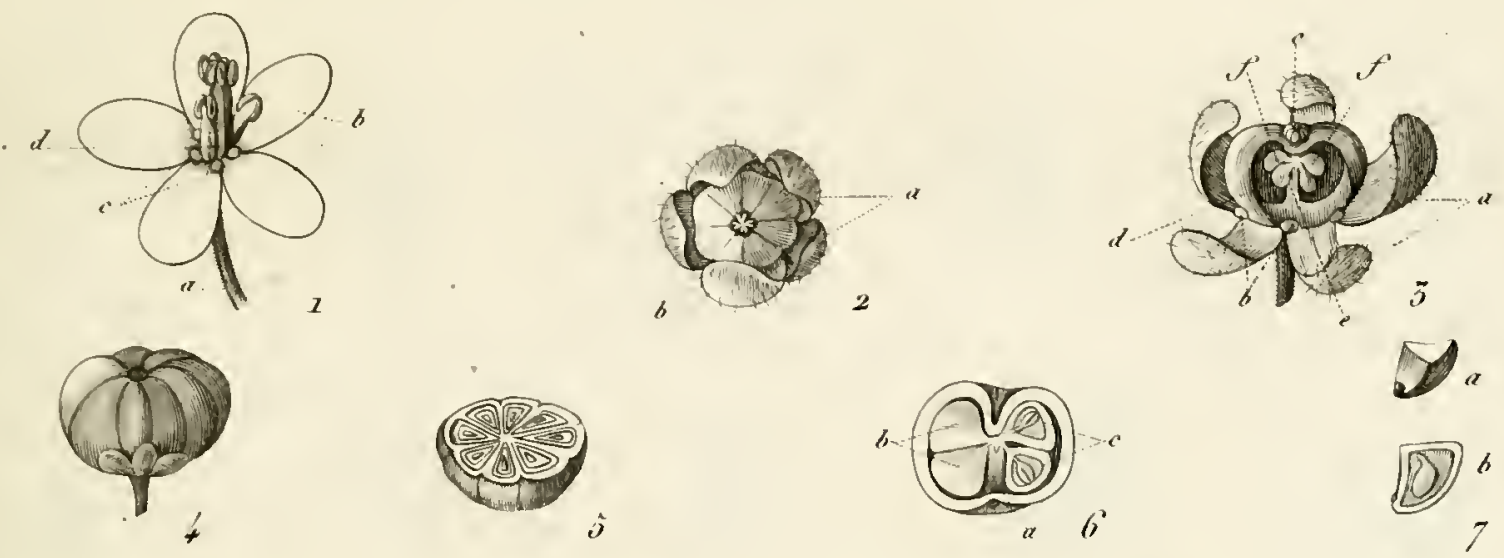

12
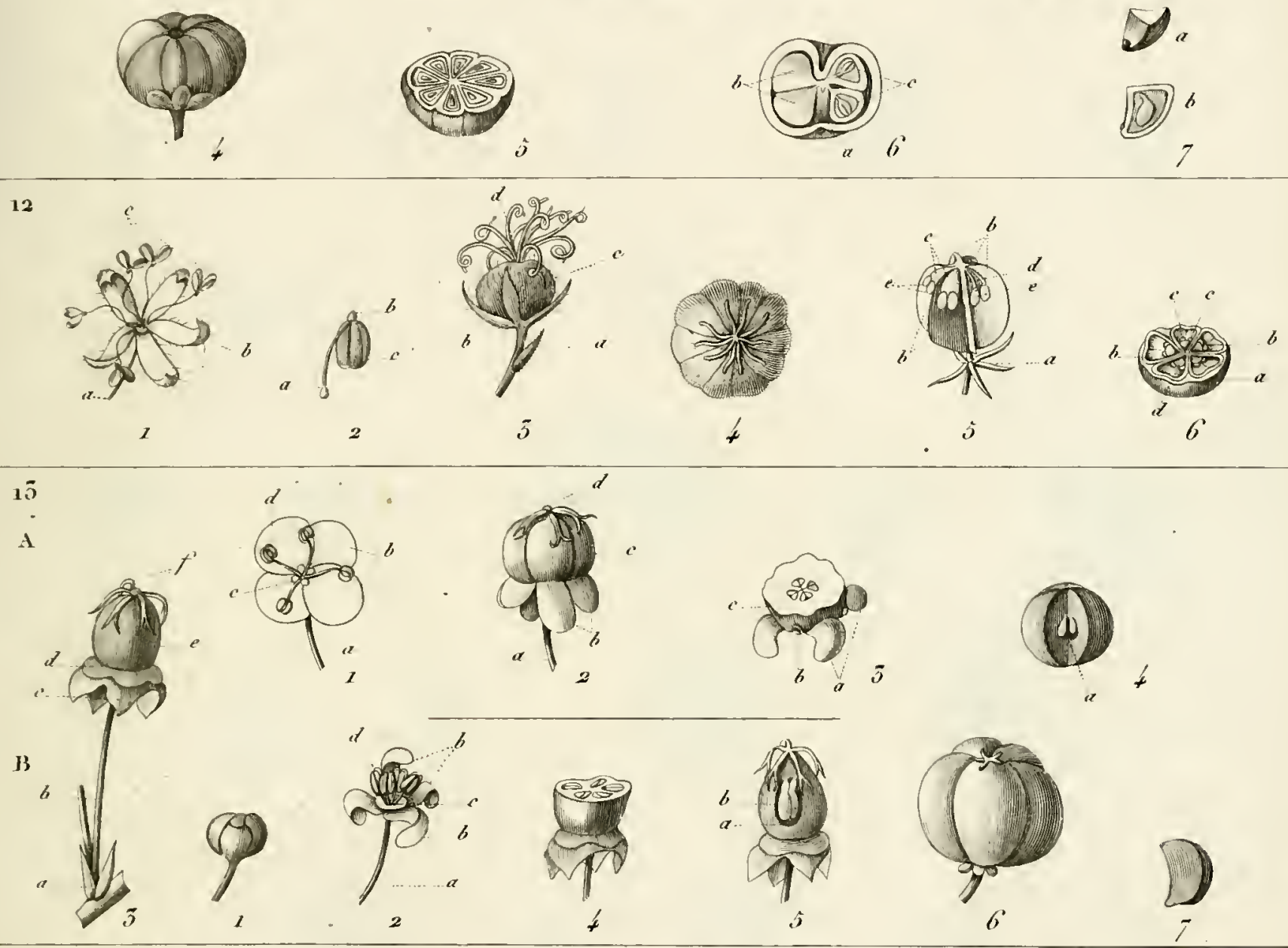

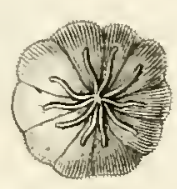

t
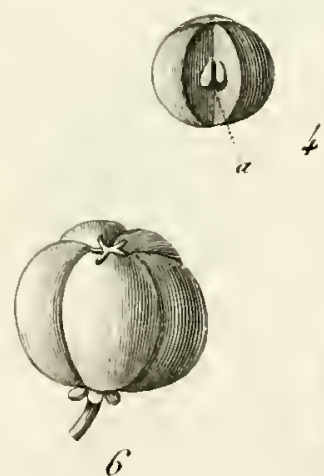

6

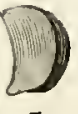

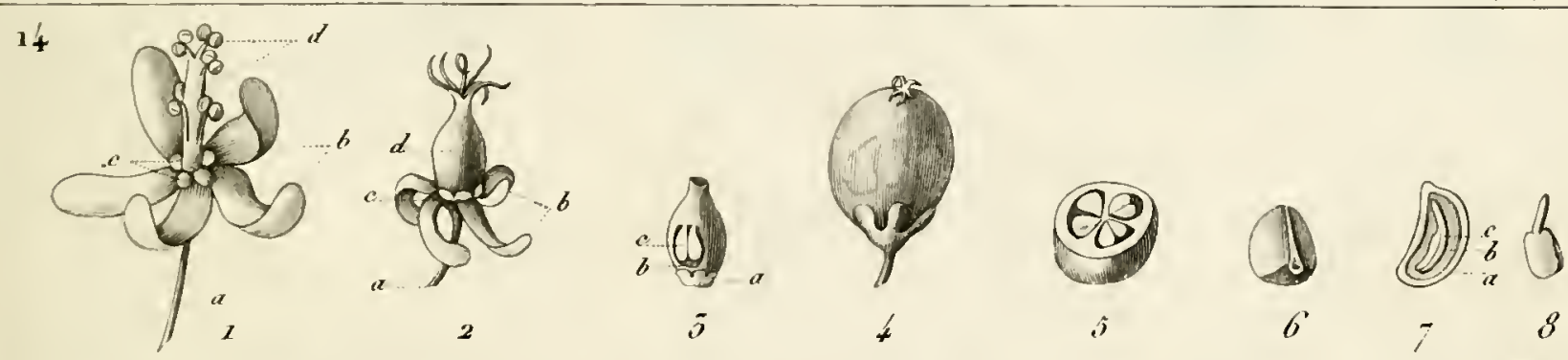

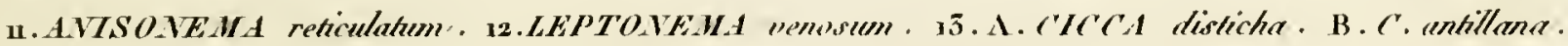



$P l . i$.

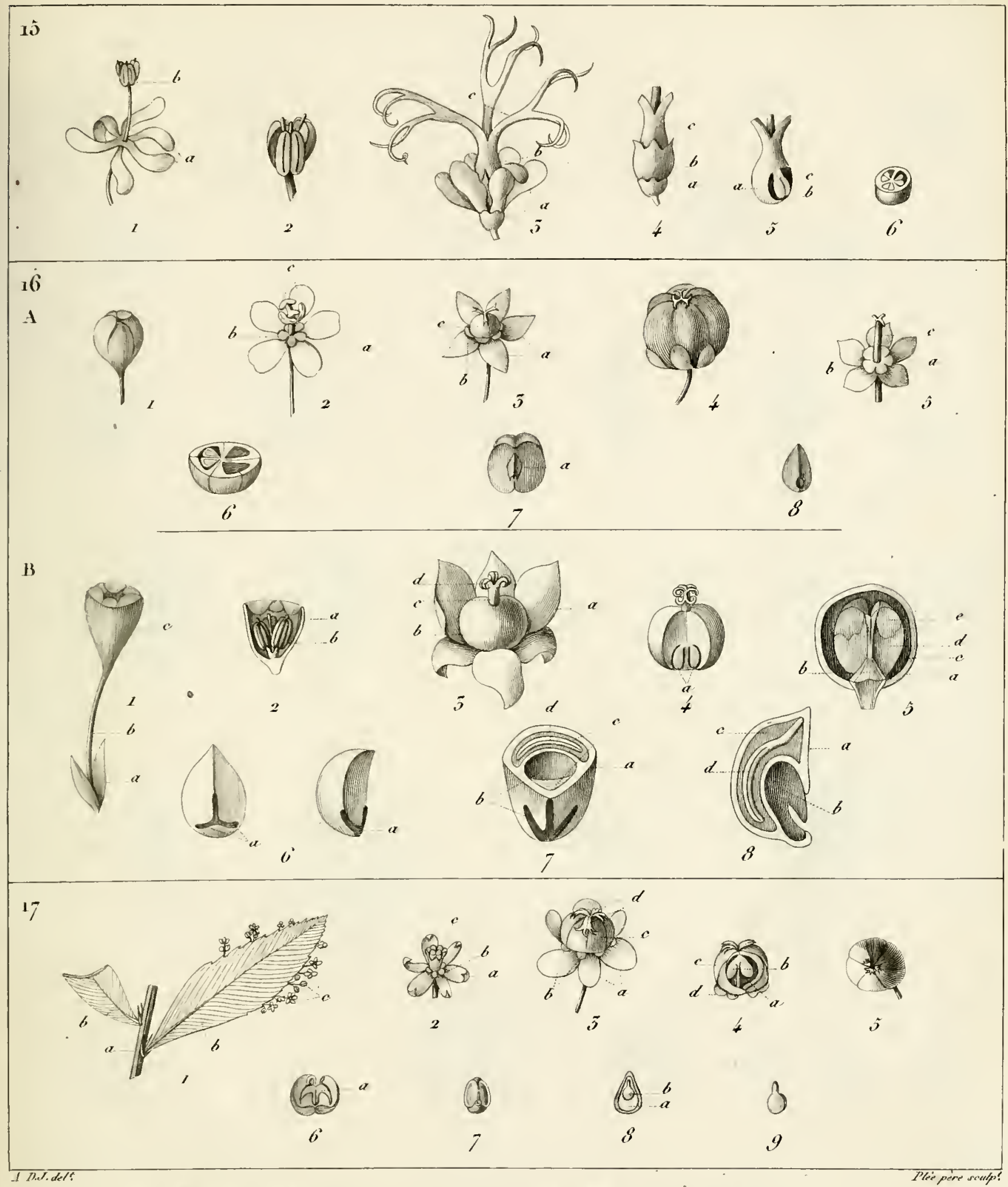

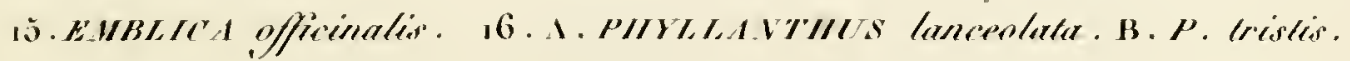

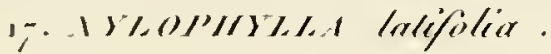



18.
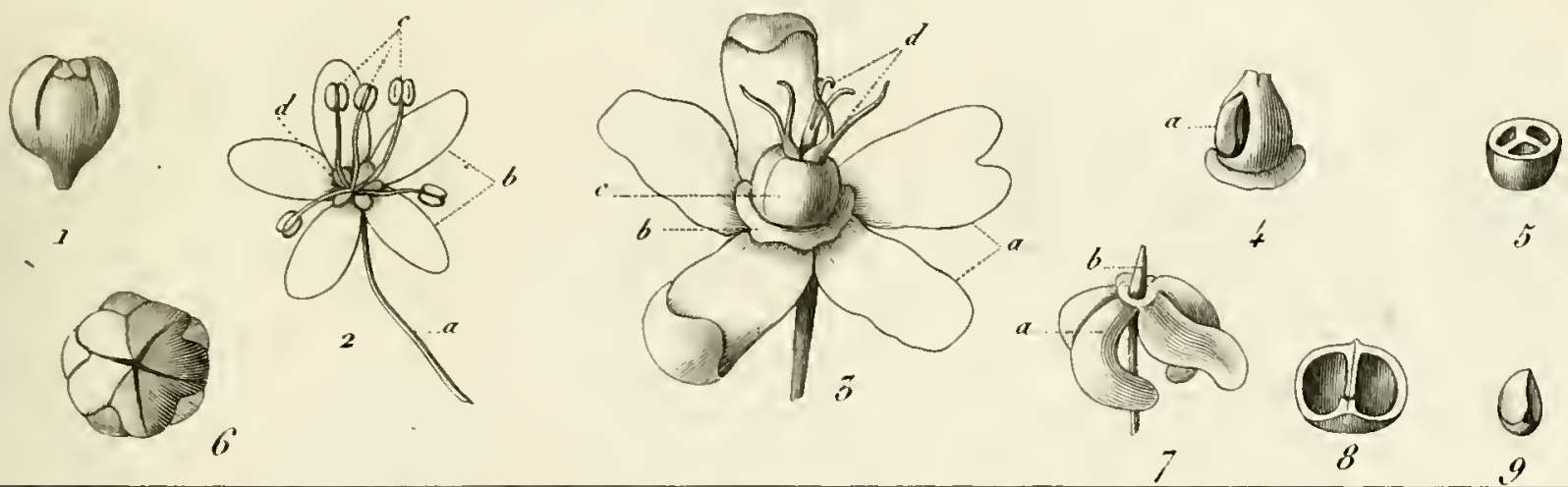

19.
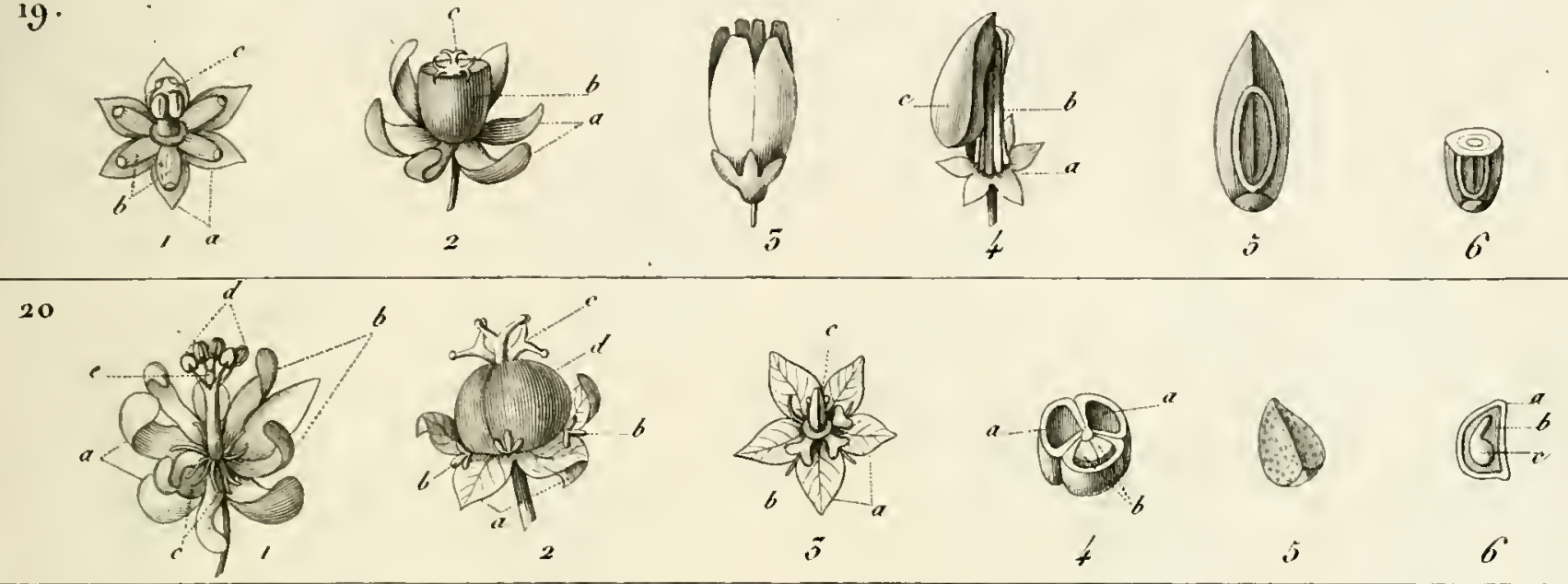

21
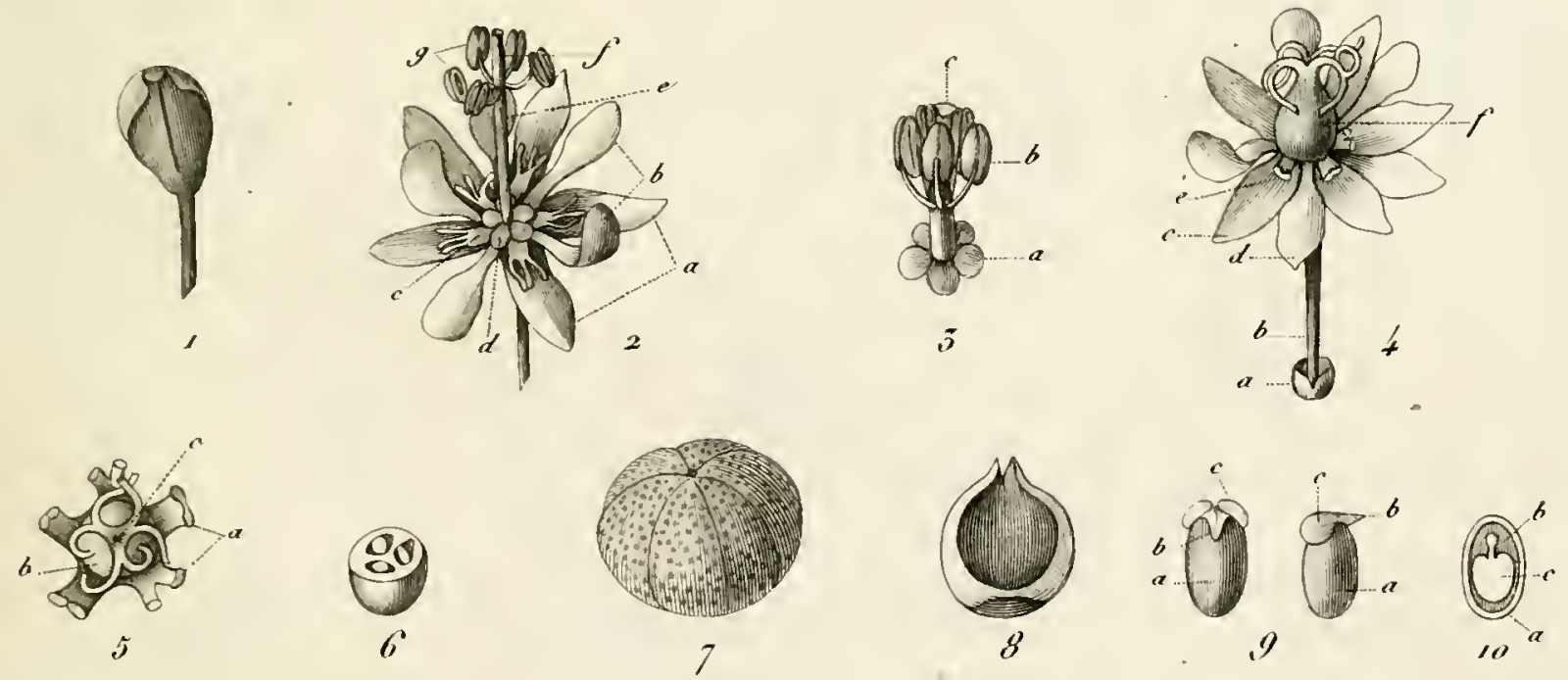

18. HE'NARIA cryplophila.

19. AGYNE'A impubes.

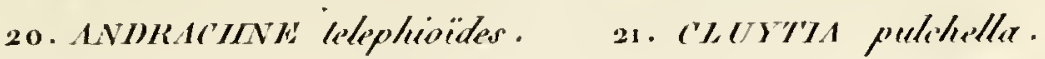





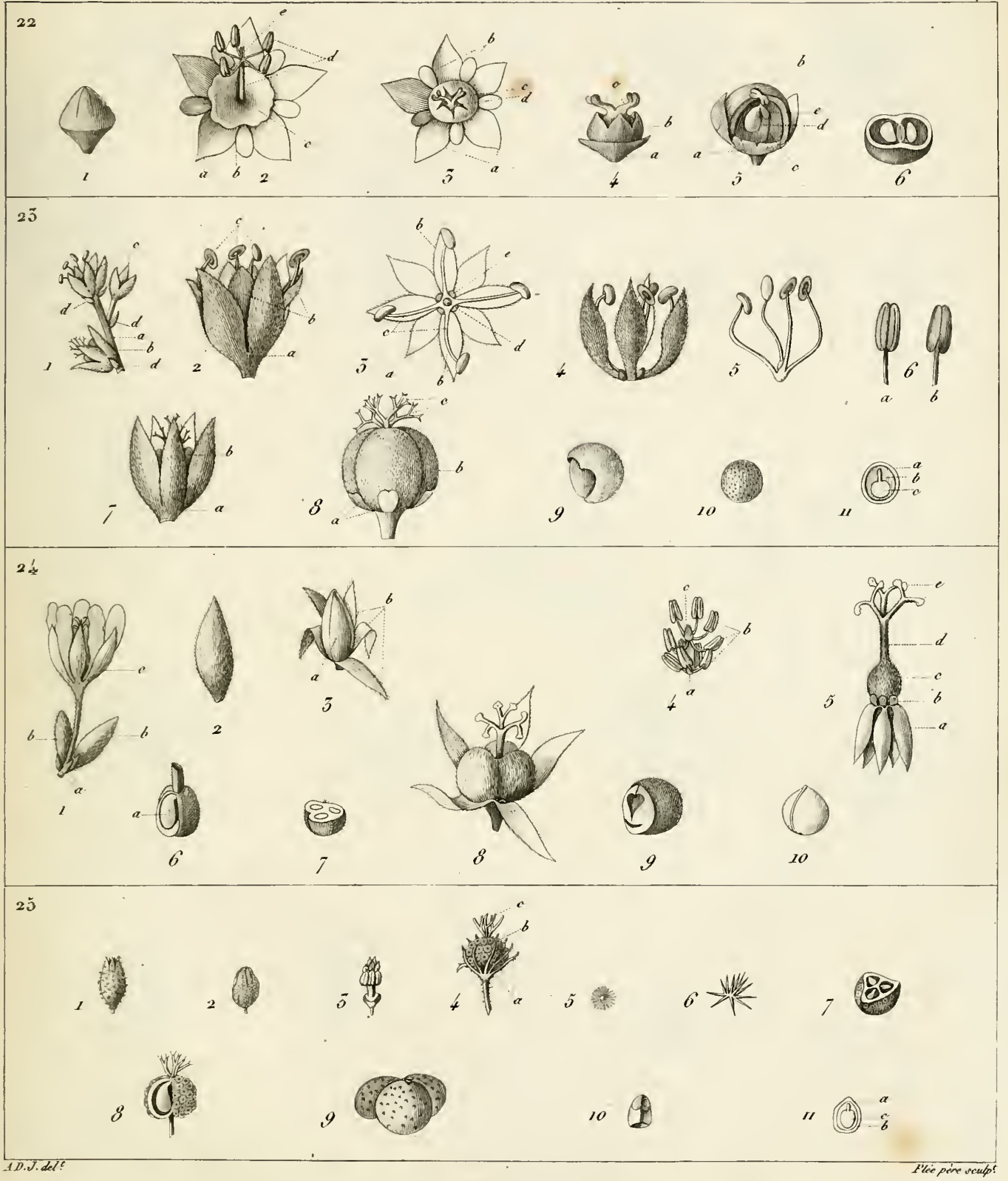

22. BRIEDELIA retusa'. 23. 1 RGYTHAMNIA candicans.

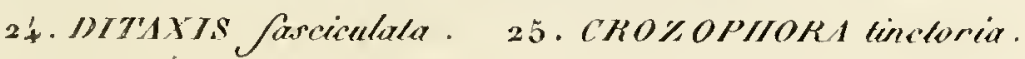


We IR⿴囗十)

i

Thath at at 
P. 8.

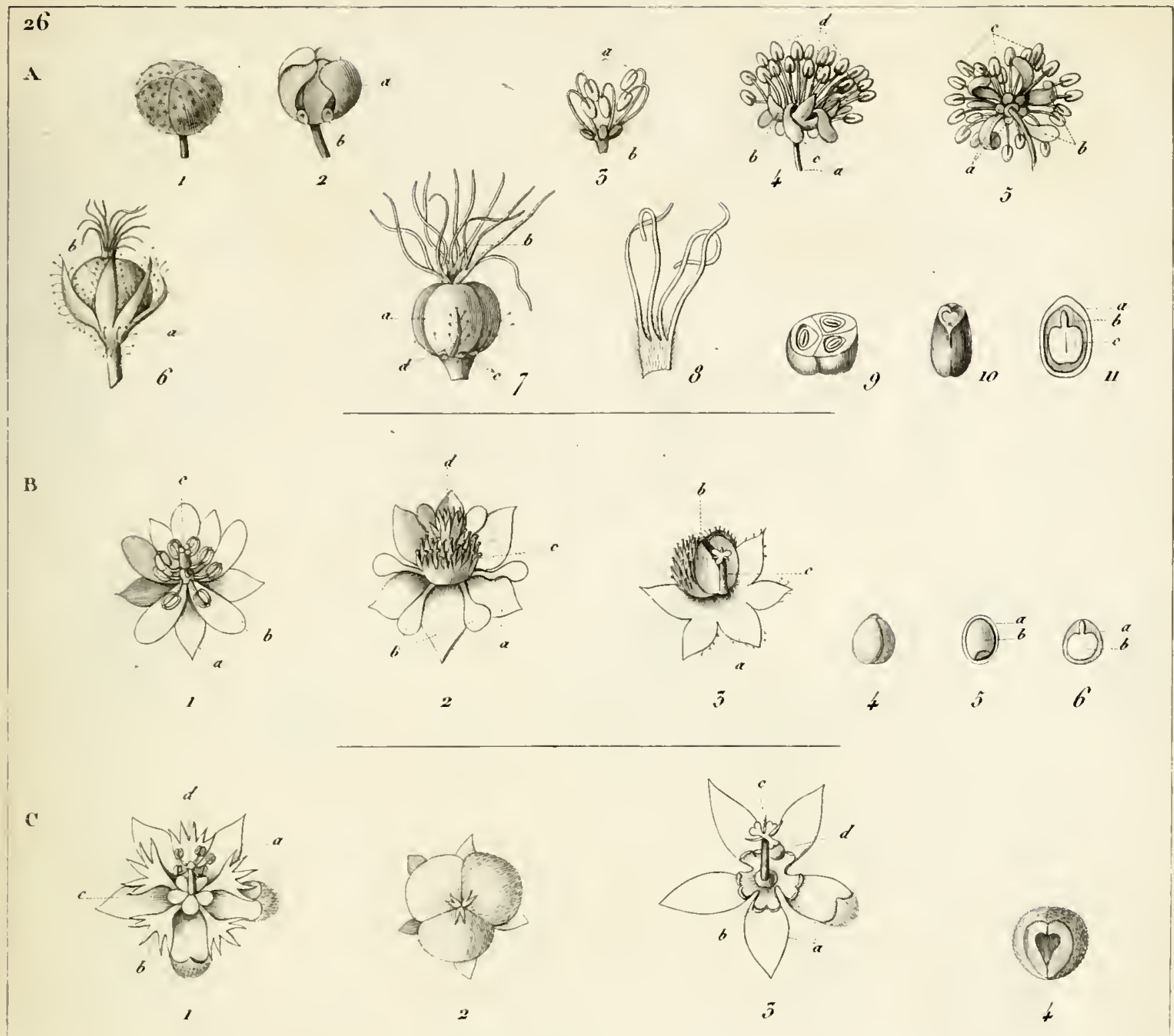

27
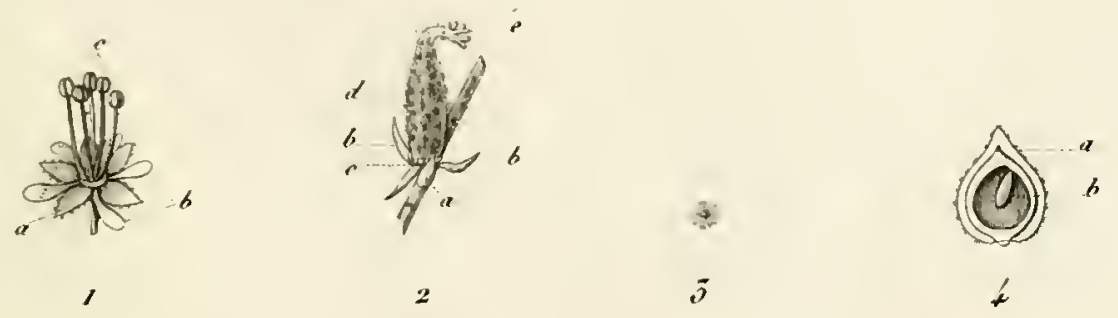

(1) ${ }^{a}$

$\hat{\jmath}$

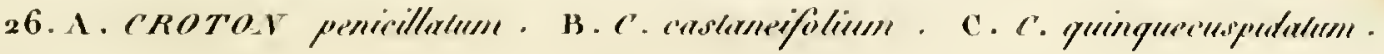





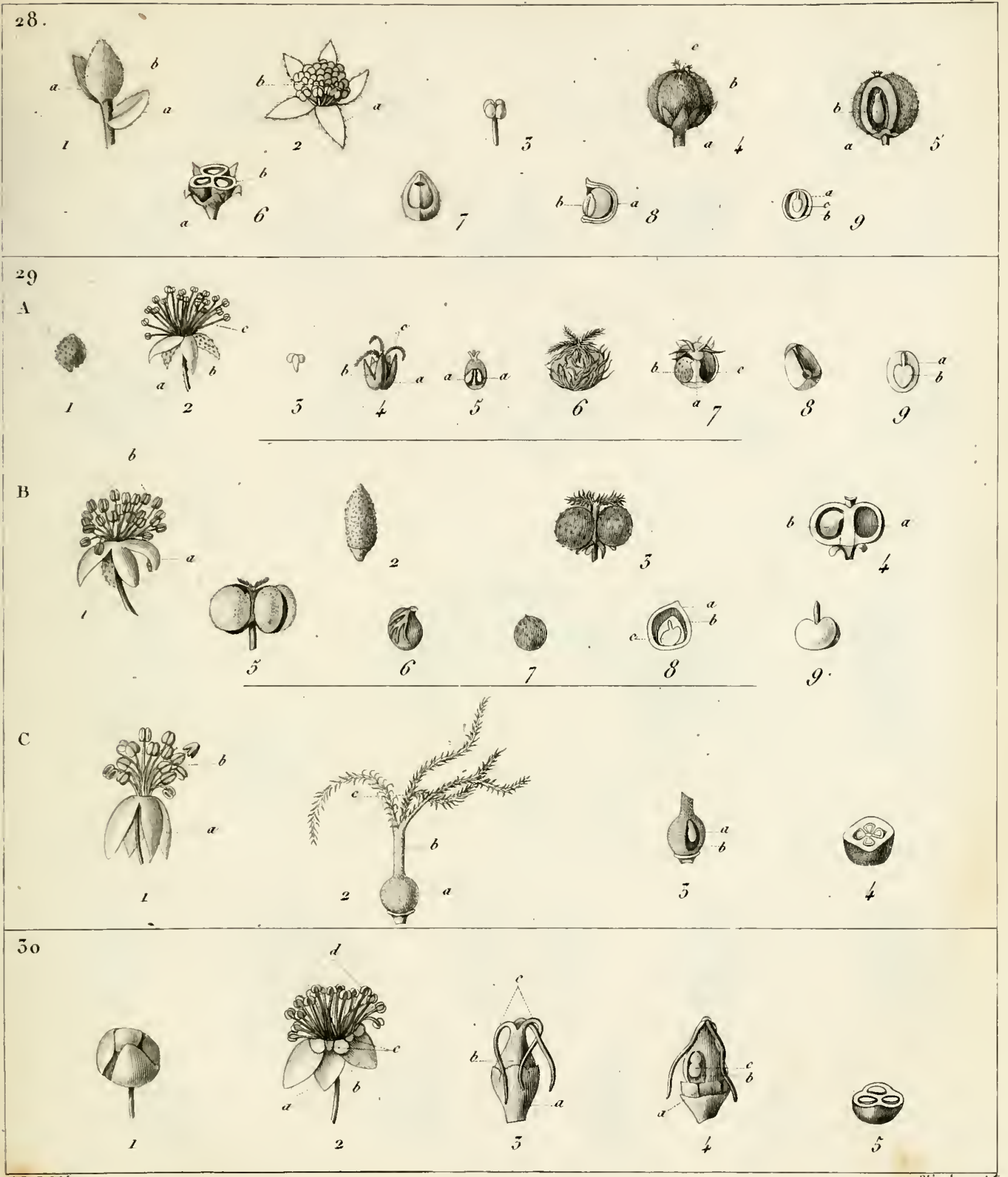

ID.J.del!

28.ADELIA bernardia. 29.A.MOTTLEHA ricinö̈les.

B. R. scabrifolix.

C.R. indica.

Plie pione siutp?

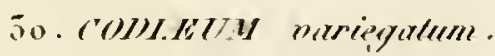



l'.10.

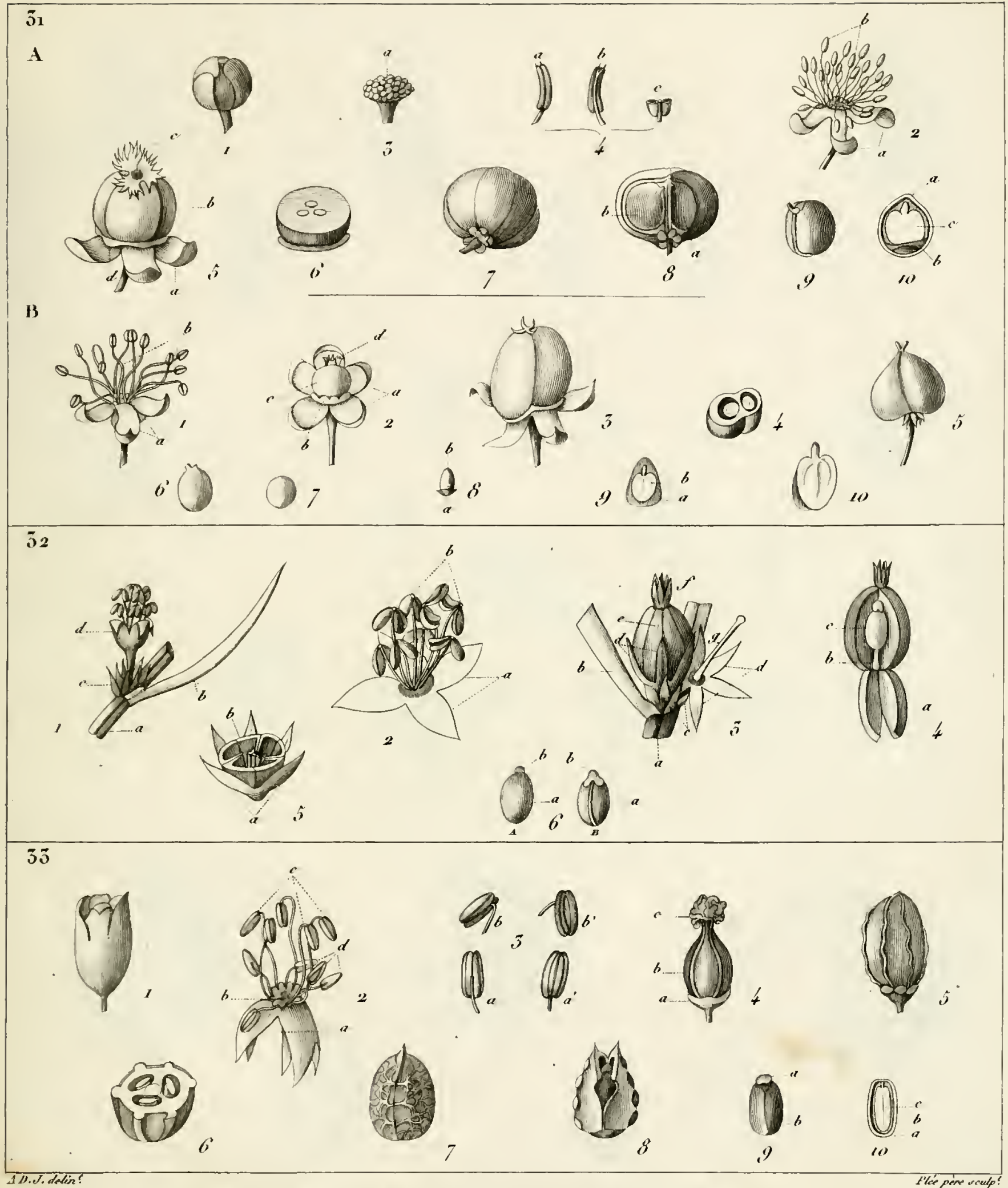

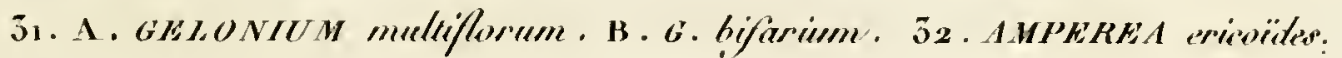
33. JANIPIIA manihol. 

$\mu \%$.
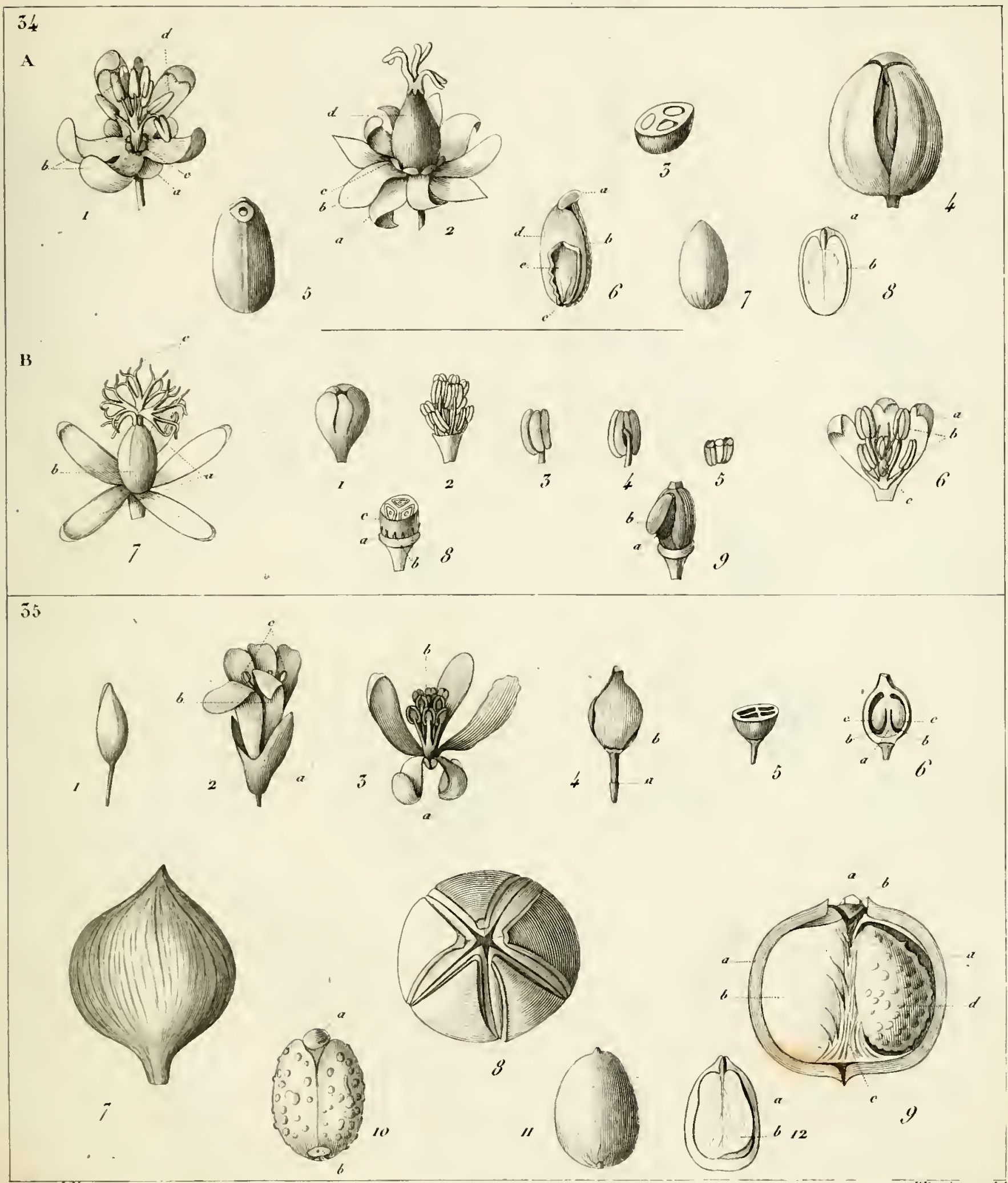

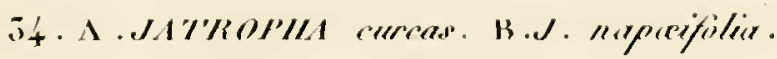



56 .

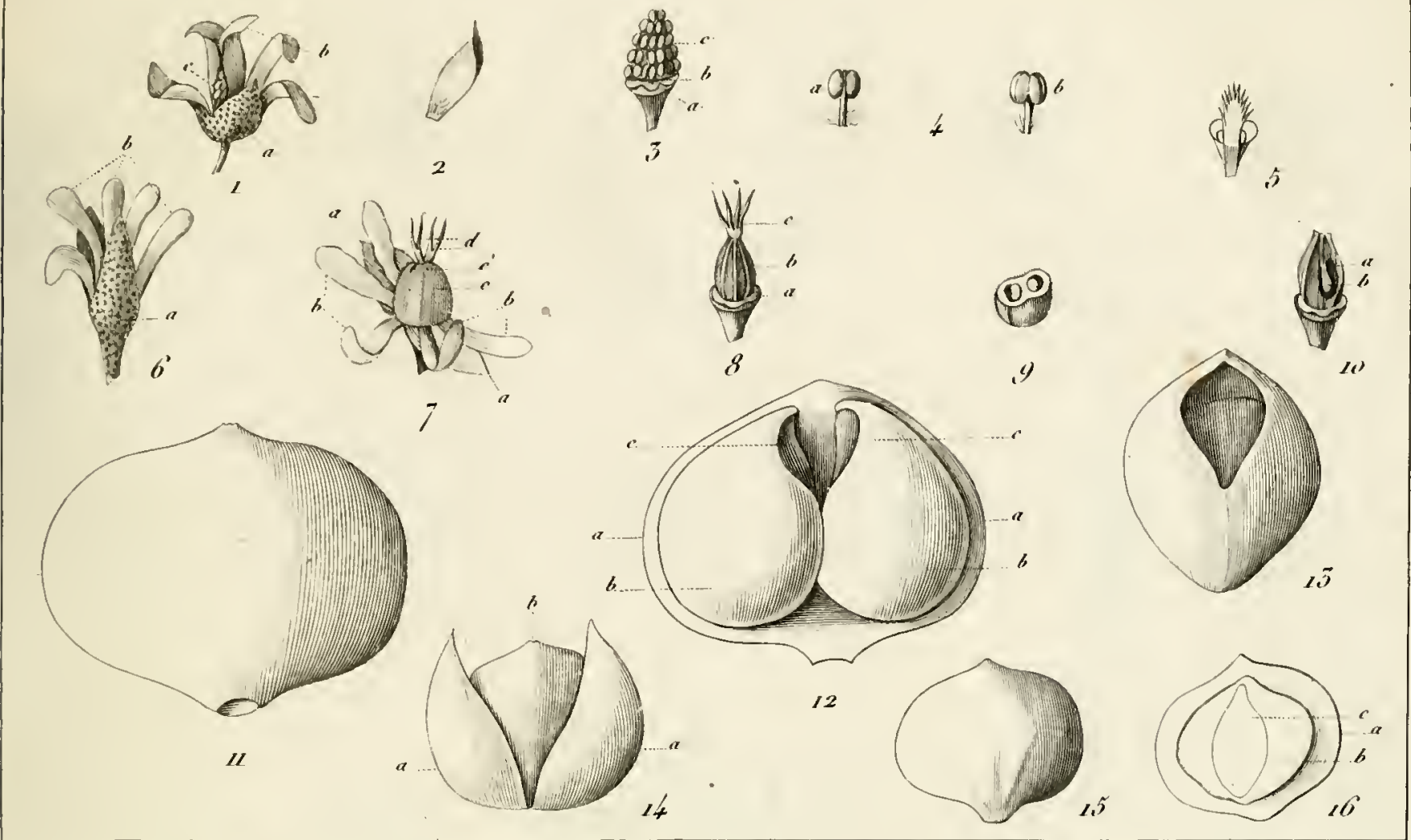

$3 \pi$.
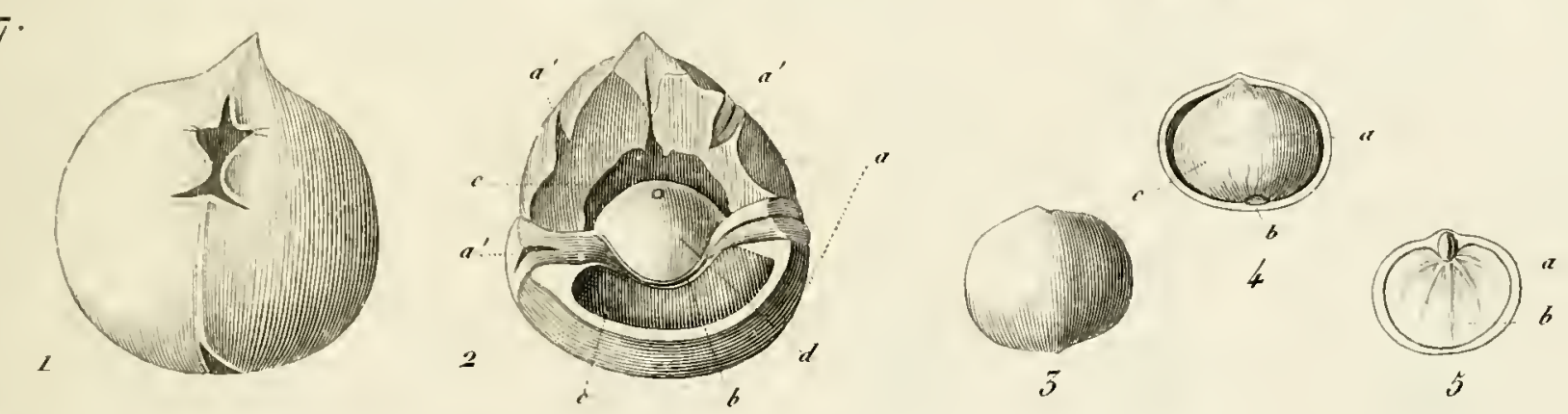

38 .

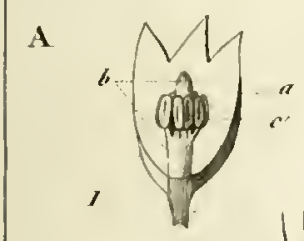

B
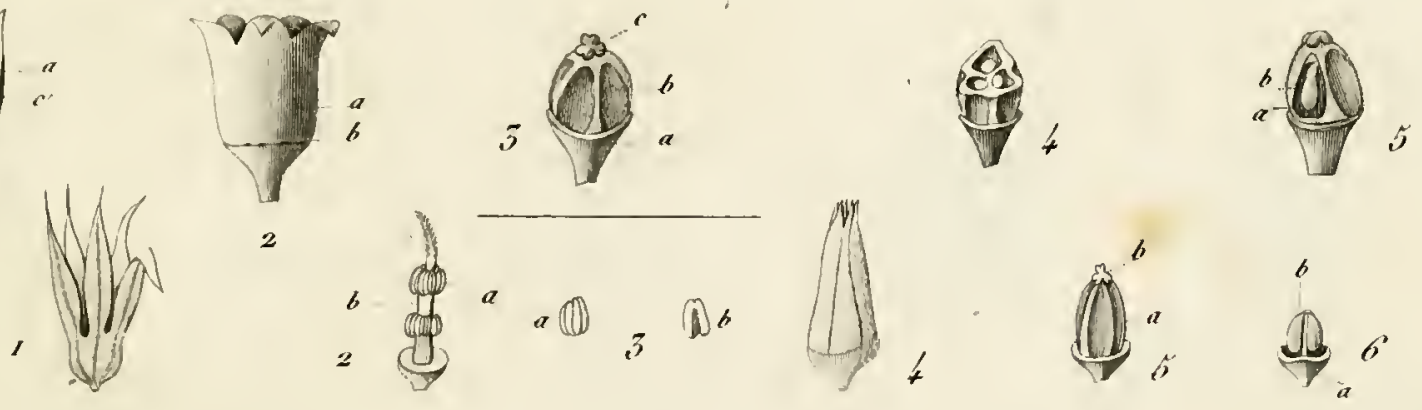

A D.J. del!

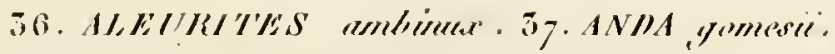
Thes perts reutfor

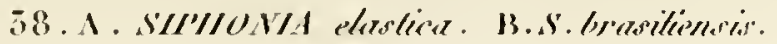





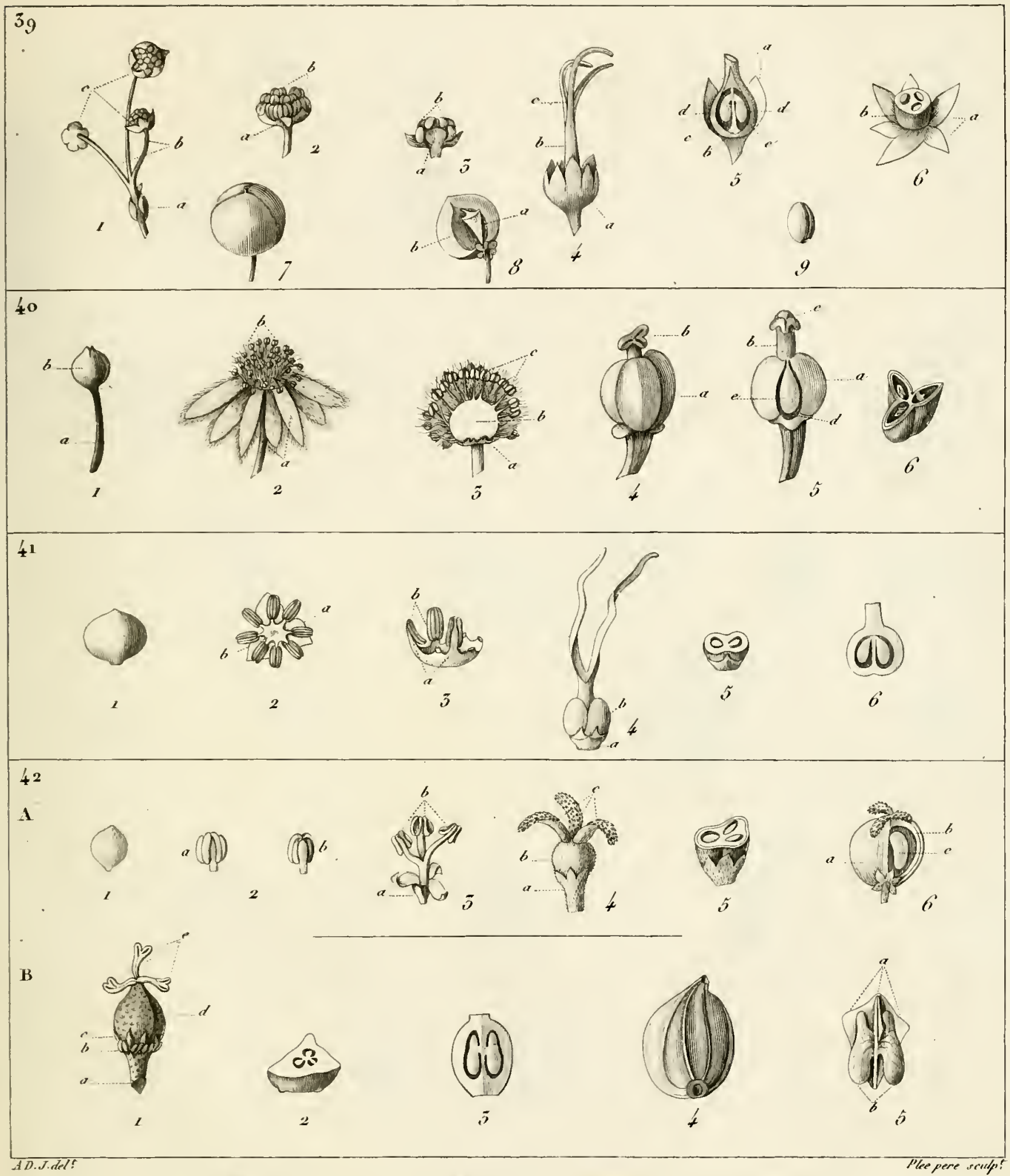

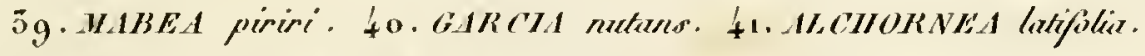

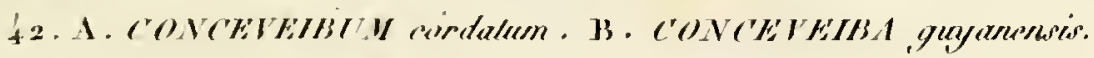





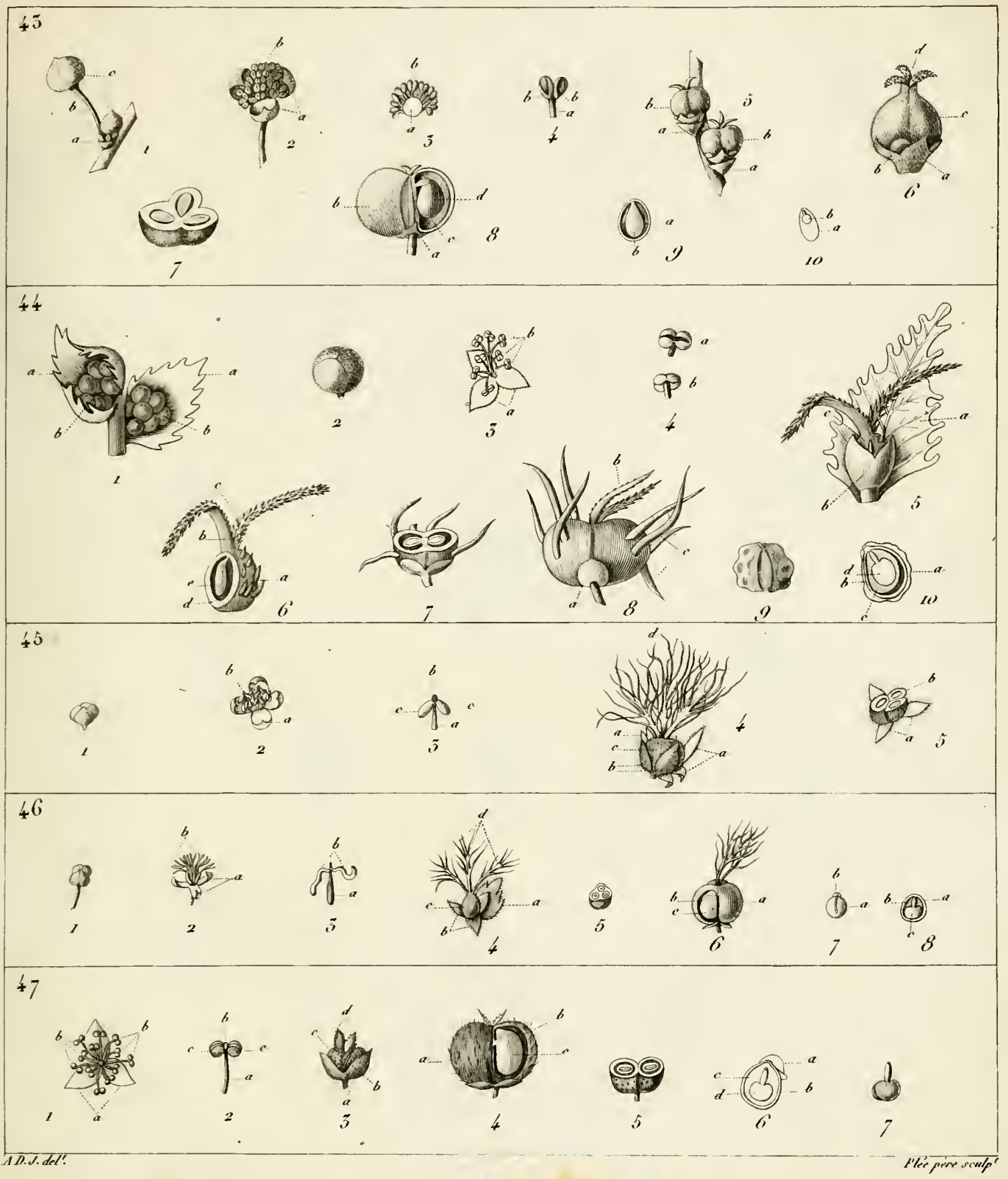

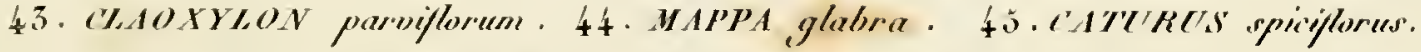

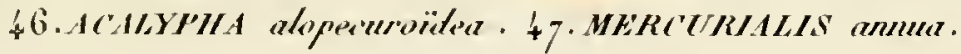


IIE LBER'

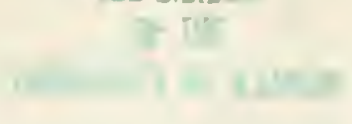

-

. 


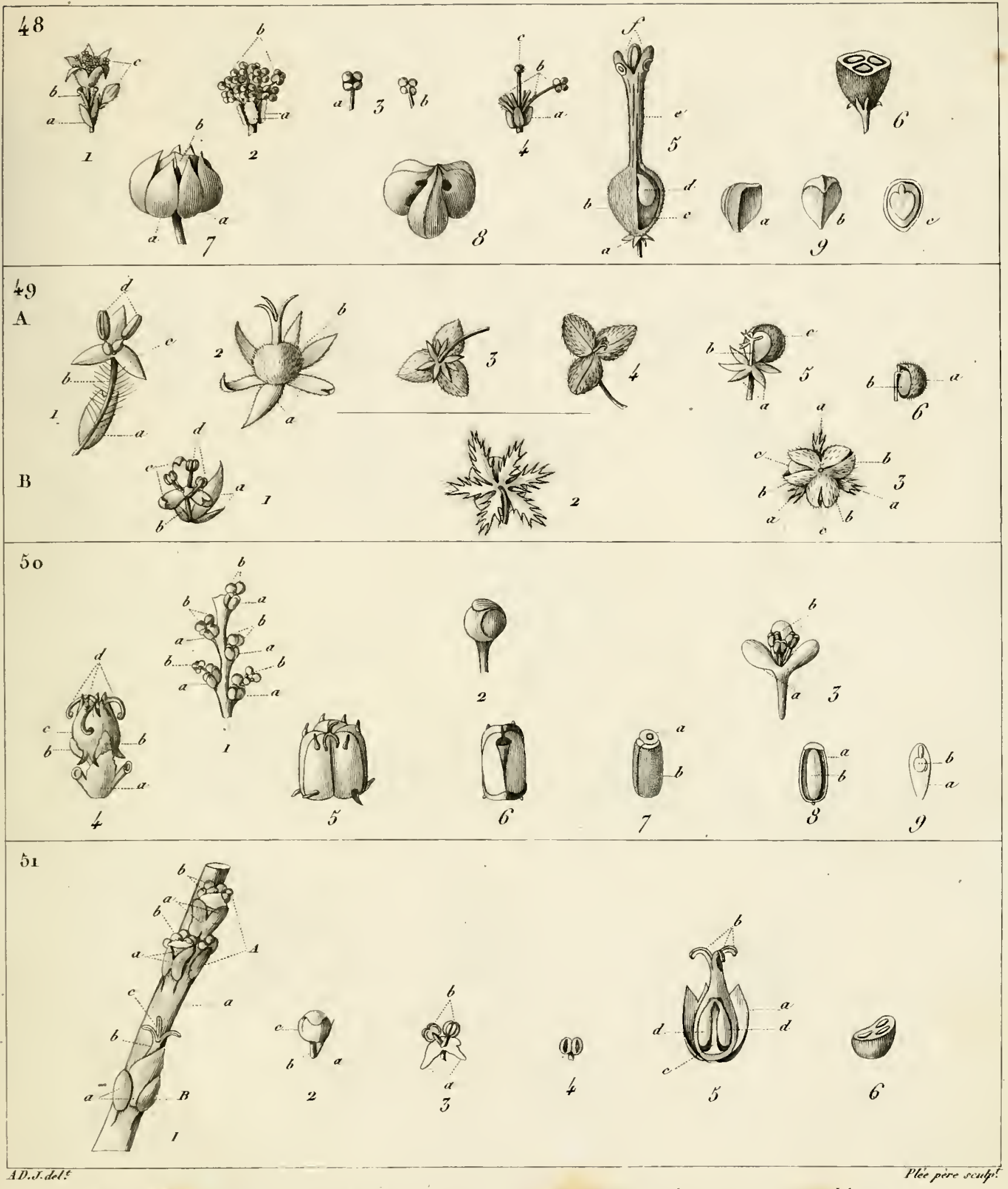

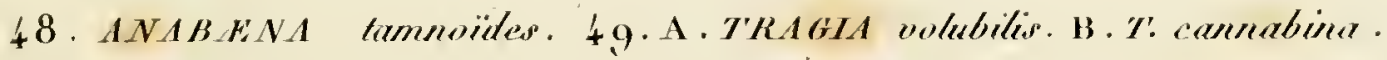
5o. MIIROSTACHYS bicarmis. 51. SAPIUM aucupurum . 


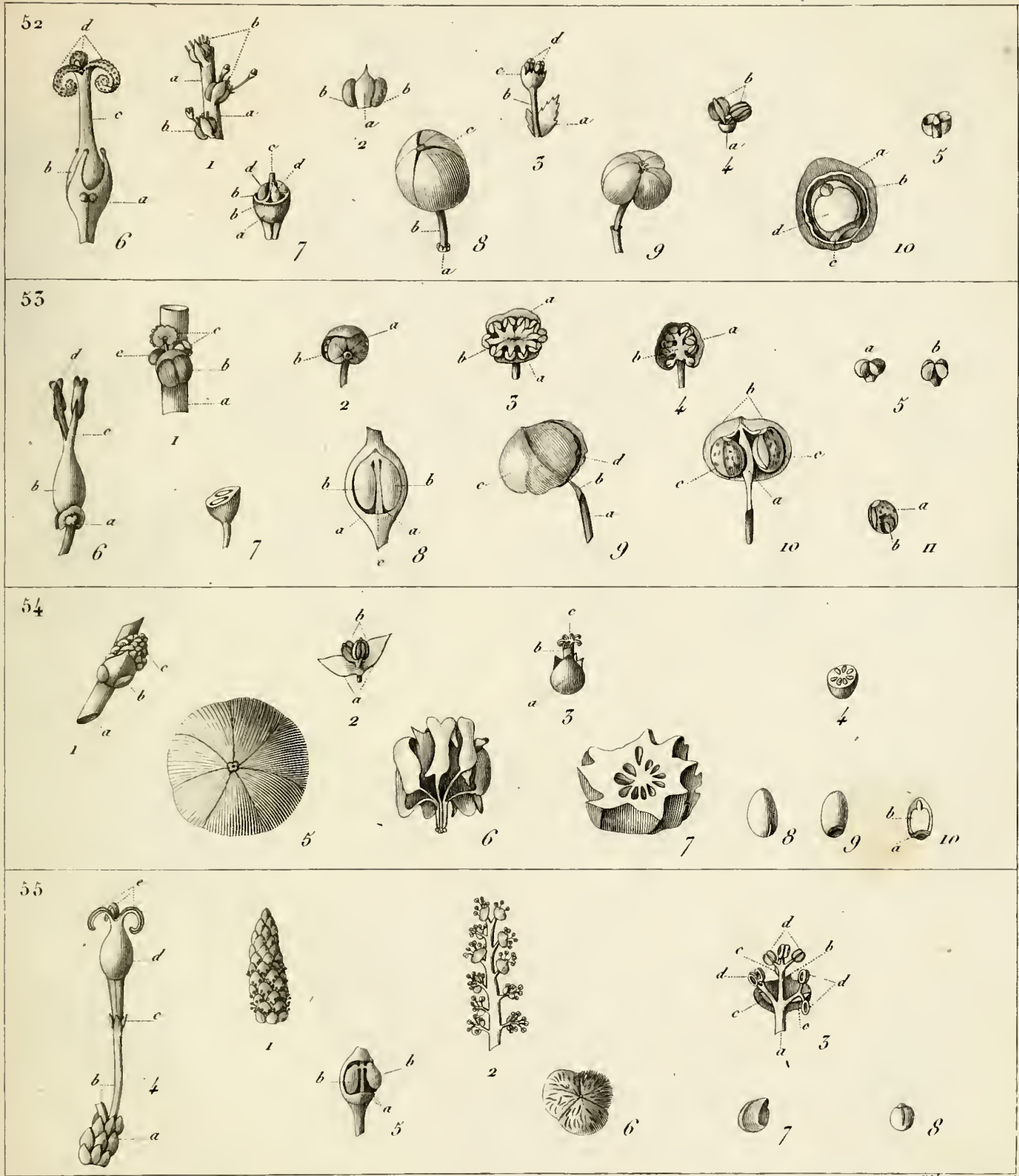

(1) $g$

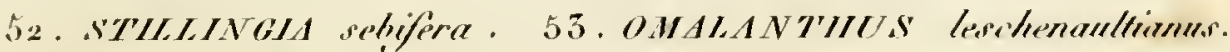

IIber pire urulfo"

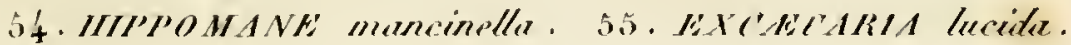





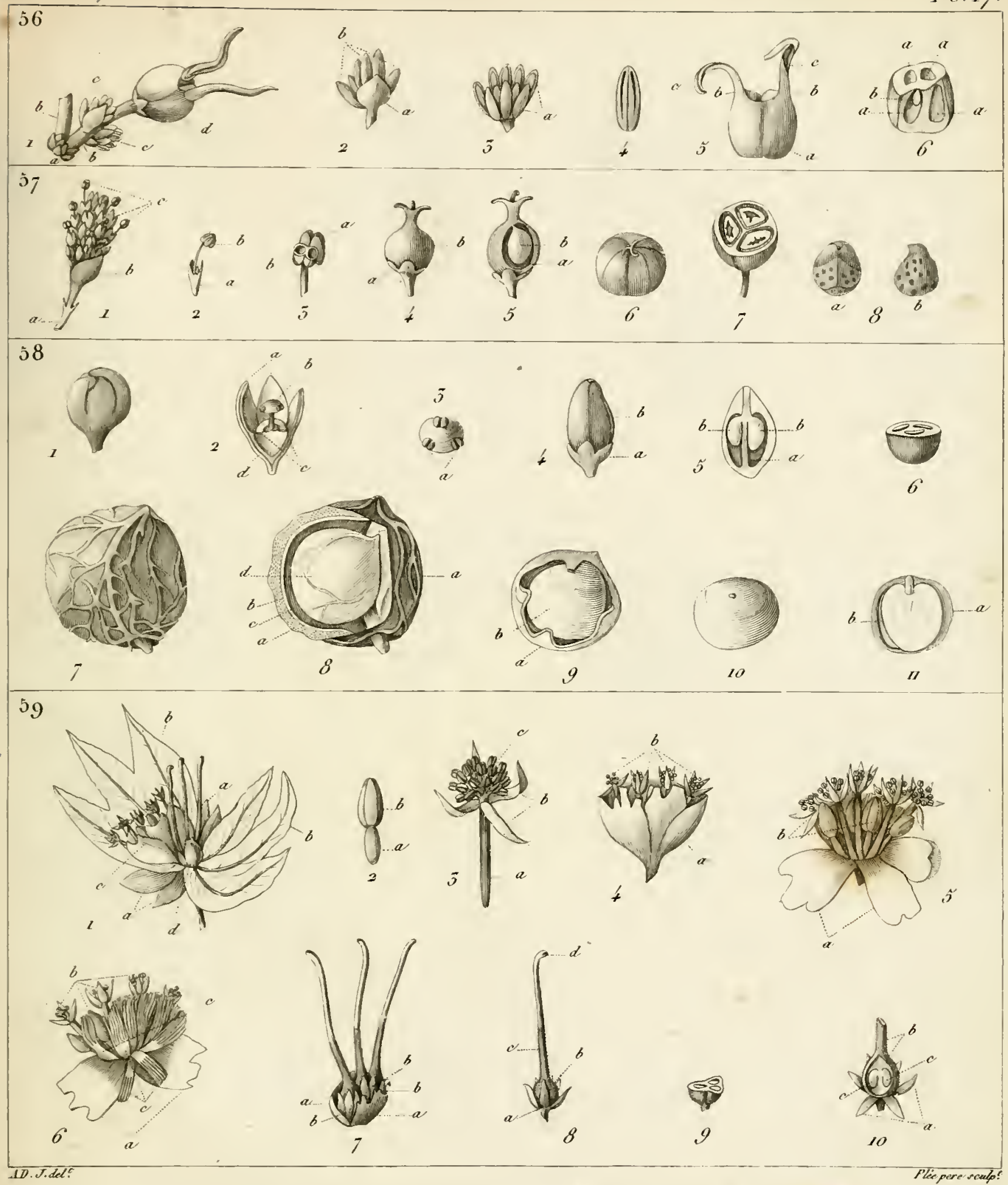

56. STYZOCERAS Kunthianum. 57. MAPROUNE'A ginymensis.

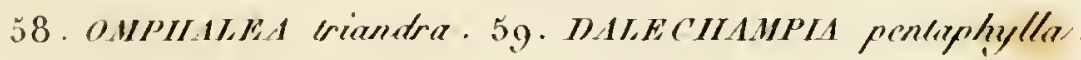


-

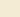




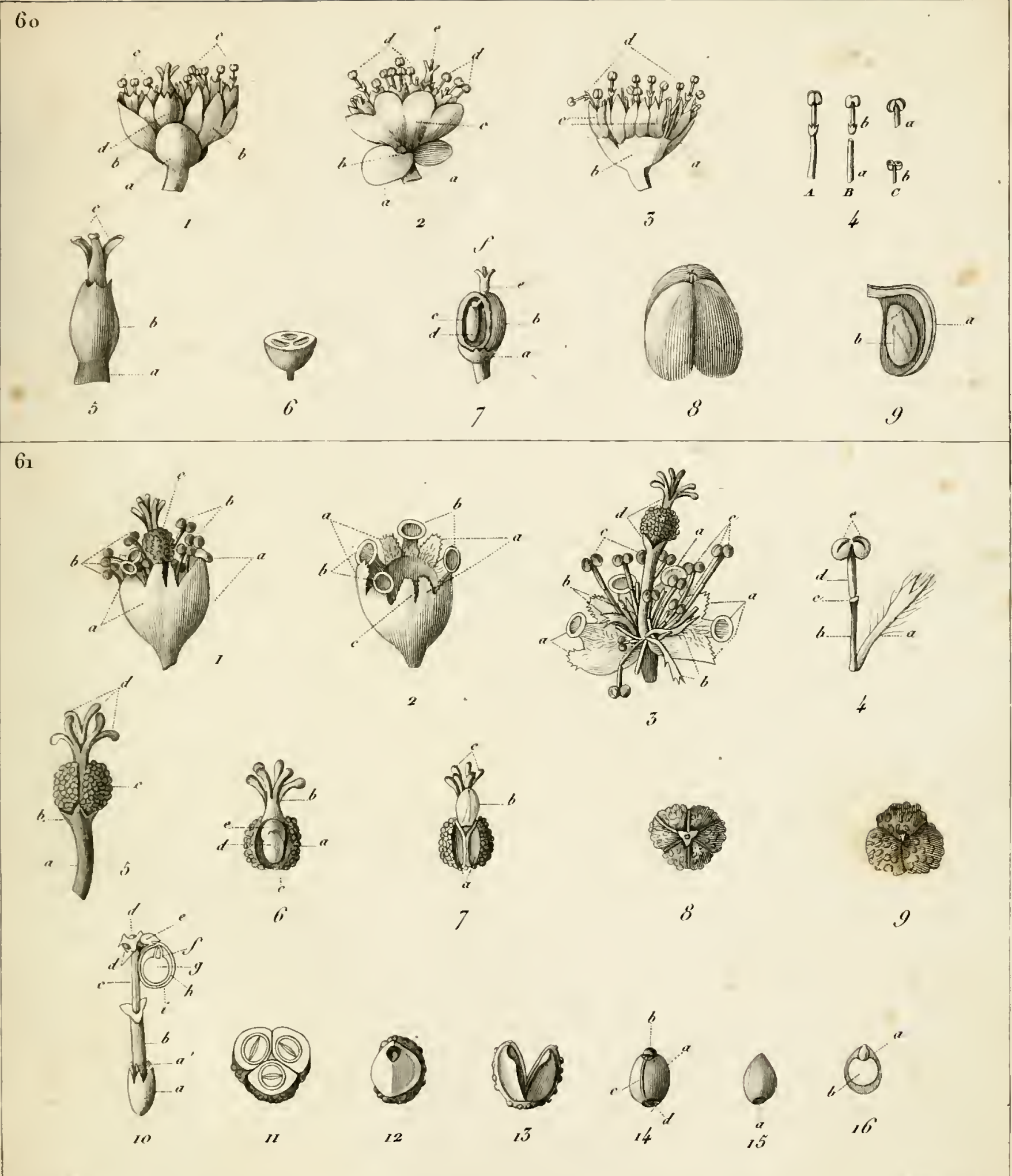

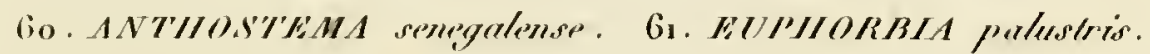




